\title{
Synthesis and Properties of V-Shaped Xanthene Dyes with Tunable and Predictable Absorption and Emission Wavelengths
}

\author{
Akari Yamagami, Kotaro Kiyotaki, Sae Wakabayashi, Naoki Egami, Kenichi Kawano, \\ Shiroh Futaki, * Ayumi Imayoshi, Kazunori Tsubaki* \\ Email Addresses; $\quad$ tsubaki@,kpu.ac.jp, futaki@scl.kyoto-u.ac.jp
}

\section{Supporting Information}

\section{Table of Contents}

\section{Computational study}

Table S1: The DFT calculation of anionic V-shaped xanthene dye $\mathbf{1}$ by changing the dihedral angle $(\theta)$ from $0^{\circ}$ to $90^{\circ}$ at $\mathrm{B} 3 \mathrm{LYP} / 6-31+\mathrm{G}(\mathrm{d}, \mathrm{p})$ level of theory.

Figure S1: The HOMOs, LUMOs, the energy gaps, and observed and calculated maximum absorption wavelengths of V-shaped dyes $\mathbf{4 - 8}$ by DFT calculations at the $\mathrm{B} 3 \mathrm{LYP} / 6-31+\mathrm{G}(\mathrm{d}, \mathrm{p})$ level in a vacuum.

The three different protonation states of V-shaped dye 7.

Figure S2: UV-vis (red) and FL (blue) spectra of the three different protonation states of V-shaped dye 7.

Assay of V-shaped dye 7 using cells.

$\begin{array}{ll}\text { Figure S3: Confocal laser-scanning microscopic sequential images. } & \text { S15 }\end{array}$

Figure S4: Cell viability of HeLa cells on treatment with dye 7.

$\underline{{ }^{1} \mathrm{H} \text { NMR and }{ }^{13} \mathrm{C} \text { NMR spectra for all new compounds. }}$

HRMS spectra for all new compounds. 


\section{Computational Study}

Table S1: The DFT calculation of anionic V-shaped xanthene dye 1 by changing the dihedral angle

$(\theta)$ from $0^{\circ}$ to $90^{\circ}$ at $\mathrm{B} 3 \mathrm{LYP} / 6-31+\mathrm{G}(\mathrm{d}, \mathrm{p})$ level of theory.

Coordinates of anionic $1\left(\theta=0^{\circ}\right)$

\begin{tabular}{|c|c|c|c|c|c|}
\hline \multirow{2}{*}{$\begin{array}{l}\text { Center } \\
\text { Number }\end{array}$} & \multirow{2}{*}{$\begin{array}{l}\text { Atomic } \\
\text { Number }\end{array}$} & \multirow{2}{*}{$\begin{array}{l}\text { Atomic } \\
\text { Type }\end{array}$} & \multicolumn{3}{|c|}{ Coordinates (Angstroms) } \\
\hline & & & $\mathrm{X}$ & $\mathrm{Y}$ & $\mathrm{Z}$ \\
\hline 1 & 6 & 0 & 3.506106 & -1.042755 & 0.416249 \\
\hline 2 & 6 & 0 & 3.299493 & -2.441854 & 0.046256 \\
\hline 3 & 6 & 0 & 1.916002 & -2.794283 & -0.174980 \\
\hline 4 & 6 & 0 & 0.918012 & -1.851077 & -0.141651 \\
\hline 5 & 6 & 0 & 1.142547 & -0.436559 & 0.012343 \\
\hline 6 & 6 & 0 & 2.496230 & -0.122135 & 0.401278 \\
\hline 7 & 8 & 0 & -0.359808 & -2.334209 & -0.218473 \\
\hline 8 & 6 & 0 & -1.440891 & -1.510792 & -0.059447 \\
\hline 9 & 6 & 0 & -1.268231 & -0.079679 & -0.058688 \\
\hline 10 & 6 & 0 & 0.045831 & 0.480783 & -0.123500 \\
\hline 11 & 6 & 0 & -2.657836 & -2.137730 & 0.050729 \\
\hline 12 & 6 & 0 & -3.897999 & -1.395791 & 0.063411 \\
\hline 13 & 6 & 0 & -3.737260 & 0.039402 & -0.161868 \\
\hline 14 & 6 & 0 & -2.509428 & 0.633906 & -0.239733 \\
\hline 15 & 6 & 0 & 0.326421 & 1.938700 & 0.123774 \\
\hline 16 & 6 & 0 & 1.507691 & 2.488672 & -0.448307 \\
\hline 17 & 6 & 0 & 1.765459 & 3.857633 & -0.494874 \\
\hline 18 & 6 & 0 & 0.810211 & 4.773003 & -0.050073 \\
\hline 19 & 6 & 0 & -0.409420 & 4.278478 & 0.410333 \\
\hline 20 & 6 & 0 & -0.657342 & 2.904998 & 0.442708 \\
\hline 21 & 8 & 0 & -5.025856 & -1.931859 & 0.193300 \\
\hline 22 & 8 & 0 & 4.243522 & -3.268442 & -0.001512 \\
\hline 23 & 1 & 0 & 4.505254 & -0.761778 & 0.738948 \\
\hline 24 & 1 & 0 & 1.657136 & -3.839633 & -0.306743 \\
\hline 25 & 1 & 0 & 2.724165 & 0.875429 & 0.751810 \\
\hline 26 & 1 & 0 & -2.697097 & -3.221554 & 0.079989 \\
\hline 27 & 1 & 0 & -4.644734 & 0.620188 & -0.305029 \\
\hline 28 & 1 & 0 & -2.476600 & 1.682722 & -0.497270 \\
\hline 29 & 1 & 0 & 2.221676 & 1.830729 & -0.923044 \\
\hline 30 & 1 & 0 & 2.701010 & 4.205770 & -0.925145 \\
\hline 31 & 1 & 0 & 0.999974 & 5.842277 & -0.089164 \\
\hline 32 & 1 & 0 & -1.190809 & 4.960397 & 0.735357 \\
\hline 33 & 1 & 0 & -1.596433 & 2.584014 & 0.870004 \\
\hline
\end{tabular}


Coordinates of anionic $1\left(\theta=10^{\circ}\right)$

\begin{tabular}{|c|c|c|c|c|c|}
\hline \multirow{2}{*}{$\begin{array}{l}\text { Center } \\
\text { Number }\end{array}$} & \multirow{2}{*}{$\begin{array}{l}\text { Atomic } \\
\text { Number }\end{array}$} & \multirow{2}{*}{$\begin{array}{l}\text { Atomic } \\
\text { Type }\end{array}$} & \multicolumn{3}{|c|}{ Coordinates (Angstroms) } \\
\hline & & & $X$ & $\mathrm{Y}$ & $\mathrm{Z}$ \\
\hline 1 & 6 & 0 & -3.656259 & 0.496575 & 0.318882 \\
\hline 2 & 6 & 0 & -3.640849 & 1.934730 & 0.055676 \\
\hline 3 & 6 & 0 & -2.317849 & 2.495995 & -0.096706 \\
\hline 4 & 6 & 0 & -1.194177 & 1.706481 & -0.085514 \\
\hline 5 & 6 & 0 & -1.217531 & 0.268969 & 0.000131 \\
\hline 6 & 6 & 0 & -2.522754 & -0.266409 & 0.296537 \\
\hline 7 & 8 & 0 & 0.002583 & 2.371070 & -0.113803 \\
\hline 8 & 6 & 0 & 1.195006 & 1.704492 & -0.029675 \\
\hline 9 & 6 & 0 & 1.224137 & 0.264984 & -0.061210 \\
\hline 10 & 6 & 0 & 0.002690 & -0.469677 & -0.116233 \\
\hline 11 & 6 & 0 & 2.318061 & 2.490599 & 0.055762 \\
\hline 12 & 6 & 0 & 3.647726 & 1.924687 & 0.016346 \\
\hline 13 & 6 & 0 & 3.680563 & 0.481243 & -0.214999 \\
\hline 14 & 6 & 0 & 2.544930 & -0.276387 & -0.266334 \\
\hline 15 & 6 & 0 & -0.046627 & -1.953929 & 0.100920 \\
\hline 16 & 6 & 0 & -1.057848 & -2.702542 & -0.555732 \\
\hline 17 & 6 & 0 & -1.062901 & -4.096504 & -0.581983 \\
\hline 18 & 6 & 0 & -0.012860 & -4.817870 & -0.010183 \\
\hline 19 & 6 & 0 & 1.045397 & -4.111016 & 0.561558 \\
\hline 20 & 6 & 0 & 1.046550 & -2.715061 & 0.572294 \\
\hline 21 & 8 & 0 & 4.695118 & 2.609984 & 0.116484 \\
\hline 22 & 8 & 0 & -4.692546 & 2.620188 & 0.025753 \\
\hline 23 & 1 & 0 & -4.617515 & 0.052404 & 0.563803 \\
\hline 24 & 1 & 0 & -2.212660 & 3.573381 & -0.169876 \\
\hline 25 & 1 & 0 & -2.614075 & -1.312027 & 0.558393 \\
\hline 26 & 1 & 0 & 2.211411 & 3.568915 & 0.110404 \\
\hline 27 & 1 & 0 & 4.656272 & 0.031642 & -0.379771 \\
\hline 28 & 1 & 0 & 2.644628 & -1.324627 & -0.515439 \\
\hline 29 & 1 & 0 & -1.832229 & -2.180216 & -1.101933 \\
\hline 30 & 1 & 0 & -1.874378 & -4.615623 & -1.085523 \\
\hline 31 & 1 & 0 & -0.008349 & -5.904366 & -0.030949 \\
\hline 32 & 1 & 0 & 1.889679 & -4.642431 & 0.992885 \\
\hline 33 & 1 & 0 & 1.863554 & -2.213146 & 1.073304 \\
\hline
\end{tabular}


Coordinates of anionic $1\left(\theta=20^{\circ}\right)$

\begin{tabular}{|c|c|c|c|c|c|}
\hline \multirow{2}{*}{$\begin{array}{l}\text { Center } \\
\text { Number }\end{array}$} & \multirow{2}{*}{$\begin{array}{l}\text { Atomic } \\
\text { Number }\end{array}$} & \multirow{2}{*}{$\begin{array}{l}\text { Atomic } \\
\text { Type }\end{array}$} & \multicolumn{3}{|c|}{ Coordinates (Angstroms) } \\
\hline & & & $\mathrm{X}$ & $\mathrm{Y}$ & $\mathrm{Z}$ \\
\hline 1 & 6 & 0 & 3.698650 & -0.218247 & 0.258729 \\
\hline 2 & 6 & 0 & 3.779873 & -1.666082 & 0.069293 \\
\hline 3 & 6 & 0 & 2.499354 & -2.327450 & -0.046141 \\
\hline 4 & 6 & 0 & 1.321766 & -1.621222 & -0.052252 \\
\hline 5 & 6 & 0 & 1.246711 & -0.184419 & -0.004658 \\
\hline 6 & 6 & 0 & 2.512935 & 0.460503 & 0.228598 \\
\hline 7 & 8 & 0 & 0.172650 & -2.367404 & -0.064217 \\
\hline 8 & 6 & 0 & -1.065821 & -1.784109 & -0.021403 \\
\hline 9 & 6 & 0 & -1.192228 & -0.350891 & -0.062002 \\
\hline 10 & 6 & 0 & -0.022593 & 0.458714 & -0.102735 \\
\hline 11 & 6 & 0 & -2.136318 & -2.642107 & 0.041792 \\
\hline 12 & 6 & 0 & -3.499421 & -2.162750 & -0.017181 \\
\hline 13 & 6 & 0 & -3.626026 & -0.720679 & -0.226336 \\
\hline 14 & 6 & 0 & -2.542696 & 0.110946 & -0.258820 \\
\hline 15 & 6 & 0 & -0.090364 & 1.944154 & 0.074455 \\
\hline 16 & 6 & 0 & 0.792202 & 2.772364 & -0.659505 \\
\hline 17 & 6 & 0 & 0.668574 & 4.161620 & -0.670671 \\
\hline 18 & 6 & 0 & -0.379301 & 4.782719 & 0.013086 \\
\hline 19 & 6 & 0 & -1.306486 & 3.985997 & 0.687047 \\
\hline 20 & 6 & 0 & -1.183960 & 2.595422 & 0.683370 \\
\hline 21 & 8 & 0 & -4.500778 & -2.916770 & 0.057877 \\
\hline 22 & 8 & 0 & 4.877065 & -2.276904 & 0.057427 \\
\hline 23 & 1 & 0 & 4.632118 & 0.304498 & 0.449896 \\
\hline 24 & 1 & 0 & 2.473835 & -3.411329 & -0.087160 \\
\hline 25 & 1 & 0 & 2.530084 & 1.525172 & 0.423401 \\
\hline 26 & 1 & 0 & -1.961990 & -3.711345 & 0.100496 \\
\hline 27 & 1 & 0 & -4.629196 & -0.333636 & -0.384743 \\
\hline 28 & 1 & 0 & -2.706330 & 1.158773 & -0.478114 \\
\hline 29 & 1 & 0 & 1.564098 & 2.315114 & -1.266513 \\
\hline 30 & 1 & 0 & 1.378653 & 4.755461 & -1.240387 \\
\hline 31 & 1 & 0 & -0.481321 & 5.864606 & 0.005463 \\
\hline 32 & 1 & 0 & -2.141729 & 4.442892 & 1.211350 \\
\hline 33 & 1 & 0 & -1.898851 & 2.011525 & 1.249606 \\
\hline
\end{tabular}


Coordinates of anionic $1\left(\theta=30^{\circ}\right)$

\begin{tabular}{|c|c|c|c|c|c|}
\hline \multirow{2}{*}{$\begin{array}{l}\text { Center } \\
\text { Number }\end{array}$} & \multirow{2}{*}{$\begin{array}{l}\text { Atomic } \\
\text { Number }\end{array}$} & \multirow{2}{*}{$\begin{array}{l}\text { Atomic } \\
\text { Type }\end{array}$} & \multicolumn{3}{|c|}{ Coordinates (Angstroms) } \\
\hline & & & $\mathrm{X}$ & $\mathrm{Y}$ & Z \\
\hline 1 & 6 & 0 & 3.708008 & -0.123497 & 0.218043 \\
\hline 2 & 6 & 0 & 3.819530 & -1.575689 & 0.079893 \\
\hline 3 & 6 & 0 & 2.554708 & -2.271855 & -0.011899 \\
\hline 4 & 6 & 0 & 1.360380 & -1.594925 & -0.028109 \\
\hline 5 & 6 & 0 & 1.255361 & -0.160321 & -0.001026 \\
\hline 6 & 6 & 0 & 2.506134 & 0.525880 & 0.184524 \\
\hline 7 & 8 & 0 & 0.225824 & -2.364637 & -0.037474 \\
\hline 8 & 6 & 0 & -1.026405 & -1.807379 & -0.020170 \\
\hline 9 & 6 & 0 & -1.181164 & -0.377229 & -0.057609 \\
\hline 10 & 6 & 0 & -0.026679 & 0.448987 & -0.081901 \\
\hline 11 & 6 & 0 & -2.081839 & -2.684813 & 0.019801 \\
\hline 12 & 6 & 0 & -3.452757 & -2.227205 & -0.043263 \\
\hline 13 & 6 & 0 & -3.606184 & -0.782318 & -0.214696 \\
\hline 14 & 6 & 0 & -2.538390 & 0.069745 & -0.230553 \\
\hline 15 & 6 & 0 & -0.136044 & 1.934349 & 0.049087 \\
\hline 16 & 6 & 0 & 0.658574 & 2.775410 & -0.760562 \\
\hline 17 & 6 & 0 & 0.493498 & 4.160947 & -0.762501 \\
\hline 18 & 6 & 0 & -0.499062 & 4.754095 & 0.021806 \\
\hline 19 & 6 & 0 & -1.330002 & 3.938204 & 0.792878 \\
\hline 20 & 6 & 0 & -1.169430 & 2.551432 & 0.782016 \\
\hline 21 & 8 & 0 & -4.440784 & -3.000690 & 0.007267 \\
\hline 22 & 8 & 0 & 4.930499 & -2.161248 & 0.079971 \\
\hline 23 & 1 & 0 & 4.633005 & 0.426618 & 0.369161 \\
\hline 24 & 1 & 0 & 2.557612 & -3.356511 & -0.036432 \\
\hline 25 & 1 & 0 & 2.494862 & 1.599225 & 0.330302 \\
\hline 26 & 1 & 0 & -1.890814 & -3.751584 & 0.070775 \\
\hline 27 & 1 & 0 & -4.617694 & -0.409823 & -0.353532 \\
\hline 28 & 1 & 0 & -2.718767 & 1.123161 & -0.409667 \\
\hline 29 & 1 & 0 & 1.393812 & 2.331076 & -1.421886 \\
\hline 30 & 1 & 0 & 1.129909 & 4.774252 & -1.395121 \\
\hline 31 & 1 & 0 & -0.630857 & 5.832804 & 0.022351 \\
\hline 32 & 1 & 0 & -2.116316 & 4.378081 & 1.400732 \\
\hline 33 & 1 & 0 & -1.808485 & 1.942390 & 1.410657 \\
\hline
\end{tabular}


Coordinates of anionic $1\left(\theta=40^{\circ}\right)$

\begin{tabular}{|c|c|c|c|c|c|}
\hline \multirow{2}{*}{$\begin{array}{l}\text { Center } \\
\text { Number }\end{array}$} & \multirow{2}{*}{$\begin{array}{l}\text { Atomic } \\
\text { Number }\end{array}$} & \multirow{2}{*}{$\begin{array}{l}\text { Atomic } \\
\text { Type }\end{array}$} & \multicolumn{3}{|c|}{ Coordinates (Angstroms) } \\
\hline & & & $\mathrm{X}$ & $\mathrm{Y}$ & Z \\
\hline 1 & 6 & 0 & 3.707659 & -0.119389 & 0.185678 \\
\hline 2 & 6 & 0 & 3.816587 & -1.575413 & 0.086040 \\
\hline 3 & 6 & 0 & 2.552034 & -2.275550 & 0.011637 \\
\hline 4 & 6 & 0 & 1.357074 & -1.600290 & -0.009310 \\
\hline 5 & 6 & 0 & 1.255214 & -0.165898 & 0.006601 \\
\hline 6 & 6 & 0 & 2.505240 & 0.528895 & 0.152211 \\
\hline 7 & 8 & 0 & 0.219641 & -2.367162 & -0.021483 \\
\hline 8 & 6 & 0 & -1.032601 & -1.807103 & -0.020185 \\
\hline 9 & 6 & 0 & -1.182385 & -0.376645 & -0.047963 \\
\hline 10 & 6 & 0 & -0.024829 & 0.440441 & -0.057008 \\
\hline 11 & 6 & 0 & -2.092881 & -2.679014 & -0.003791 \\
\hline 12 & 6 & 0 & -3.461007 & -2.210837 & -0.063308 \\
\hline 13 & 6 & 0 & -3.608347 & -0.760242 & -0.189479 \\
\hline 14 & 6 & 0 & -2.536332 & 0.086805 & -0.189197 \\
\hline 15 & 6 & 0 & -0.139226 & 1.927261 & 0.028782 \\
\hline 16 & 6 & 0 & 0.578969 & 2.750241 & -0.861817 \\
\hline 17 & 6 & 0 & 0.417401 & 4.136723 & -0.860835 \\
\hline 18 & 6 & 0 & -0.483793 & 4.740379 & 0.020134 \\
\hline 19 & 6 & 0 & -1.228341 & 3.938289 & 0.888912 \\
\hline 20 & 6 & 0 & -1.073858 & 2.550637 & 0.876886 \\
\hline 21 & 8 & 0 & -4.453196 & -2.980254 & -0.037453 \\
\hline 22 & 8 & 0 & 4.927597 & -2.160921 & 0.093776 \\
\hline 23 & 1 & 0 & 4.635614 & 0.433723 & 0.303909 \\
\hline 24 & 1 & 0 & 2.557980 & -3.360347 & -0.004368 \\
\hline 25 & 1 & 0 & 2.489903 & 1.607581 & 0.259437 \\
\hline 26 & 1 & 0 & -1.909839 & -3.747774 & 0.032936 \\
\hline 27 & 1 & 0 & -4.619786 & -0.379108 & -0.302748 \\
\hline 28 & 1 & 0 & -2.708791 & 1.148921 & -0.322119 \\
\hline 29 & 1 & 0 & 1.253125 & 2.291205 & -1.577168 \\
\hline 30 & 1 & 0 & 0.988008 & 4.743254 & -1.559283 \\
\hline 31 & 1 & 0 & -0.610491 & 5.819706 & 0.023814 \\
\hline 32 & 1 & 0 & -1.939834 & 4.390670 & 1.574764 \\
\hline 33 & 1 & 0 & -1.647693 & 1.943126 & 1.568163 \\
\hline
\end{tabular}


Coordinates of anionic $1\left(\theta=50^{\circ}\right)$

\begin{tabular}{|c|c|c|c|c|c|}
\hline \multirow{2}{*}{$\begin{array}{l}\text { Center } \\
\text { Number }\end{array}$} & \multirow{2}{*}{$\begin{array}{l}\text { Atomic } \\
\text { Number }\end{array}$} & \multirow{2}{*}{$\begin{array}{l}\text { Atomic } \\
\text { Type }\end{array}$} & \multicolumn{3}{|c|}{ Coordinates (Angstroms) } \\
\hline & & & $\mathrm{X}$ & $\mathrm{Y}$ & $\mathrm{Z}$ \\
\hline 1 & 6 & 0 & 3.703822 & -0.146374 & 0.152470 \\
\hline 2 & 6 & 0 & 3.799773 & -1.605907 & 0.087458 \\
\hline 3 & 6 & 0 & 2.529647 & -2.299744 & 0.028579 \\
\hline 4 & 6 & 0 & 1.339449 & -1.616910 & 0.003823 \\
\hline 5 & 6 & 0 & 1.251707 & -0.181742 & 0.010040 \\
\hline 6 & 6 & 0 & 2.505958 & 0.510027 & 0.119371 \\
\hline 7 & 8 & 0 & 0.193389 & -2.372204 & -0.009976 \\
\hline 8 & 6 & 0 & -1.054032 & -1.799439 & -0.020767 \\
\hline 9 & 6 & 0 & -1.187122 & -0.367623 & -0.042479 \\
\hline 10 & 6 & 0 & -0.021225 & 0.432571 & -0.038332 \\
\hline 11 & 6 & 0 & -2.126164 & -2.656359 & -0.019268 \\
\hline 12 & 6 & 0 & -3.487770 & -2.166439 & -0.073226 \\
\hline 13 & 6 & 0 & -3.617106 & -0.711019 & -0.162726 \\
\hline 14 & 6 & 0 & -2.533742 & 0.121384 & -0.153042 \\
\hline 15 & 6 & 0 & -0.128698 & 1.921049 & 0.010621 \\
\hline 16 & 6 & 0 & 0.502999 & 2.720717 & -0.959357 \\
\hline 17 & 6 & 0 & 0.360376 & 4.109829 & -0.953225 \\
\hline 18 & 6 & 0 & -0.424575 & 4.732933 & 0.020889 \\
\hline 19 & 6 & 0 & -1.070924 & 3.951149 & 0.982269 \\
\hline 20 & 6 & 0 & -0.935740 & 2.561423 & 0.967874 \\
\hline 21 & 8 & 0 & -4.490216 & -2.922833 & -0.064426 \\
\hline 22 & 8 & 0 & 4.906079 & -2.199852 & 0.102383 \\
\hline 23 & 1 & 0 & 4.638294 & 0.401178 & 0.241010 \\
\hline 24 & 1 & 0 & 2.530169 & -3.384632 & 0.020778 \\
\hline 25 & 1 & 0 & 2.493931 & 1.592445 & 0.191244 \\
\hline 26 & 1 & 0 & -1.960366 & -3.728198 & 0.007703 \\
\hline 27 & 1 & 0 & -4.625119 & -0.314726 & -0.251207 \\
\hline 28 & 1 & 0 & -2.688360 & 1.191038 & -0.246506 \\
\hline 29 & 1 & 0 & 1.097903 & 2.242642 & -1.731178 \\
\hline 30 & 1 & 0 & 0.858178 & 4.703857 & -1.715168 \\
\hline 31 & 1 & 0 & -0.534980 & 5.814017 & 0.027984 \\
\hline 32 & 1 & 0 & -1.687701 & 4.421727 & 1.743427 \\
\hline 33 & 1 & 0 & -1.435747 & 1.962604 & 1.722248 \\
\hline
\end{tabular}


Coordinates of anionic $1\left(\theta=60^{\circ}\right)$

\begin{tabular}{|c|c|c|c|c|c|}
\hline \multirow{2}{*}{$\begin{array}{l}\text { Center } \\
\text { Number }\end{array}$} & \multirow{2}{*}{$\begin{array}{l}\text { Atomic } \\
\text { Number }\end{array}$} & \multirow{2}{*}{$\begin{array}{l}\text { Atomic } \\
\text { Type }\end{array}$} & \multicolumn{3}{|c|}{ Coordinates (Angstroms) } \\
\hline & & & $X$ & $\mathrm{Y}$ & $\mathrm{Z}$ \\
\hline 1 & 6 & 0 & 3.692488 & -0.245044 & 0.123445 \\
\hline 2 & 6 & 0 & 3.748127 & -1.707844 & 0.079616 \\
\hline 3 & 6 & 0 & 2.460330 & -2.370449 & 0.034139 \\
\hline 4 & 6 & 0 & 1.288128 & -1.657452 & 0.012400 \\
\hline 5 & 6 & 0 & 1.240894 & -0.220569 & 0.016870 \\
\hline 6 & 6 & 0 & 2.511957 & 0.442233 & 0.096502 \\
\hline 7 & 8 & 0 & 0.120266 & -2.379973 & -0.003120 \\
\hline 8 & 6 & 0 & -1.110914 & -1.771561 & -0.018713 \\
\hline 9 & 6 & 0 & -1.200915 & -0.336740 & -0.031647 \\
\hline 10 & 6 & 0 & -0.013337 & 0.425915 & -0.016971 \\
\hline 11 & 6 & 0 & -2.209828 & -2.593360 & -0.029109 \\
\hline 12 & 6 & 0 & -3.555045 & -2.057386 & -0.073991 \\
\hline 13 & 6 & 0 & -3.639498 & -0.596530 & -0.129620 \\
\hline 14 & 6 & 0 & -2.530037 & 0.200616 & -0.112718 \\
\hline 15 & 6 & 0 & -0.083168 & 1.917913 & 0.002146 \\
\hline 16 & 6 & 0 & 0.455239 & 2.677810 & -1.050059 \\
\hline 17 & 6 & 0 & 0.366720 & 4.071866 & -1.046679 \\
\hline 18 & 6 & 0 & -0.261564 & 4.734727 & 0.011403 \\
\hline 19 & 6 & 0 & -0.805074 & 3.990439 & 1.062324 \\
\hline 20 & 6 & 0 & -0.723441 & 2.596110 & 1.053021 \\
\hline 21 & 8 & 0 & -4.581100 & -2.781398 & -0.078179 \\
\hline 22 & 8 & 0 & 4.838569 & -2.330443 & 0.093461 \\
\hline 23 & 1 & 0 & 4.642902 & 0.277943 & 0.187431 \\
\hline 24 & 1 & 0 & 2.434496 & -3.455056 & 0.027602 \\
\hline 25 & 1 & 0 & 2.524410 & 1.526614 & 0.144770 \\
\hline 26 & 1 & 0 & -2.080295 & -3.670433 & -0.013439 \\
\hline 27 & 1 & 0 & -4.635788 & -0.167405 & -0.194399 \\
\hline 28 & 1 & 0 & -2.646692 & 1.278198 & -0.170973 \\
\hline 29 & 1 & 0 & 0.937540 & 2.166026 & -1.877392 \\
\hline 30 & 1 & 0 & 0.787212 & 4.639062 & -1.872951 \\
\hline 31 & 1 & 0 & -0.328634 & 5.819395 & 0.015997 \\
\hline 32 & 1 & 0 & -1.296736 & 4.494221 & 1.890411 \\
\hline 33 & 1 & 0 & -1.146666 & 2.021777 & 1.871485 \\
\hline
\end{tabular}


Coordinates of anionic $1\left(\theta=70^{\circ}\right)$

\begin{tabular}{|c|c|c|c|c|c|}
\hline \multirow{2}{*}{$\begin{array}{l}\text { Center } \\
\text { Number }\end{array}$} & \multirow{2}{*}{$\begin{array}{l}\text { Atomic } \\
\text { Number }\end{array}$} & \multirow{2}{*}{$\begin{array}{l}\text { Atomic } \\
\text { Type }\end{array}$} & \multicolumn{3}{|c|}{ Coordinates (Angstroms) } \\
\hline & & & $\mathrm{X}$ & $\mathrm{Y}$ & $\mathrm{Z}$ \\
\hline 1 & 6 & 0 & 3.672429 & -0.391201 & 0.091296 \\
\hline 2 & 6 & 0 & 3.669515 & -1.855817 & 0.062358 \\
\hline 3 & 6 & 0 & 2.356874 & -2.469363 & 0.030112 \\
\hline 4 & 6 & 0 & 1.213142 & -1.711642 & 0.014538 \\
\hline 5 & 6 & 0 & 1.224140 & -0.274221 & 0.019386 \\
\hline 6 & 6 & 0 & 2.519384 & 0.341382 & 0.072681 \\
\hline 7 & 8 & 0 & 0.015995 & -2.385759 & -0.000282 \\
\hline 8 & 6 & 0 & -1.189572 & -1.726876 & -0.015188 \\
\hline 9 & 6 & 0 & -1.218885 & -0.289728 & -0.021157 \\
\hline 10 & 6 & 0 & -0.001802 & 0.420460 & -0.001933 \\
\hline 11 & 6 & 0 & -2.323587 & -2.499123 & -0.029481 \\
\hline 12 & 6 & 0 & -3.643931 & -1.902490 & -0.061709 \\
\hline 13 & 6 & 0 & -3.665519 & -0.438102 & -0.091948 \\
\hline 14 & 6 & 0 & -2.521946 & 0.309206 & -0.074569 \\
\hline 15 & 6 & 0 & -0.011249 & 1.915637 & -0.000092 \\
\hline 16 & 6 & 0 & 0.409887 & 2.637608 & -1.128106 \\
\hline 17 & 6 & 0 & 0.396069 & 4.034738 & -1.129223 \\
\hline 18 & 6 & 0 & -0.034557 & 4.734826 & 0.001469 \\
\hline 19 & 6 & 0 & -0.454022 & 4.026433 & 1.131186 \\
\hline 20 & 6 & 0 & -0.445429 & 2.629274 & 1.128268 \\
\hline 21 & 8 & 0 & -4.700830 & -2.580499 & -0.071093 \\
\hline 22 & 8 & 0 & 4.734983 & -2.520284 & 0.072746 \\
\hline 23 & 1 & 0 & 4.643886 & 0.093893 & 0.133750 \\
\hline 24 & 1 & 0 & 2.290206 & -3.552231 & 0.023812 \\
\hline 25 & 1 & 0 & 2.570823 & 1.425741 & 0.102860 \\
\hline 26 & 1 & 0 & -2.243019 & -3.581047 & -0.022070 \\
\hline 27 & 1 & 0 & -4.643123 & 0.034497 & -0.134398 \\
\hline 28 & 1 & 0 & -2.587376 & 1.392762 & -0.105963 \\
\hline 29 & 1 & 0 & 0.745028 & 2.095187 & -2.007303 \\
\hline 30 & 1 & 0 & 0.722476 & 4.575190 & -2.013882 \\
\hline 31 & 1 & 0 & -0.043351 & 5.821551 & 0.002156 \\
\hline 32 & 1 & 0 & -0.789707 & 4.560401 & 2.016308 \\
\hline 33 & 1 & 0 & -0.772651 & 2.080390 & 2.006432 \\
\hline
\end{tabular}


Coordinates of anionic $1\left(\theta=80^{\circ}\right)$

\begin{tabular}{|c|c|c|c|c|c|}
\hline \multirow{2}{*}{$\begin{array}{l}\text { Center } \\
\text { Number }\end{array}$} & \multirow{2}{*}{$\begin{array}{l}\text { Atomic } \\
\text { Number }\end{array}$} & \multirow{2}{*}{$\begin{array}{l}\text { Atomic } \\
\text { Type }\end{array}$} & \multicolumn{3}{|c|}{ Coordinates (Angstroms) } \\
\hline & & & $X$ & $\mathrm{Y}$ & $\mathrm{Z}$ \\
\hline 1 & 6 & 0 & 3.658685 & -0.473498 & 0.049634 \\
\hline 2 & 6 & 0 & 3.622674 & -1.938229 & 0.034949 \\
\hline 3 & 6 & 0 & 2.296736 & -2.523896 & 0.017742 \\
\hline 4 & 6 & 0 & 1.169857 & -1.741451 & 0.009541 \\
\hline 5 & 6 & 0 & 1.213854 & -0.304760 & 0.012716 \\
\hline 6 & 6 & 0 & 2.521890 & 0.284073 & 0.039938 \\
\hline 7 & 8 & 0 & -0.043188 & -2.387408 & 0.000509 \\
\hline 8 & 6 & 0 & -1.233258 & -1.700163 & -0.008351 \\
\hline 9 & 6 & 0 & -1.227845 & -0.262813 & -0.009334 \\
\hline 10 & 6 & 0 & 0.005000 & 0.416610 & 0.003334 \\
\hline 11 & 6 & 0 & -2.386547 & -2.443132 & -0.019023 \\
\hline 12 & 6 & 0 & -3.691400 & -1.812010 & -0.036095 \\
\hline 13 & 6 & 0 & -3.676904 & -0.346894 & -0.047936 \\
\hline 14 & 6 & 0 & -2.514636 & 0.370968 & -0.036120 \\
\hline 15 & 6 & 0 & 0.031137 & 1.913067 & 0.000617 \\
\hline 16 & 6 & 0 & 0.274517 & 2.622510 & -1.185252 \\
\hline 17 & 6 & 0 & 0.303054 & 4.019737 & -1.188404 \\
\hline 18 & 6 & 0 & 0.092792 & 4.729893 & -0.002867 \\
\hline 19 & 6 & 0 & -0.147837 & 4.032569 & 1.184474 \\
\hline 20 & 6 & 0 & -0.179338 & 2.635368 & 1.185005 \\
\hline 21 & 8 & 0 & -4.765192 & -2.462875 & -0.043963 \\
\hline 22 & 8 & 0 & 4.673364 & -2.625800 & 0.040443 \\
\hline 23 & 1 & 0 & 4.641434 & -0.010306 & 0.071206 \\
\hline 24 & 1 & 0 & 2.207176 & -3.605125 & 0.013744 \\
\hline 25 & 1 & 0 & 2.594969 & 1.367830 & 0.054578 \\
\hline 26 & 1 & 0 & -2.334468 & -3.526814 & -0.017194 \\
\hline 27 & 1 & 0 & -4.643035 & 0.150041 & -0.069197 \\
\hline 28 & 1 & 0 & -2.549859 & 1.456671 & -0.048673 \\
\hline 29 & 1 & 0 & 0.440431 & 2.071185 & -2.106303 \\
\hline 30 & 1 & 0 & 0.490748 & 4.552043 & -2.117202 \\
\hline 31 & 1 & 0 & 0.116350 & 5.816398 & -0.004253 \\
\hline 32 & 1 & 0 & -0.311331 & 4.574901 & 2.112049 \\
\hline 33 & 1 & 0 & -0.366876 & 2.094152 & 2.107908 \\
\hline
\end{tabular}


Coordinates of anionic $1\left(\theta=90^{\circ}\right)$

\begin{tabular}{|c|c|c|c|c|c|}
\hline \multirow{2}{*}{$\begin{array}{l}\text { Center } \\
\text { Number }\end{array}$} & \multirow{2}{*}{$\begin{array}{l}\text { Atomic } \\
\text { Number }\end{array}$} & \multirow{2}{*}{$\begin{array}{l}\text { Atomic } \\
\text { Type }\end{array}$} & \multicolumn{3}{|c|}{ Coordinates (Angstroms) } \\
\hline & & & $X$ & Y & $\mathrm{Z}$ \\
\hline 1 & 6 & 0 & 3.667851 & -0.410346 & 0.000202 \\
\hline 2 & 6 & 0 & 3.657042 & -1.875677 & -0.000045 \\
\hline 3 & 6 & 0 & 2.341558 & -2.484832 & 0.000028 \\
\hline 4 & 6 & 0 & 1.201110 & -1.722299 & 0.000094 \\
\hline 5 & 6 & 0 & 1.220654 & -0.285102 & 0.000148 \\
\hline 6 & 6 & 0 & 2.517963 & 0.327208 & 0.000254 \\
\hline 7 & 8 & 0 & -0.001061 & -2.388548 & 0.000140 \\
\hline 8 & 6 & 0 & -1.202644 & -1.721289 & 0.000032 \\
\hline 9 & 6 & 0 & -1.220994 & -0.284085 & -0.000036 \\
\hline 10 & 6 & 0 & 0.000129 & 0.415238 & 0.000082 \\
\hline 11 & 6 & 0 & -2.343757 & -2.482838 & -0.000003 \\
\hline 12 & 6 & 0 & -3.658747 & -1.872597 & -0.000080 \\
\hline 13 & 6 & 0 & -3.668284 & -0.407263 & -0.000198 \\
\hline 14 & 6 & 0 & -2.517772 & 0.329325 & -0.000174 \\
\hline 15 & 6 & 0 & 0.000769 & 1.912453 & 0.000036 \\
\hline 16 & 6 & 0 & 0.001381 & 2.627985 & -1.206700 \\
\hline 17 & 6 & 0 & 0.002106 & 4.025618 & -1.207782 \\
\hline 18 & 6 & 0 & 0.002258 & 4.729448 & -0.000073 \\
\hline 19 & 6 & 0 & 0.001675 & 4.025713 & 1.207688 \\
\hline 20 & 6 & 0 & 0.000938 & 2.628077 & 1.206712 \\
\hline 21 & 8 & 0 & -4.721945 & -2.540723 & 0.000035 \\
\hline 22 & 8 & 0 & 4.719705 & -2.544717 & -0.000310 \\
\hline 23 & 1 & 0 & 4.642646 & 0.069809 & 0.000290 \\
\hline 24 & 1 & 0 & 2.271208 & -3.567477 & -0.000060 \\
\hline 25 & 1 & 0 & 2.571176 & 1.412375 & 0.000451 \\
\hline 26 & 1 & 0 & -2.274277 & -3.565546 & 0.000099 \\
\hline 27 & 1 & 0 & -4.642654 & 0.073766 & -0.000288 \\
\hline 28 & 1 & 0 & -2.570072 & 1.414534 & -0.000328 \\
\hline 29 & 1 & 0 & 0.001271 & 2.081589 & -2.145521 \\
\hline 30 & 1 & 0 & 0.002553 & 4.563143 & -2.152409 \\
\hline 31 & 1 & 0 & 0.002833 & 5.816215 & -0.000115 \\
\hline 32 & 1 & 0 & 0.001821 & 4.563308 & 2.152275 \\
\hline 33 & 1 & 0 & 0.000490 & 2.081756 & 2.145578 \\
\hline
\end{tabular}

Gaussian 09w, Revision D.01, Frisch, M. J.; Trucks, G. W.; Schlegel, H. B.; Scuseria, G. E.; Robb, M. A.; Cheeseman, J. R.; Scalmani, G.; Barone, V.; Mennucci, B.; Petersson, G. A.; Nakatsuji, H.; Caricato, M.; Li, X.; Hratchian, H. P.; Izmaylov, A. F.; Bloino, J.; Zheng, G.; Sonnenberg, J. L.; Hada, M.; Ehara, M.; Toyota, K.; Fukuda, R.; Hasegawa, J.; Ishida, M.; Nakajima, T.; Honda, Y.; Kitao, O.; Nakai, H.; Vreven, T.; Montgomery, J. A., Jr.; Peralta, J. E.; Ogliaro, F.; Bearpark, M.; Heyd, J. J.; Brothers, E.; Kudin, K. N.; Staroverov, V. N.; Kobayashi, R.; Normand, J.; Raghavachari, K.; Rendell, A.; Burant, J. C.; Iyengar, S. S.; Tomasi, J.; Cossi, M.; Rega, N.; Millam, J. M.; Klene, M.; Knox, J. 
E.; Cross, J. B.; Bakken, V.; Adamo, C.; Jaramillo, J.; Gomperts, R.; Stratmann, R. E.; Yazyev, O.; Austin, A. J.; Cammi, R.; Pomelli, C.; Ochterski, J. W.; Martin, R. L.; Morokuma, K.; Zakrzewski, V. G.; Voth, G. A.; Salvador, P.; Dannenberg, J. J.; Dapprich, S.; Daniels, A. D.; Farkas, Ö.; Foresman, J. B.; Ortiz, J. V.; Cioslowski, J.; Fox, D. J. Gaussian, Inc., Wallingford CT, 2009. 
Figure S1. The HOMOs, LUMOs, the energy gaps, and observed and calculated maximum absorption wavelengths of V-shaped Dyes 4-8 by DFT calculations at the B3LYP/6-31+G(d,p) level in a vacuum.

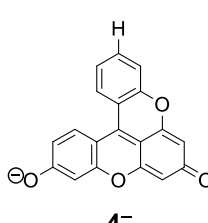

$4^{-}$

2.57

$575 \mathrm{~nm}$

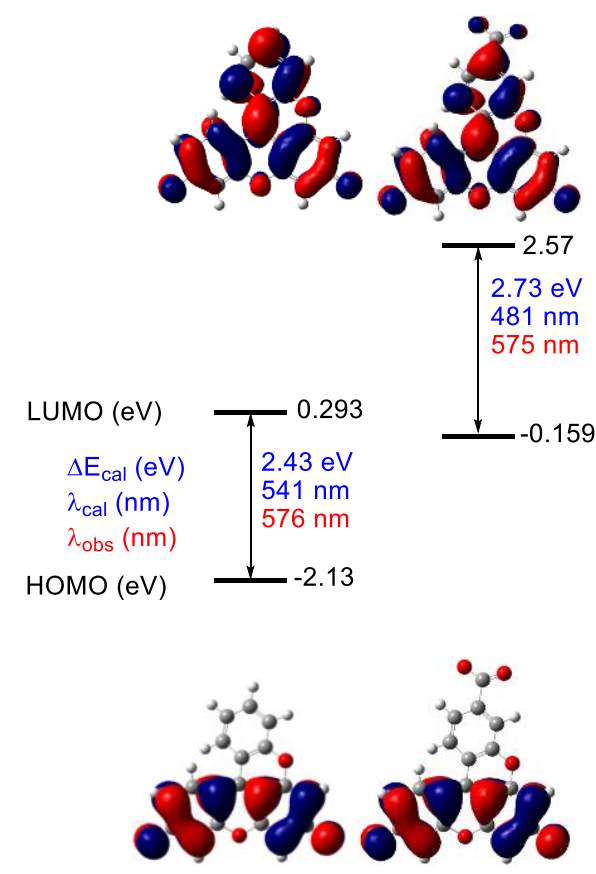

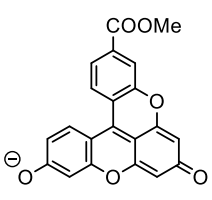

$6^{-}$
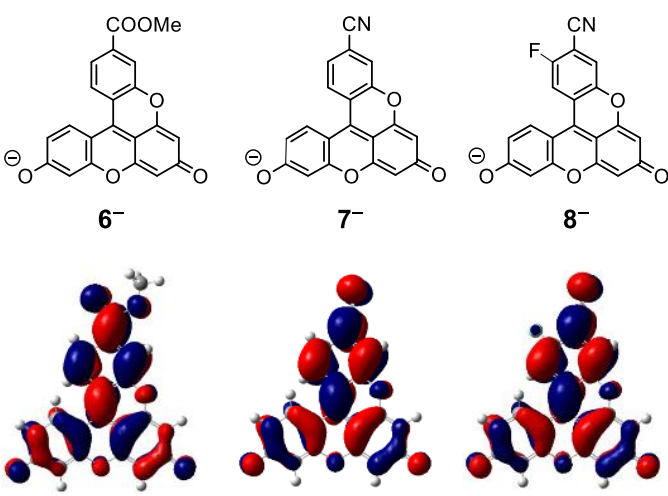

$8^{-}$
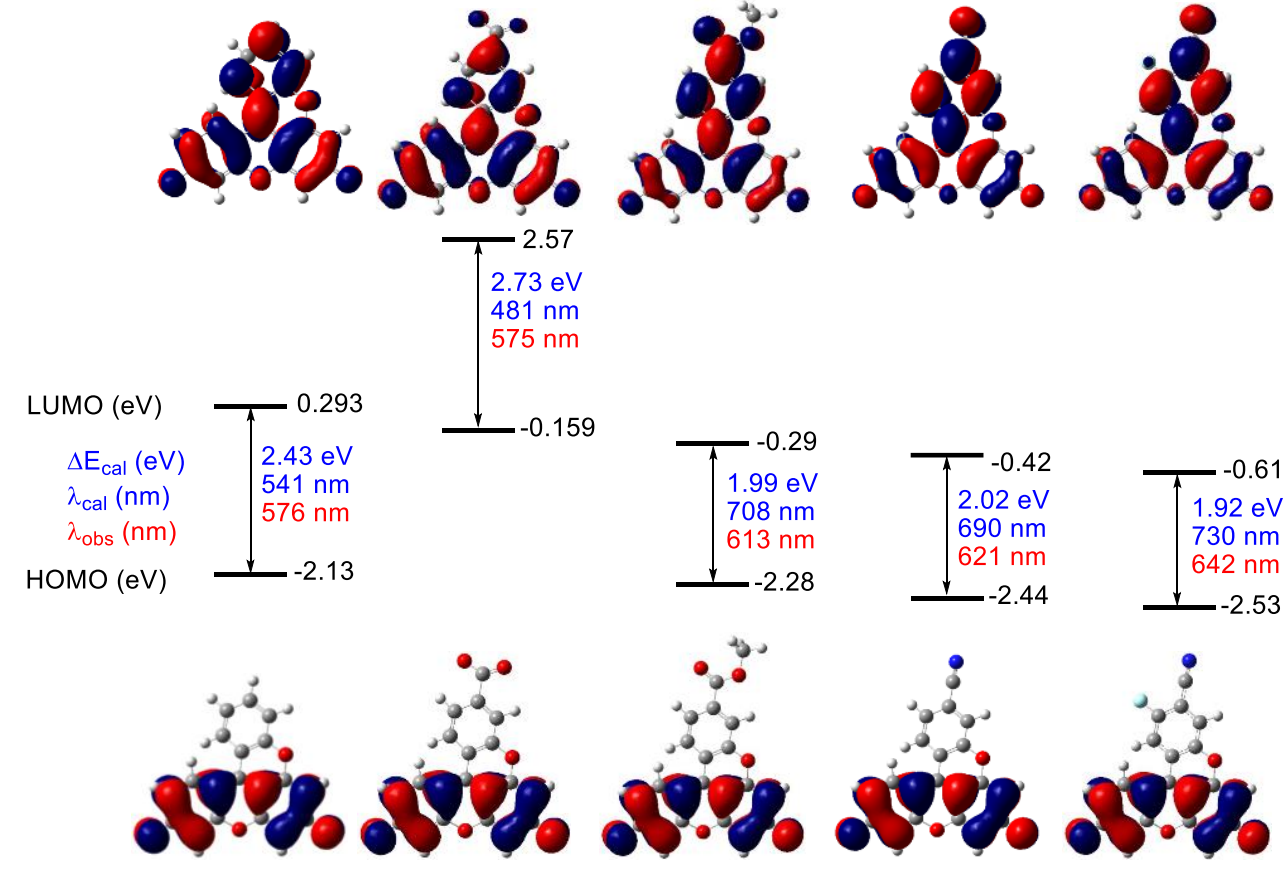
Figure S2. UV-vis (red) and FL (blue) spectra of the three different protonation states of V-shaped dye 7.

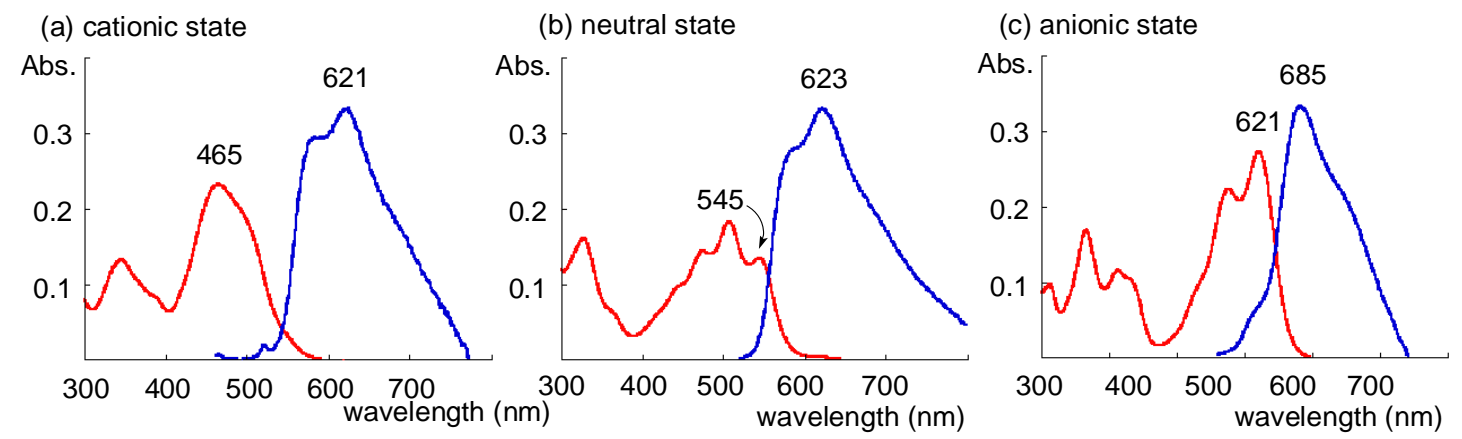

Conditions; DMSO, [7] $=1 \times 10^{-5}$ at $25^{\circ} \mathrm{C}$. 


\section{Assay of V-shaped dye 7 using cells.}

Figure S3: Confocal laser-scanning microscopic sequential images.

(a)

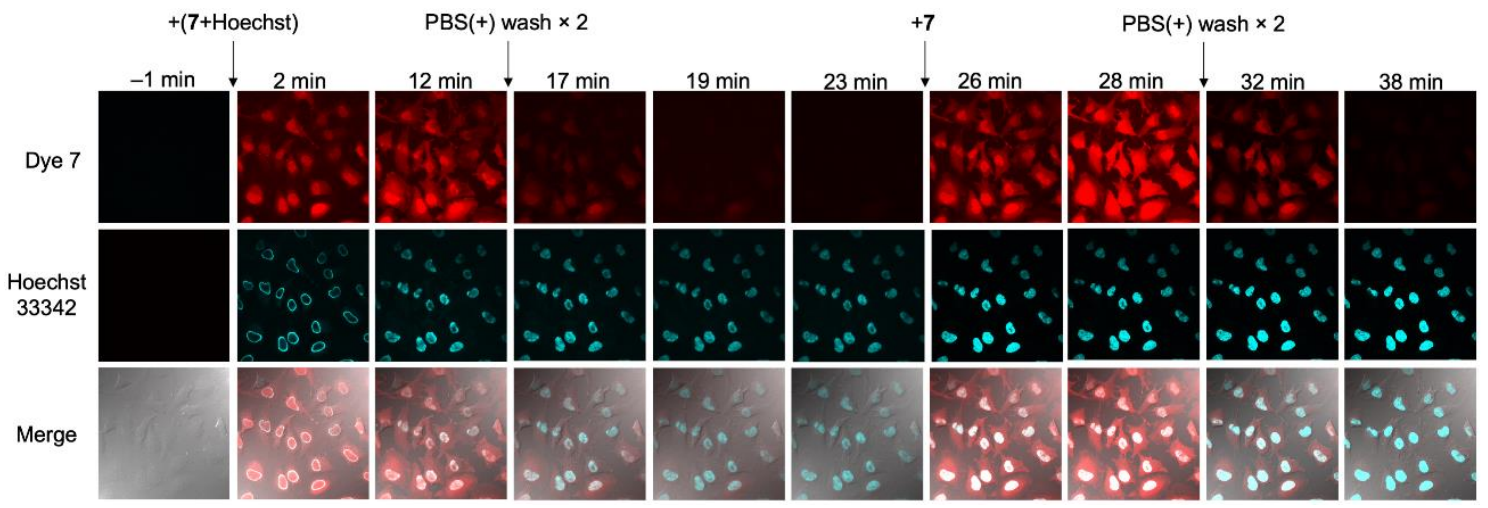

(b)

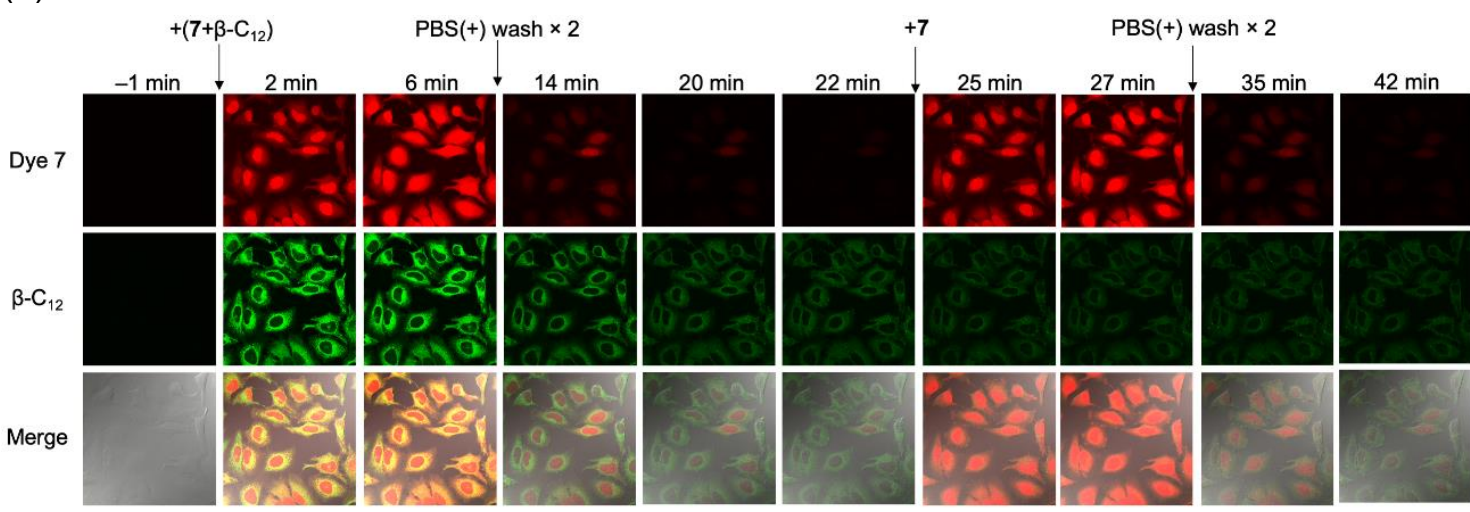

Sequential confocal laser-scanning microscopy images of HeLa cells treated with $7(20 \mu \mathrm{M})$ together with (a) a nuclear dye, Hoechst $33342(8 \mu \mathrm{M})$ or (b) a membrane stain, $\beta$-BODIPY FL $\mathrm{C}_{12}$-HPC ( $\beta$ $\left.\mathrm{C}_{12}\right)(1.2 \mu \mathrm{M})$, respectively. Time zero corresponds to the time 7 and Hoechst 33342 or $\beta-\mathrm{C}_{12}$ were simultaneously added to the cells. In (a), the cells were washed twice with PBS(+) at 15 min, and the cells were further incubated in fresh $\operatorname{PBS}(+)$. The PBS(+) was replaced to PBS(+) containing 7 (20 $\mu \mathrm{M})$ at $24 \mathrm{~min}$ before washout at $30 \mathrm{~min}$ and the following incubation. In (b), the cells were similarly treated, which included with PBS(+) wash at $12 \mathrm{~min}$, the addition of 7 at $23 \mathrm{~min}$, and then another PBS(+) wash at $33 \mathrm{~min}$. Bottom panels represent the DIC images merged with signals of 7 and Hoechst 33342 (a) or $\beta-C_{12}$ (b), respectively. Note that $>15$ min was needed to stain the nucleus by Hoechst 33342 effectively and to remove $\beta-\mathrm{C}_{12}$ signals from cells substantively. 
Figure S4: Cell viability of HeLa cells on treatment with dye 7.
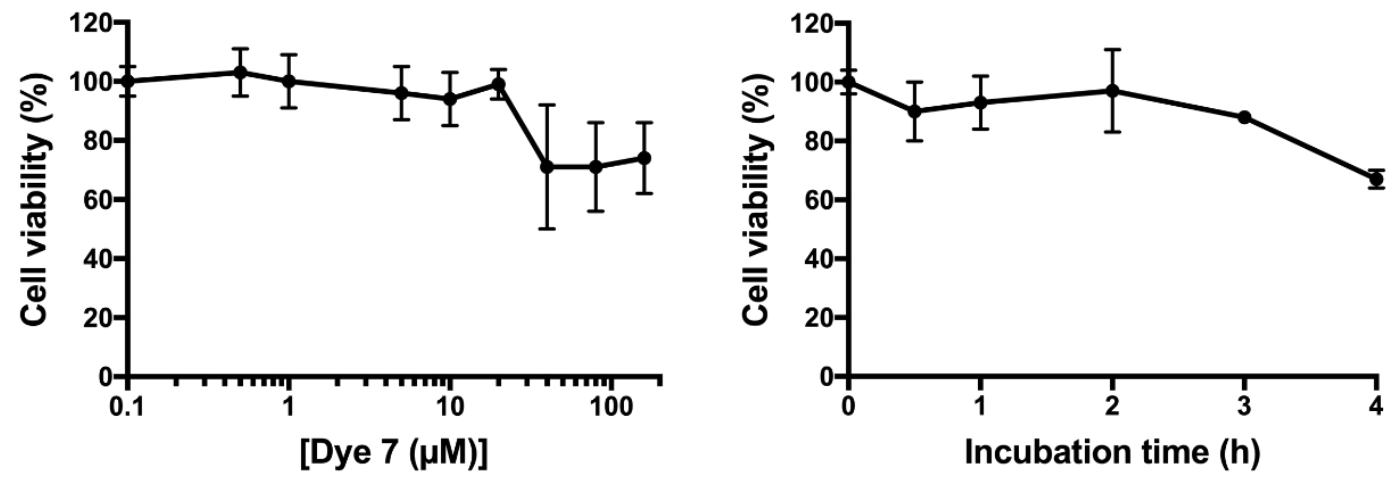

(a) Effect of concentration and (b) prolonged incubation on cell viability under treatment with dye 7. HeLa cells were incubated with 7 at the concentrations of $0,0.5,1,5,10,20,40,80$, and $160 \mu \mathrm{M}$ for 15 min (a) or treated with $20 \mu \mathrm{M} 7$ for $0,0.5,1,2,3$, and $4 \mathrm{~h}$ (b), prior to WST-8 assay. No notable cell death was observed for the incubation with $20 \mu \mathrm{M} 7$ for $2 \mathrm{~h}$. 
${ }^{1} \mathrm{H}$ NMR spectrum $(400 \mathrm{MHz})$ of $\mathbf{1 0 a}$ in $\mathrm{CDCl}_{3}$.

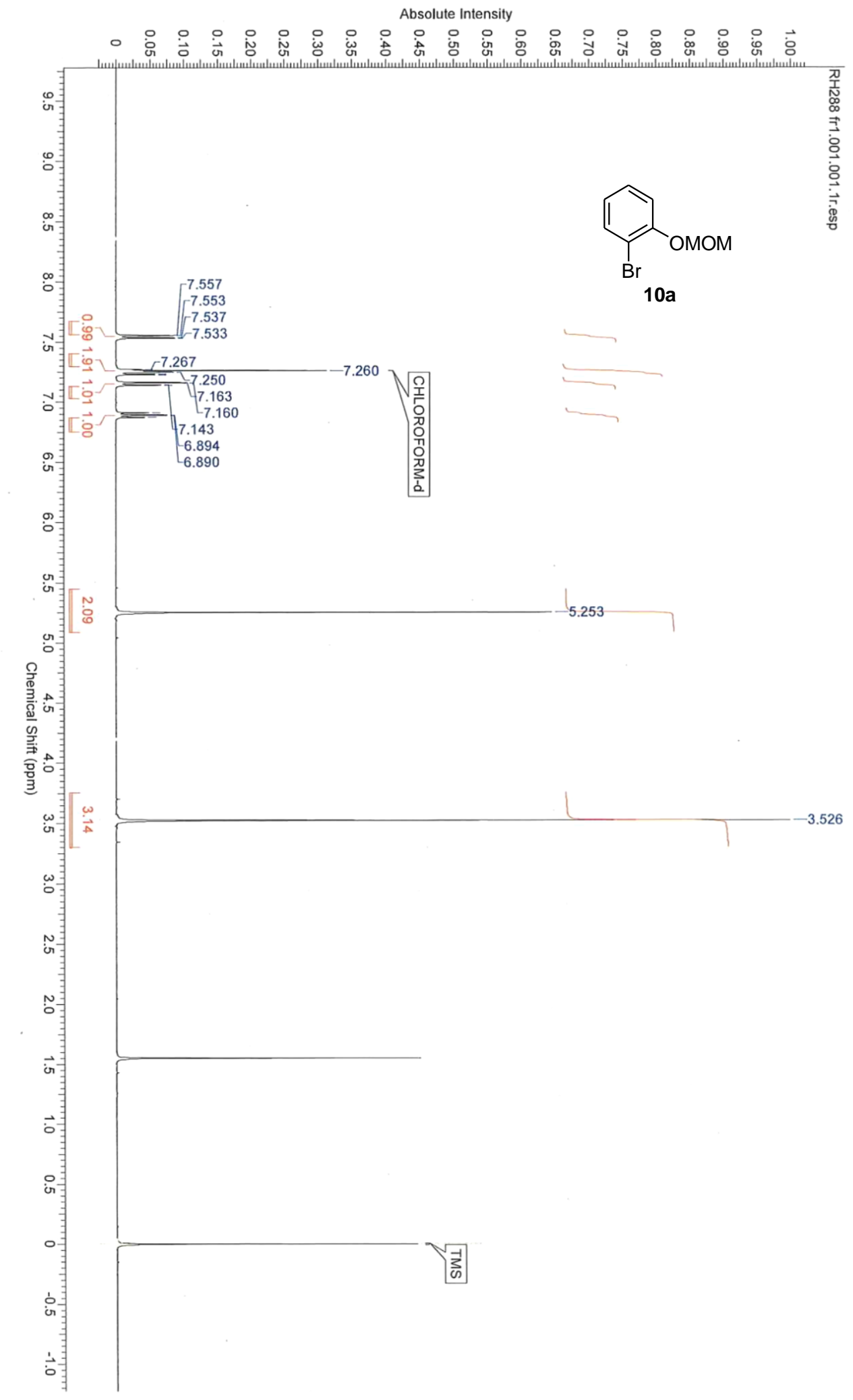


${ }^{1} \mathrm{H}$ NMR spectrum (400 MHz) of $\mathbf{1 6}$ in $\mathrm{CD}_{3} \mathrm{OD}$.

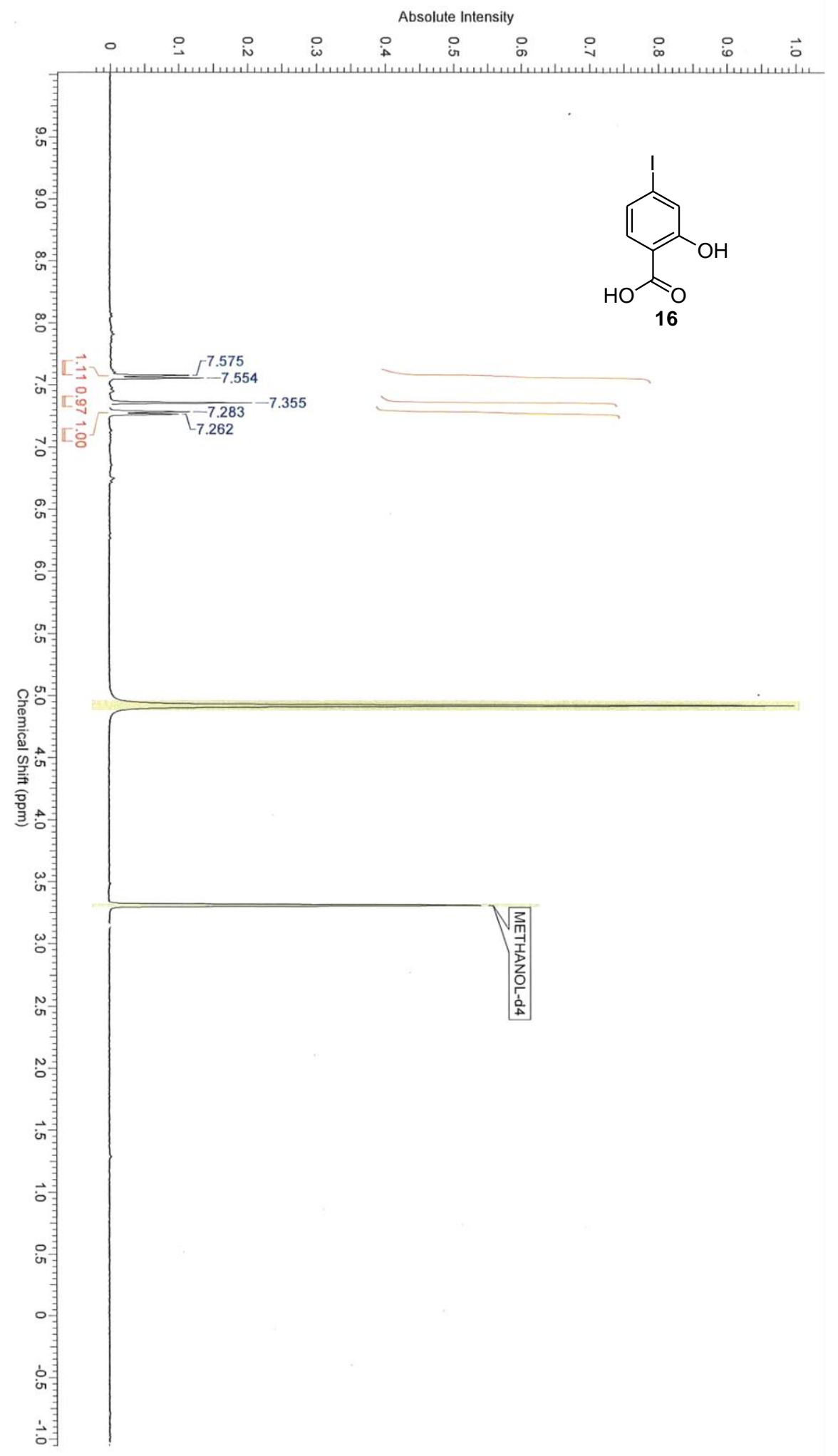


${ }^{1} \mathrm{H}$ NMR and ${ }^{13} \mathrm{C}$ NMR spectra for all new compounds.

${ }^{1} \mathrm{H}$ NMR spectrum $(800 \mathrm{MHz})$ of $\mathbf{4}$ in DMSO- $d_{6}$.

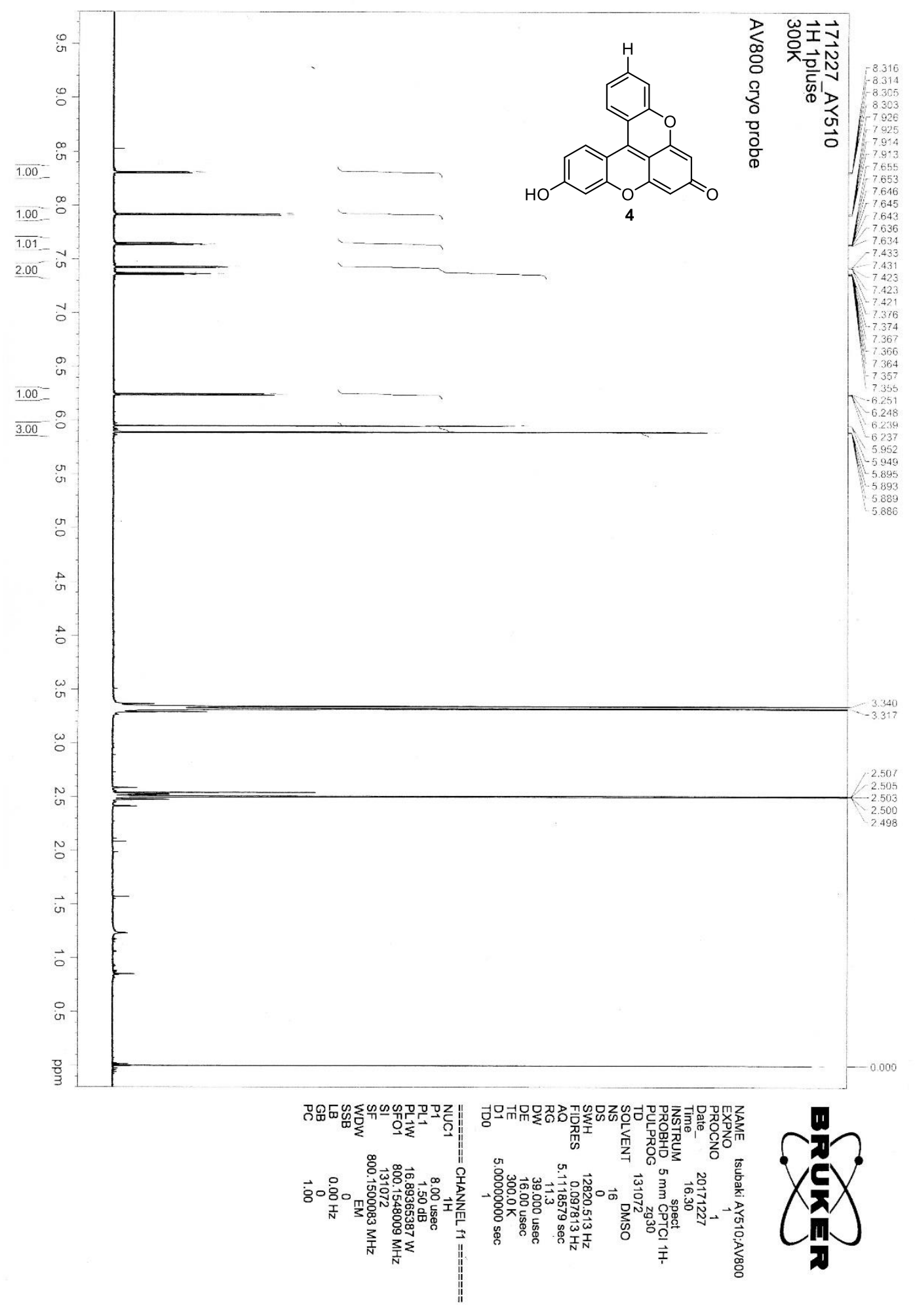


${ }^{13} \mathrm{C}\left\{{ }^{1} \mathrm{H}\right\}$ NMR spectrum $(200 \mathrm{MHz})$ of 4 in DMSO- $d_{6}$.

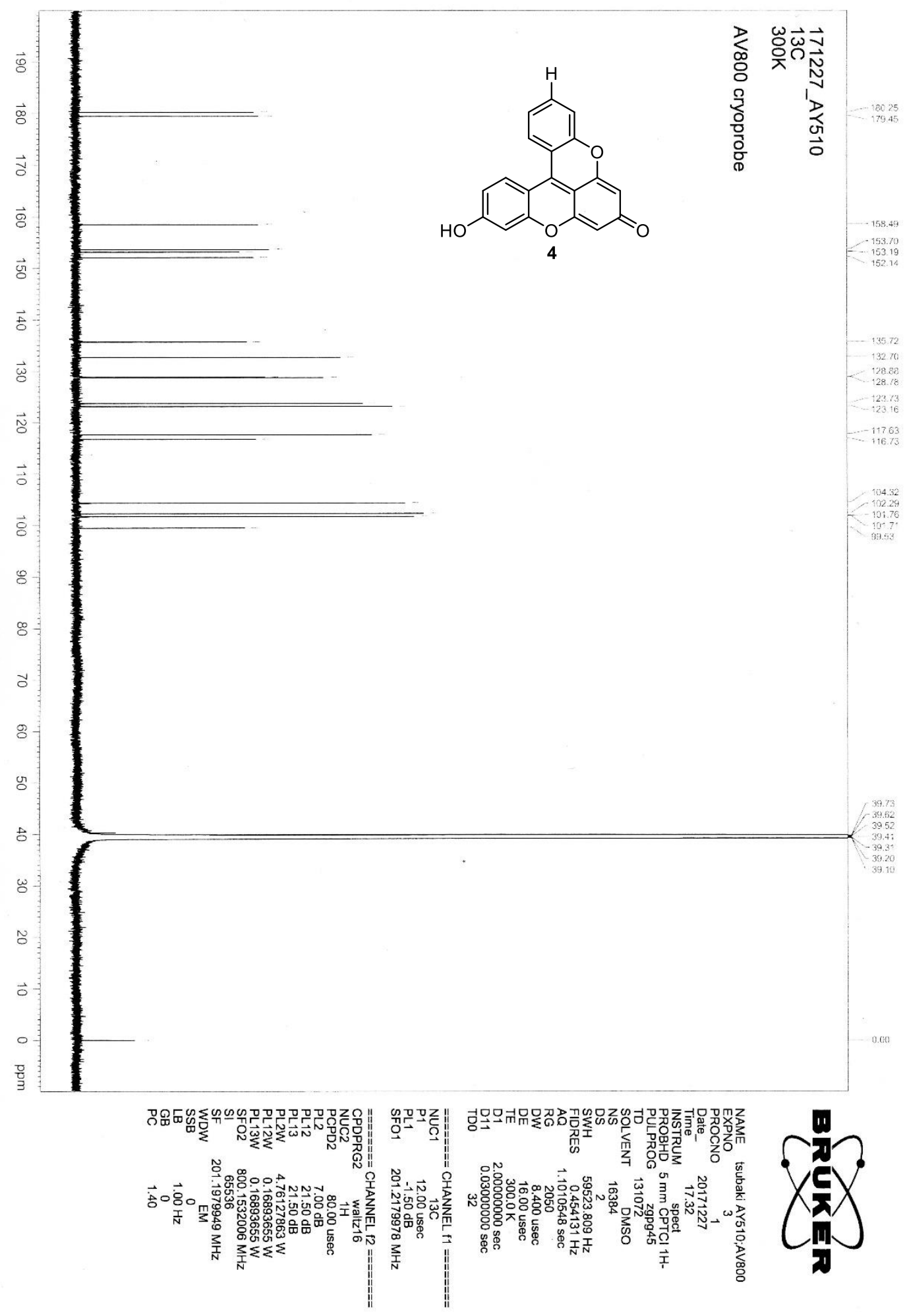


${ }^{1} \mathrm{H}$ NMR spectrum (400 MHz) of 5 in DMSO- $d_{6}$.

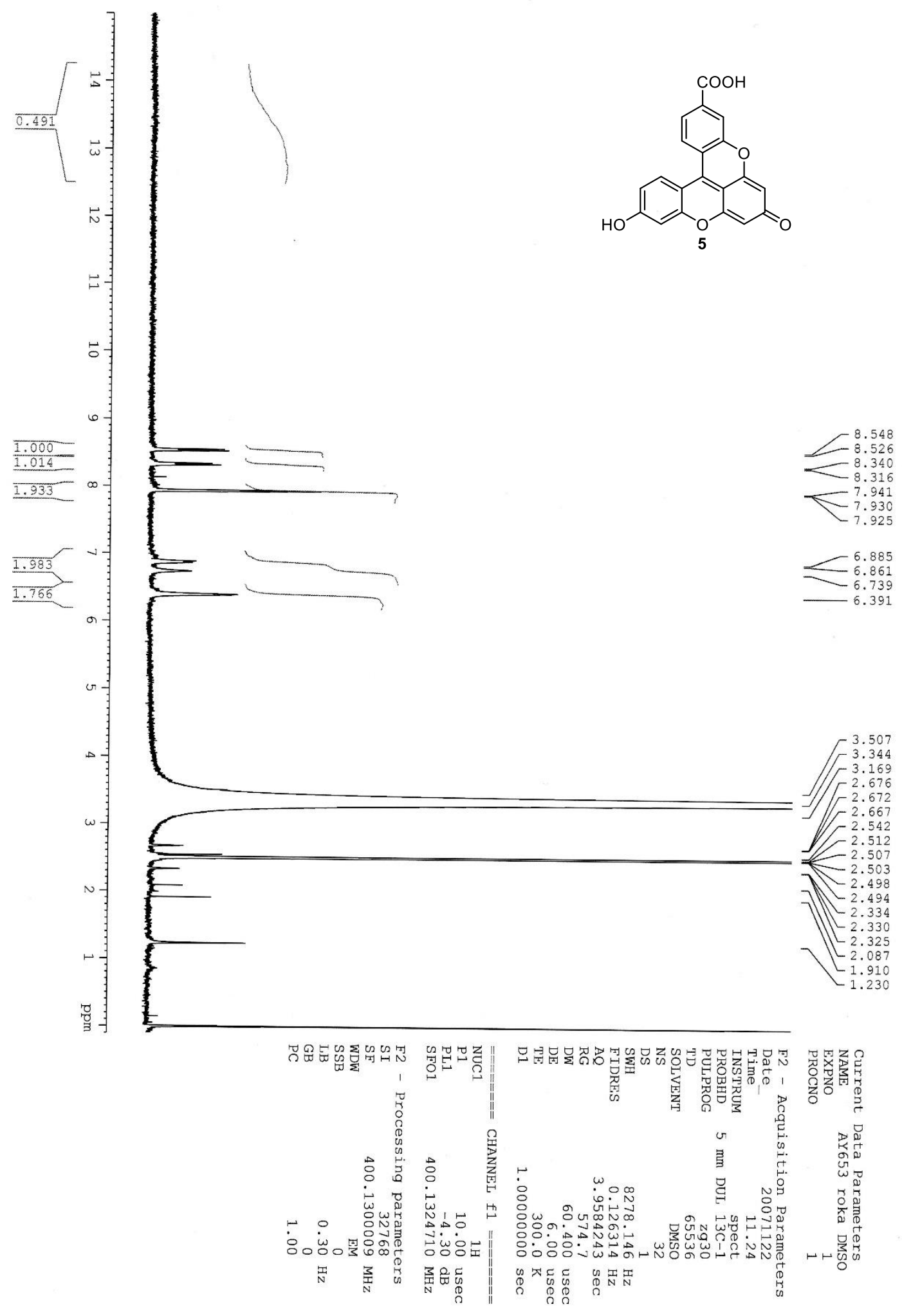


${ }^{13} \mathrm{C}\left\{{ }^{1} \mathrm{H}\right\}$ NMR spectrum $(200 \mathrm{MHz})$ of 5 in DMSO- $d_{6}$.

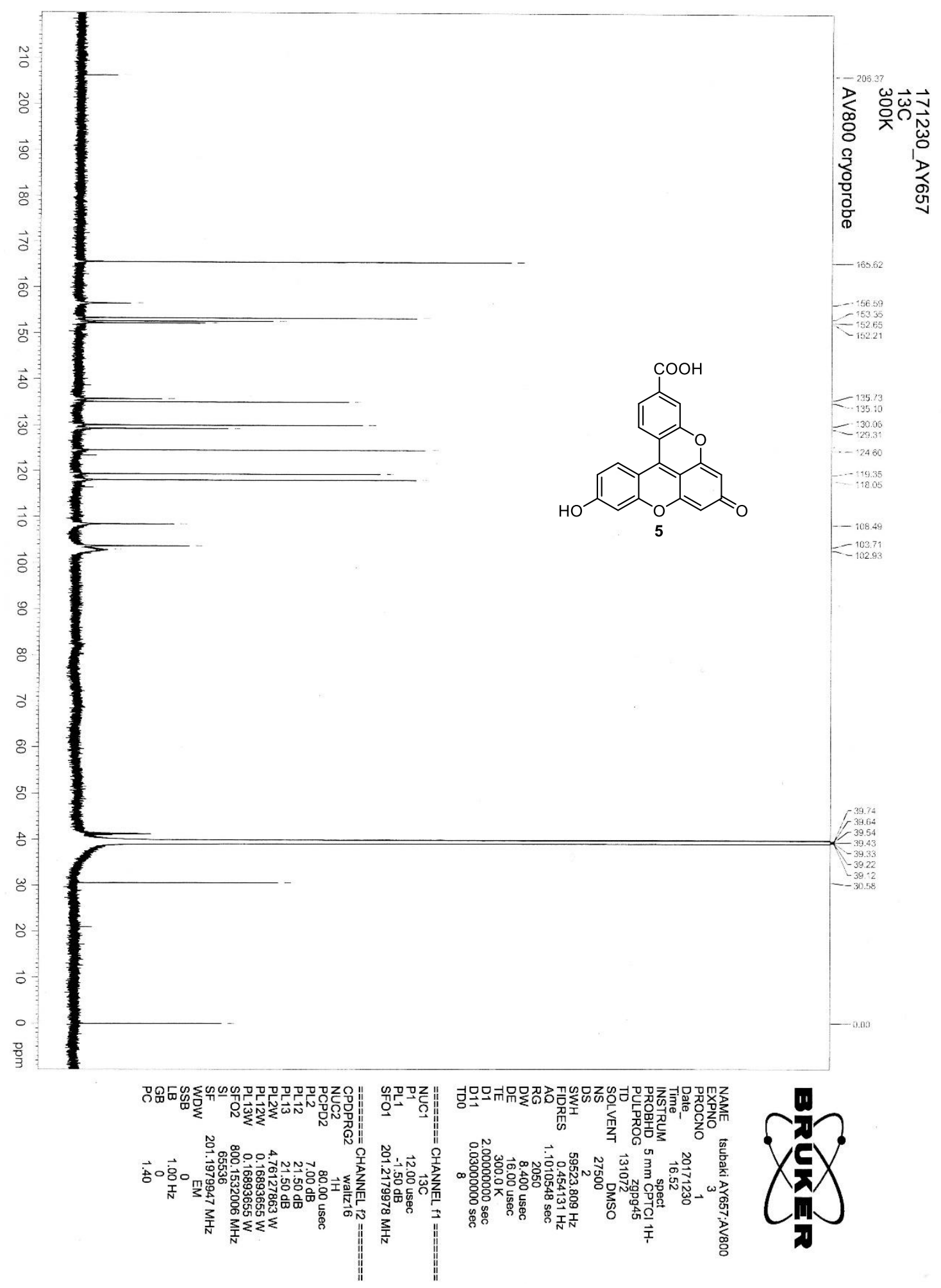


${ }^{1} \mathrm{H}$ NMR spectrum (400 MHz) of 6 in DMSO- $d_{6}$.

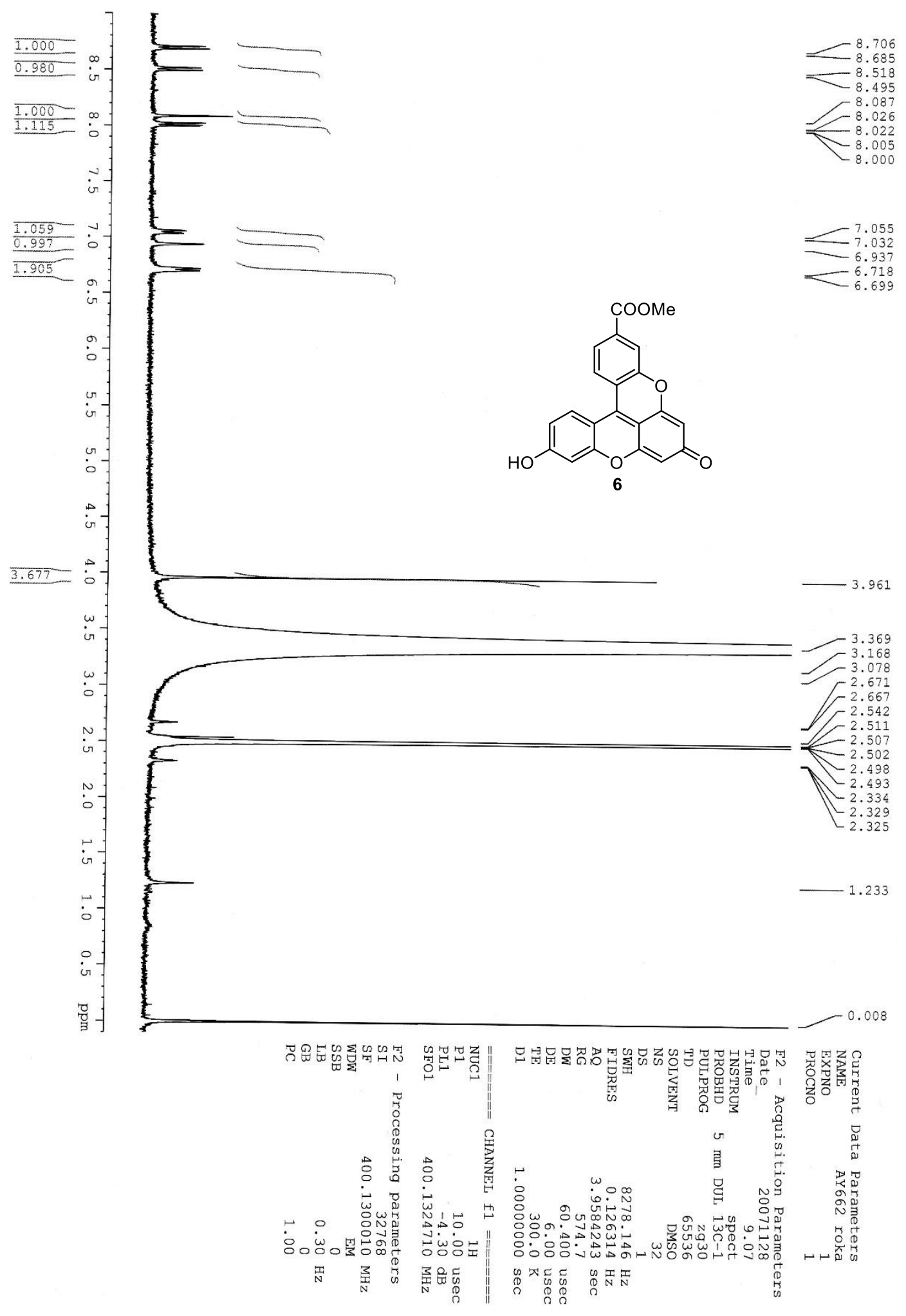


${ }^{13} \mathrm{C}\left\{{ }^{1} \mathrm{H}\right\}$ NMR spectrum (200 MHz) of 6 in DMSO- $d_{6}$.

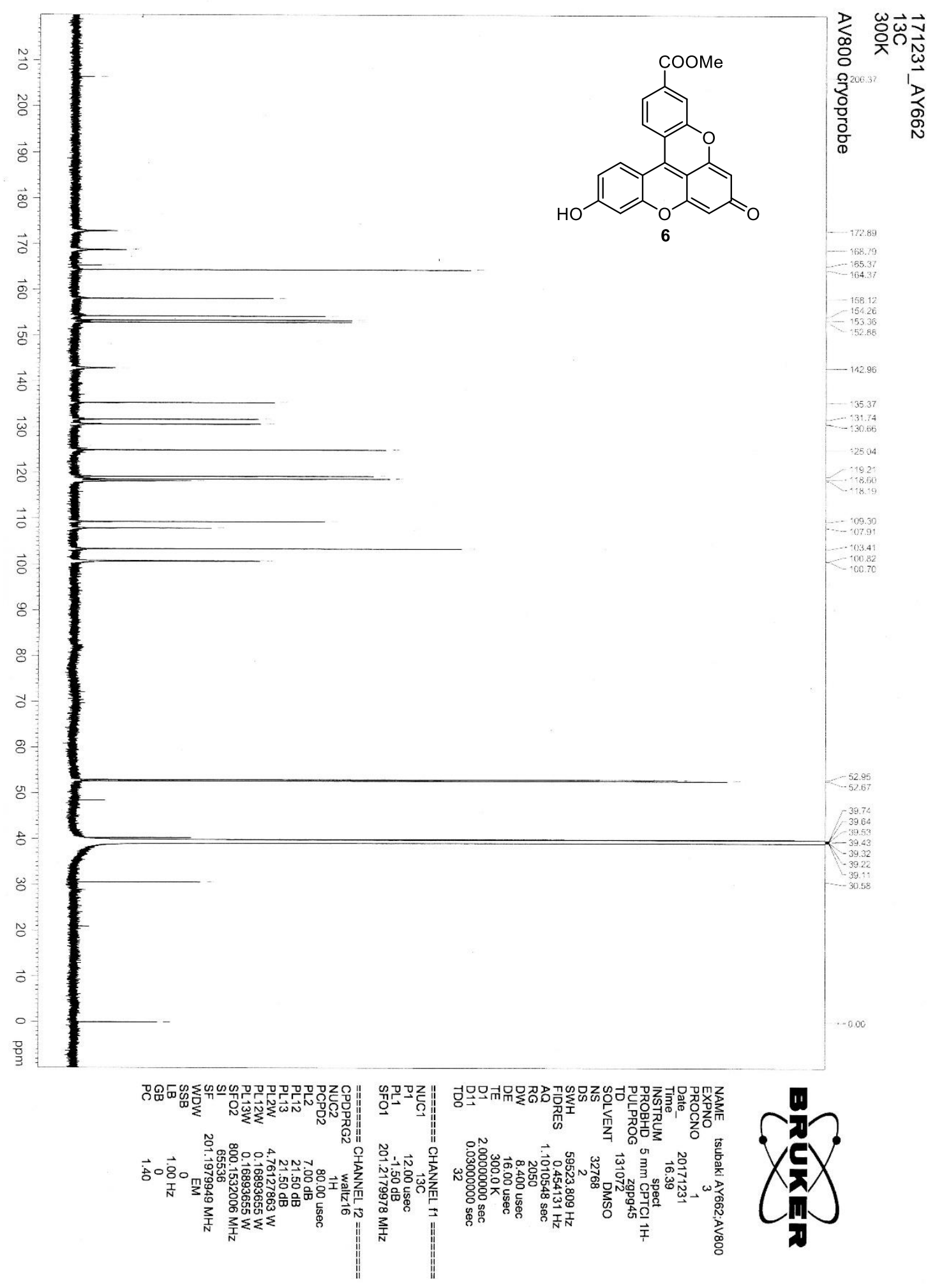




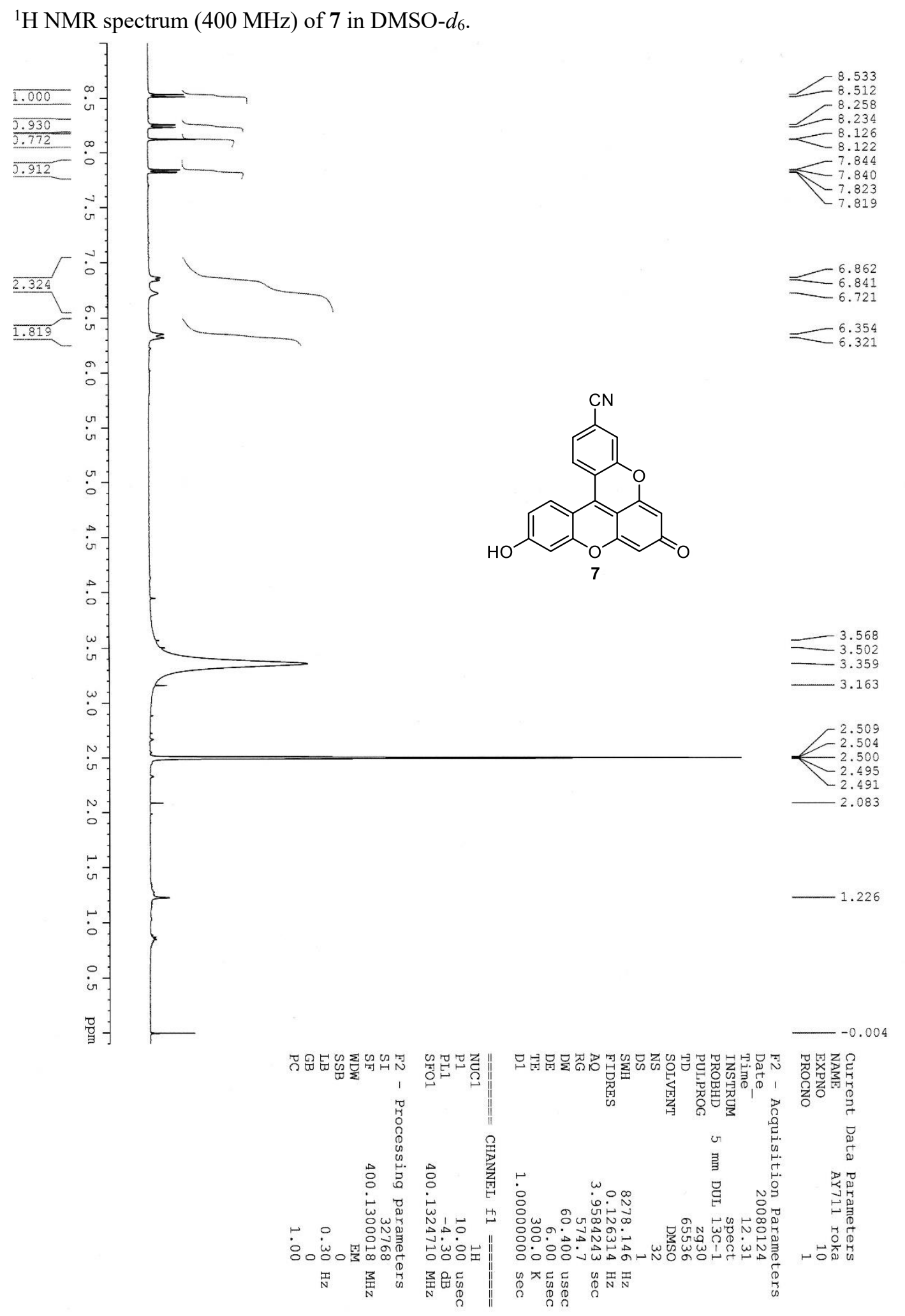


${ }^{13} \mathrm{C}\left\{{ }^{1} \mathrm{H}\right\}$ NMR spectrum (200 MHz) of 7 in DMSO- $d_{6}$.

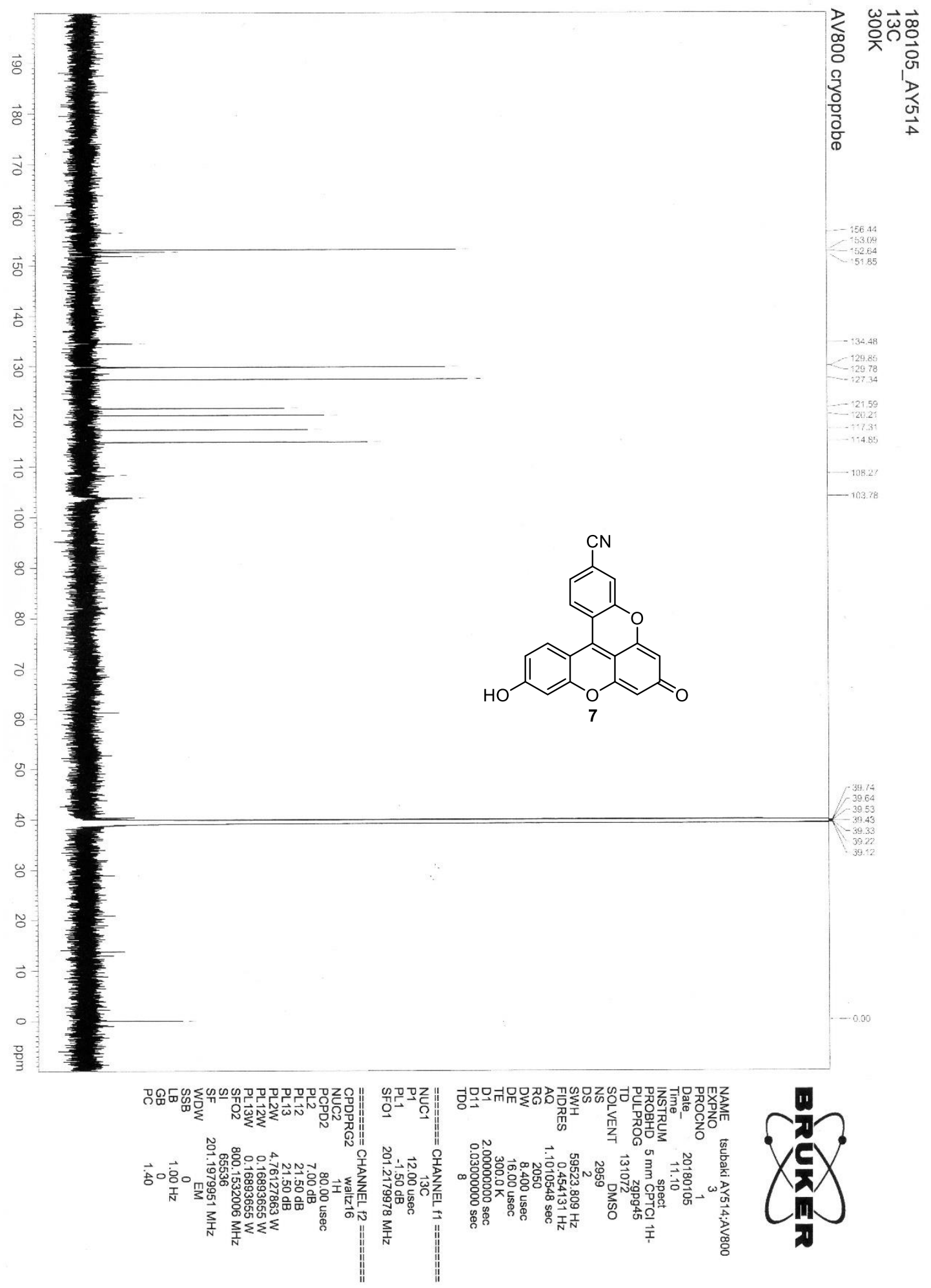


${ }^{1} \mathrm{H}$ NMR spectrum (400 MHz) of 8 in DMSO- $d_{6}$.

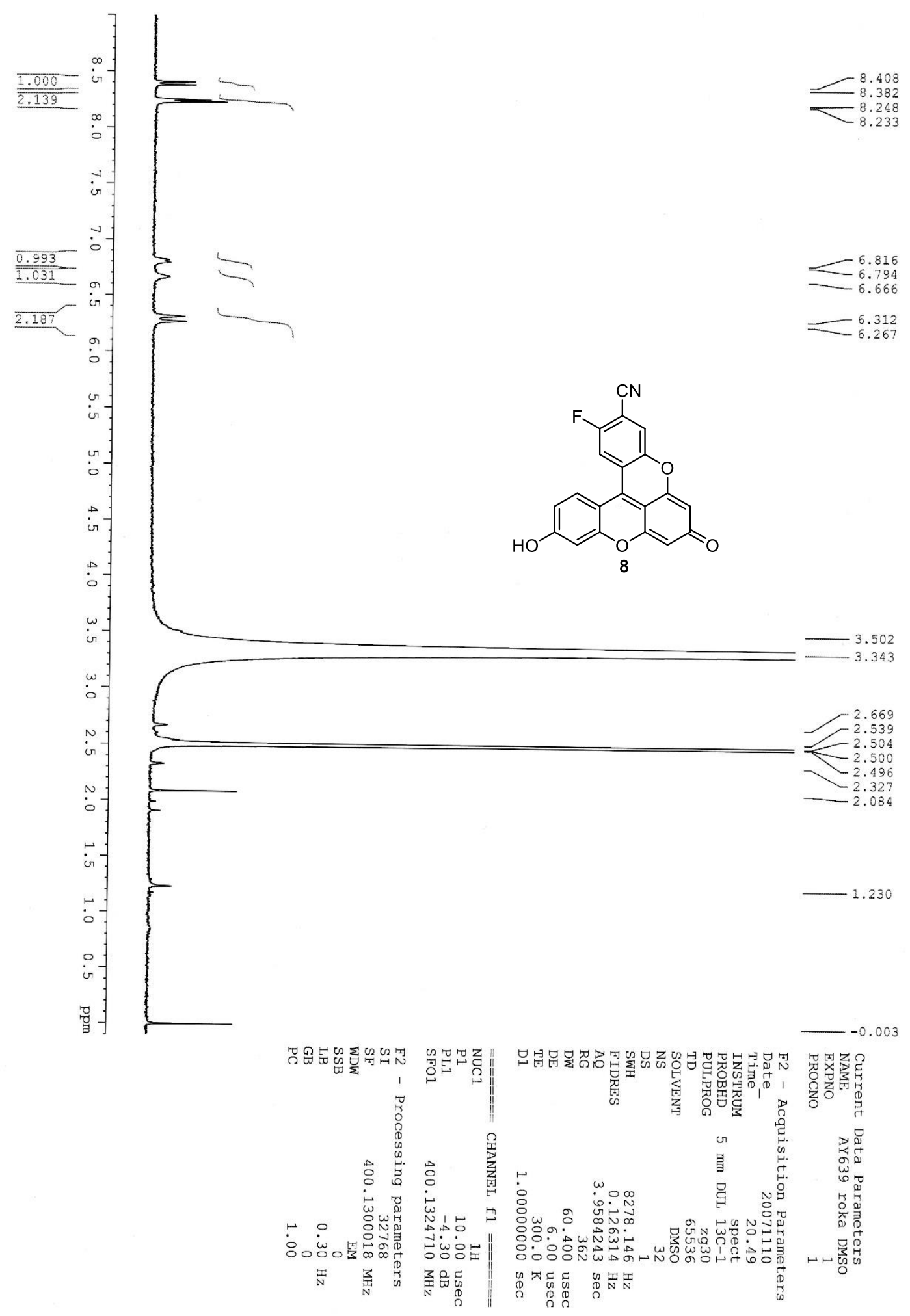


${ }^{13} \mathrm{C}\left\{{ }^{1} \mathrm{H}\right\}$ NMR spectrum (200 MHz) of 8 in DMSO- $d_{6}$.

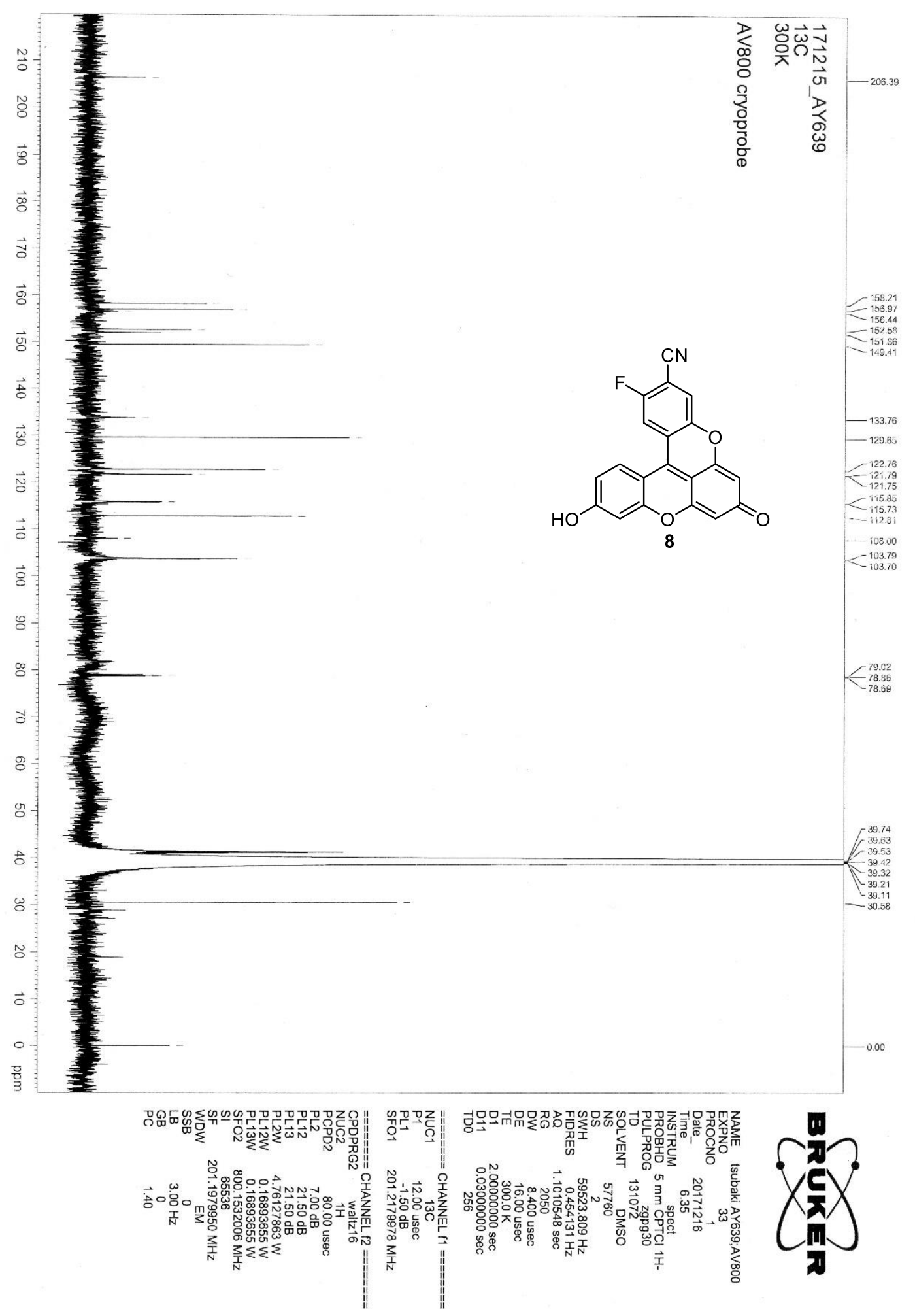


HSQC NMR spectrum of compound 8 in DMSO- $d_{6}$.
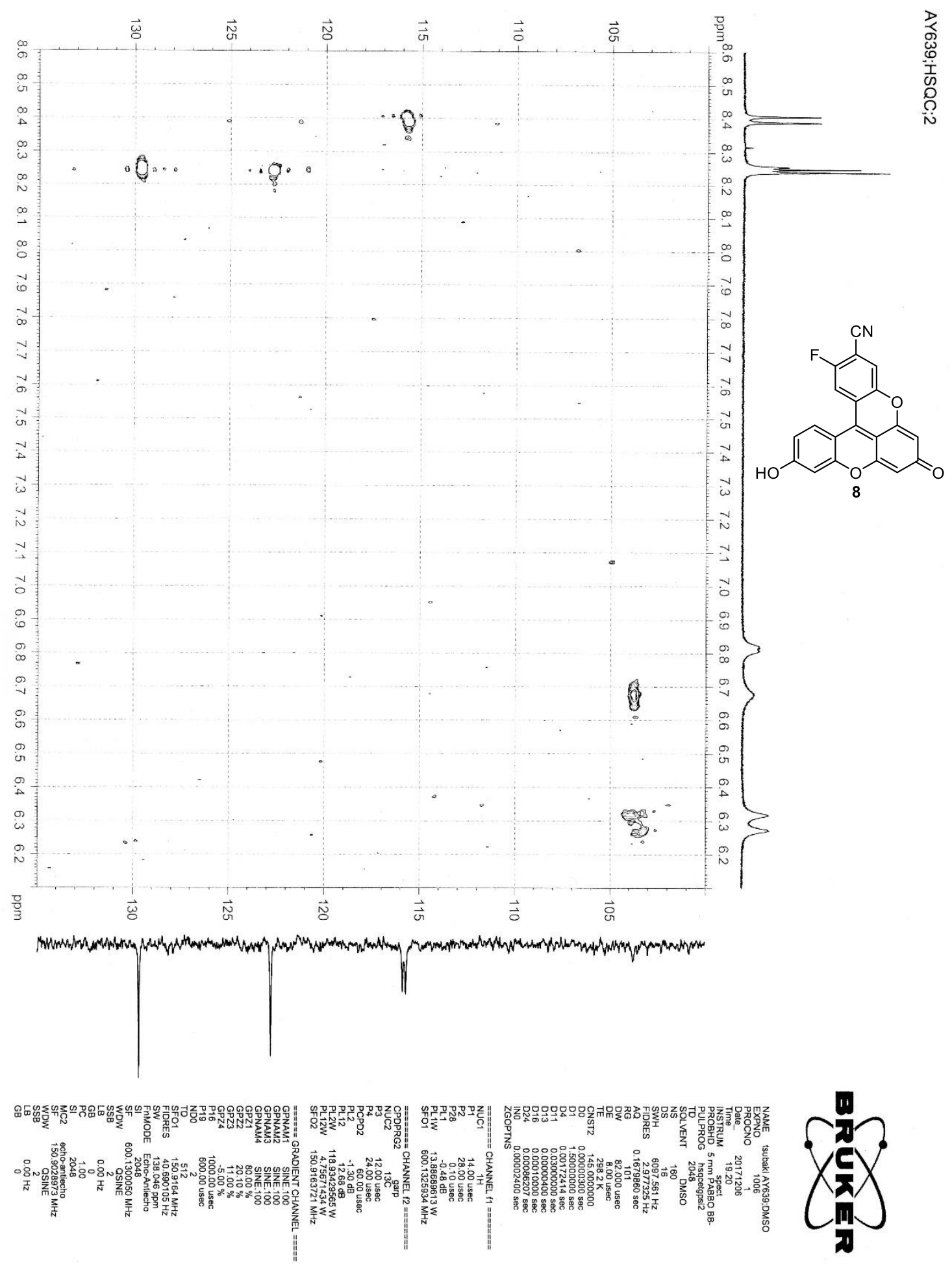

- S29- 
DEPT135 spectrum of compound 8 in DMSO- $d_{6}$.

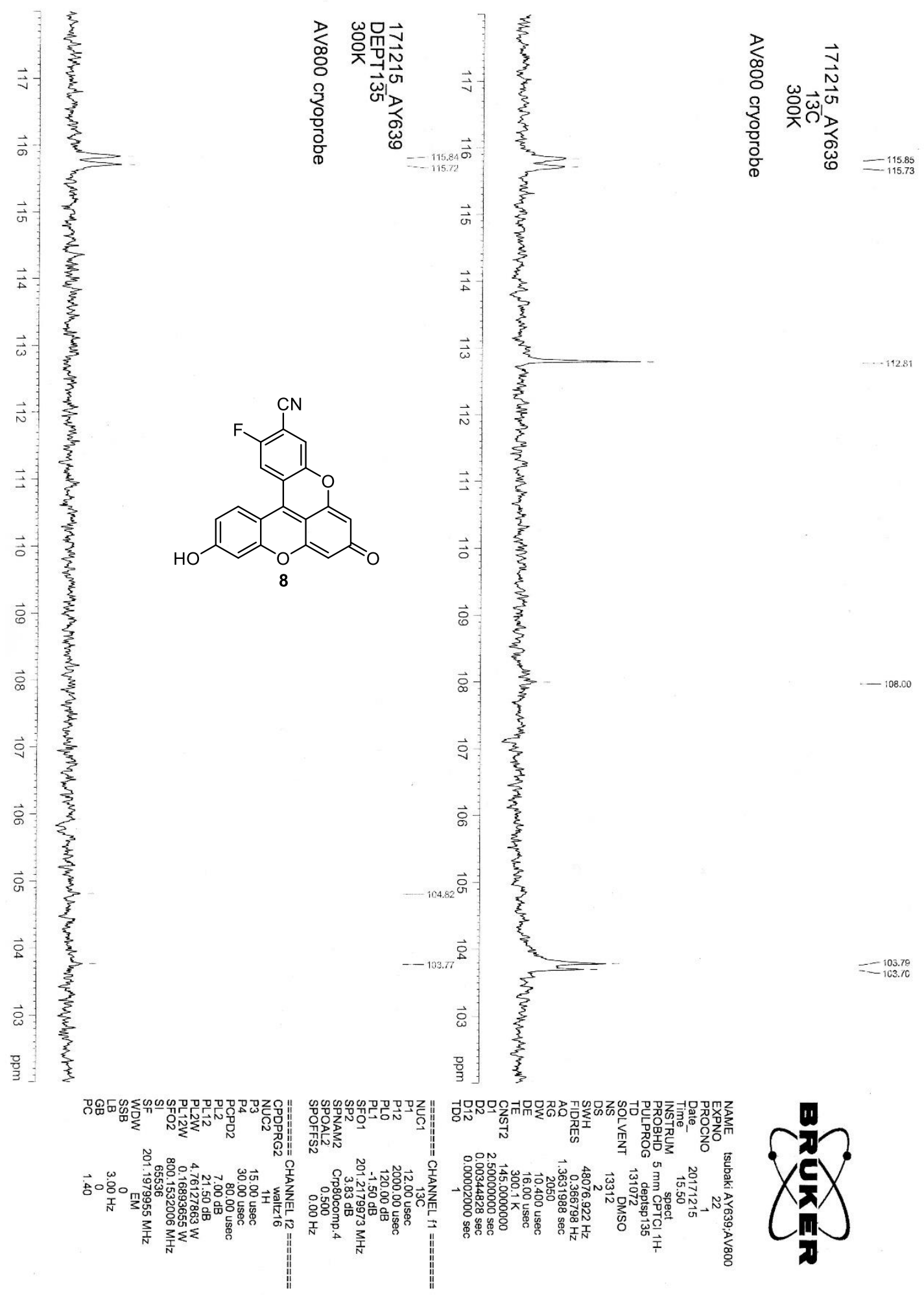


H-H NOESY spectrum of compound 8 in DMSO- $d_{6}$.

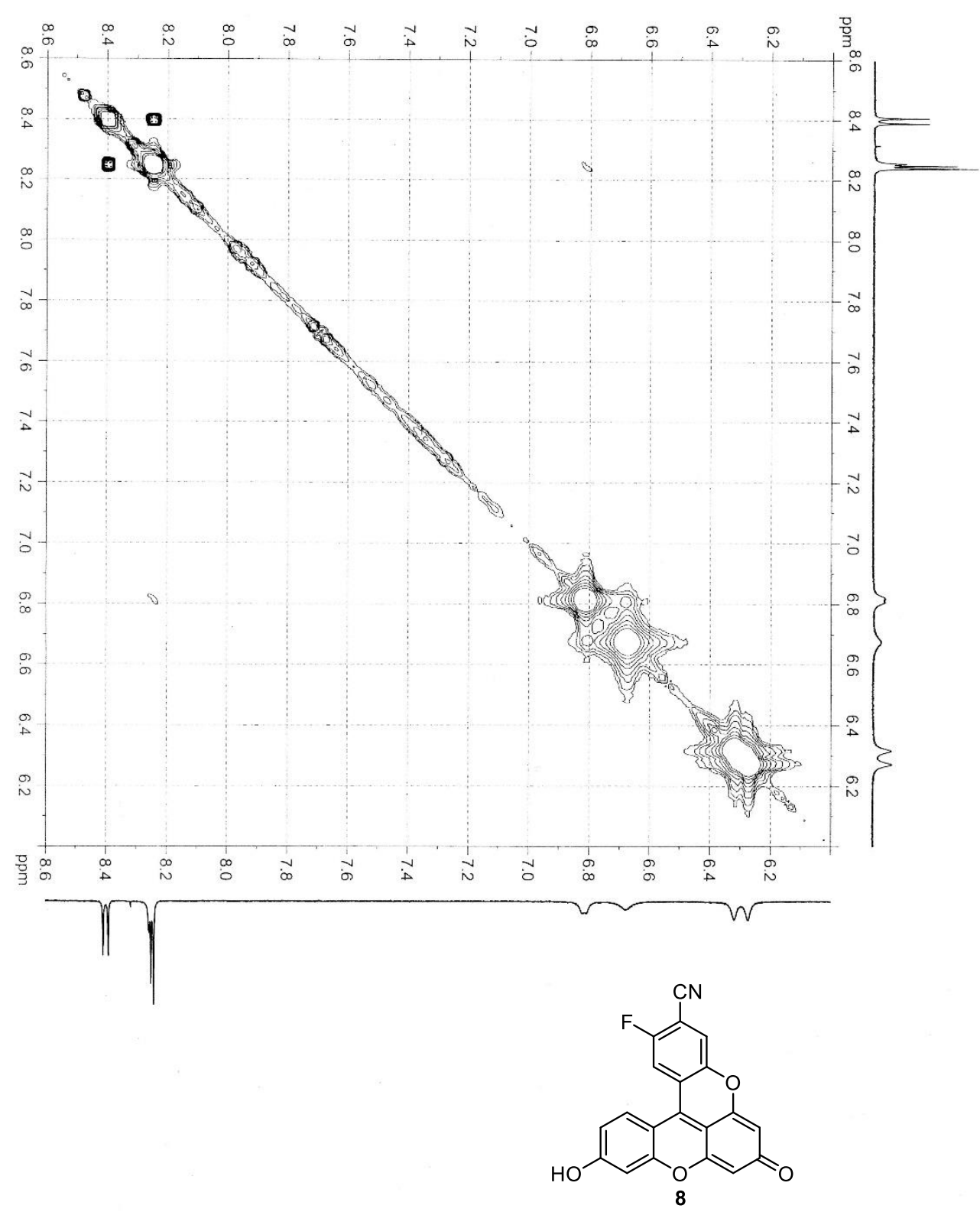

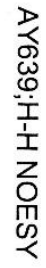

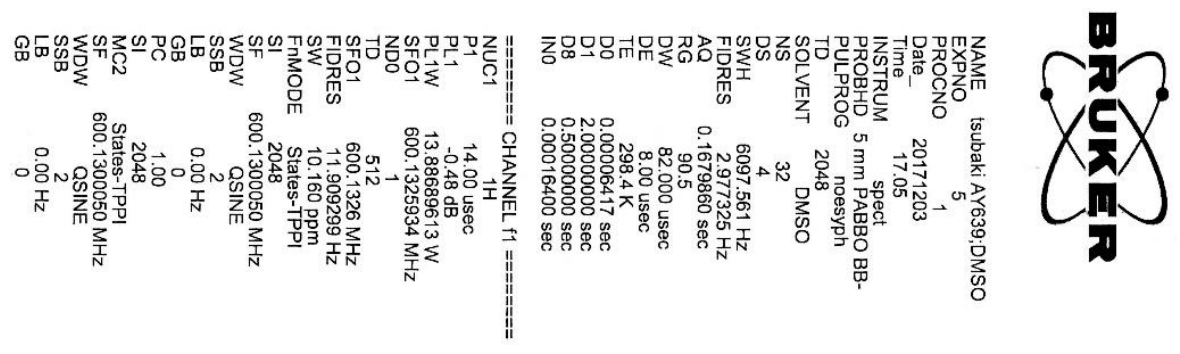


${ }^{1} \mathrm{H}\left\{{ }^{19} \mathrm{~F}\right\}$ NMR spectrum (800 MHz) of 8 in DMSO- $d_{6}$.

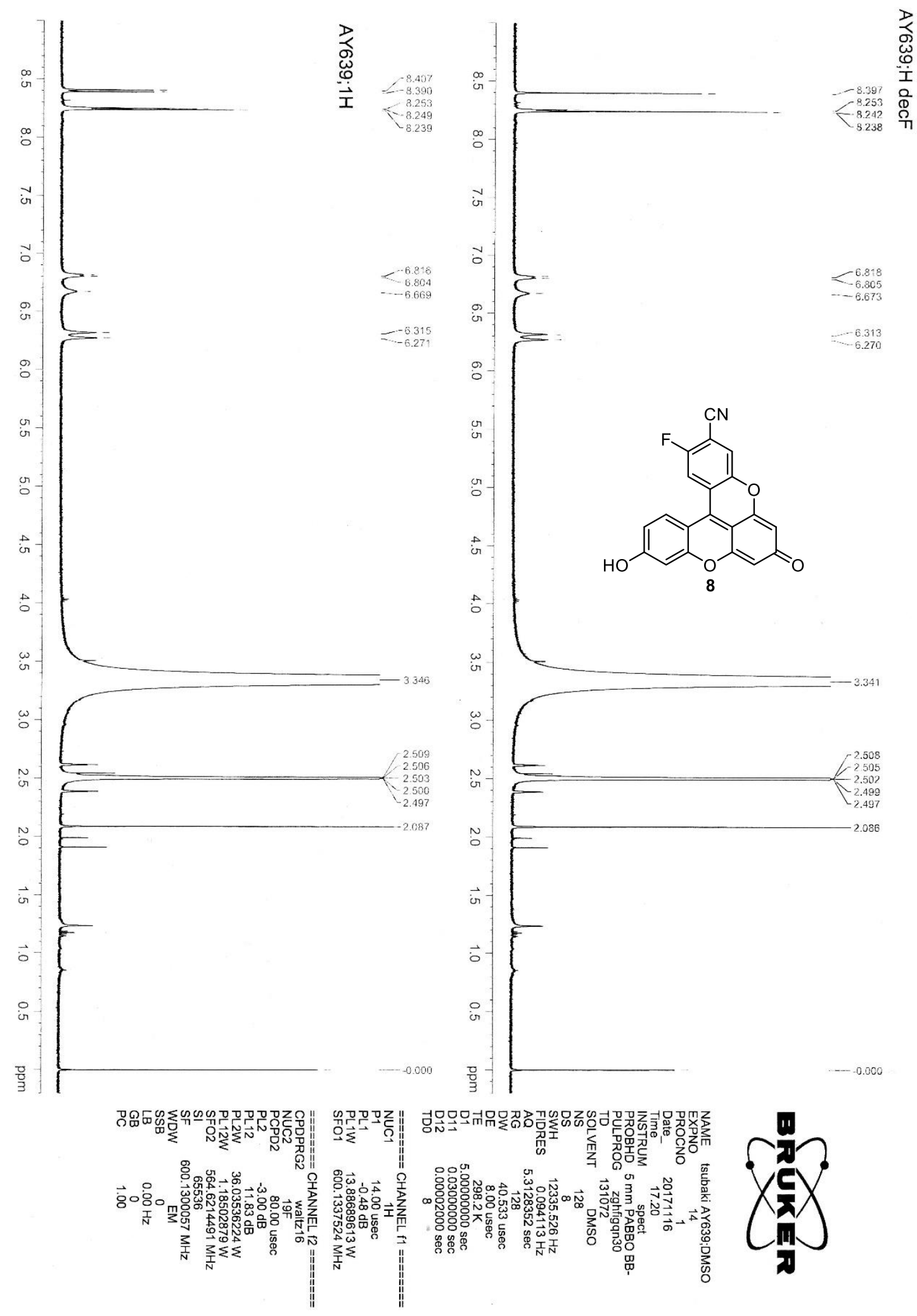


${ }^{1} \mathrm{H}\left\{{ }^{19} \mathrm{~F}\right\}$ NMR spectrum (800 MHz) of 8 in DMSO- $d_{6}$.

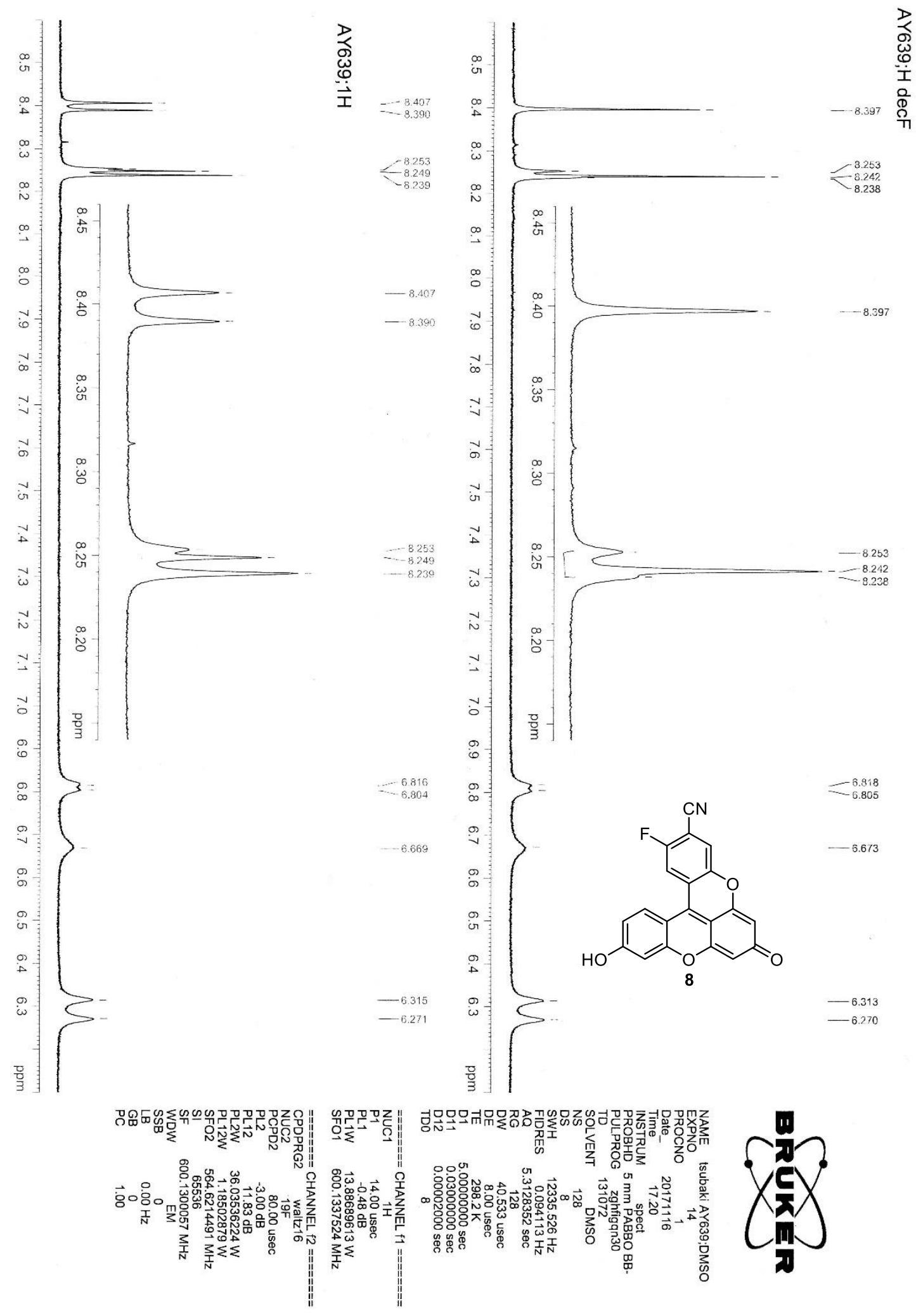


${ }^{1} \mathrm{H}$ NMR spectrum (400 MHz) of 17 in $\mathrm{CDCl}_{3}$.

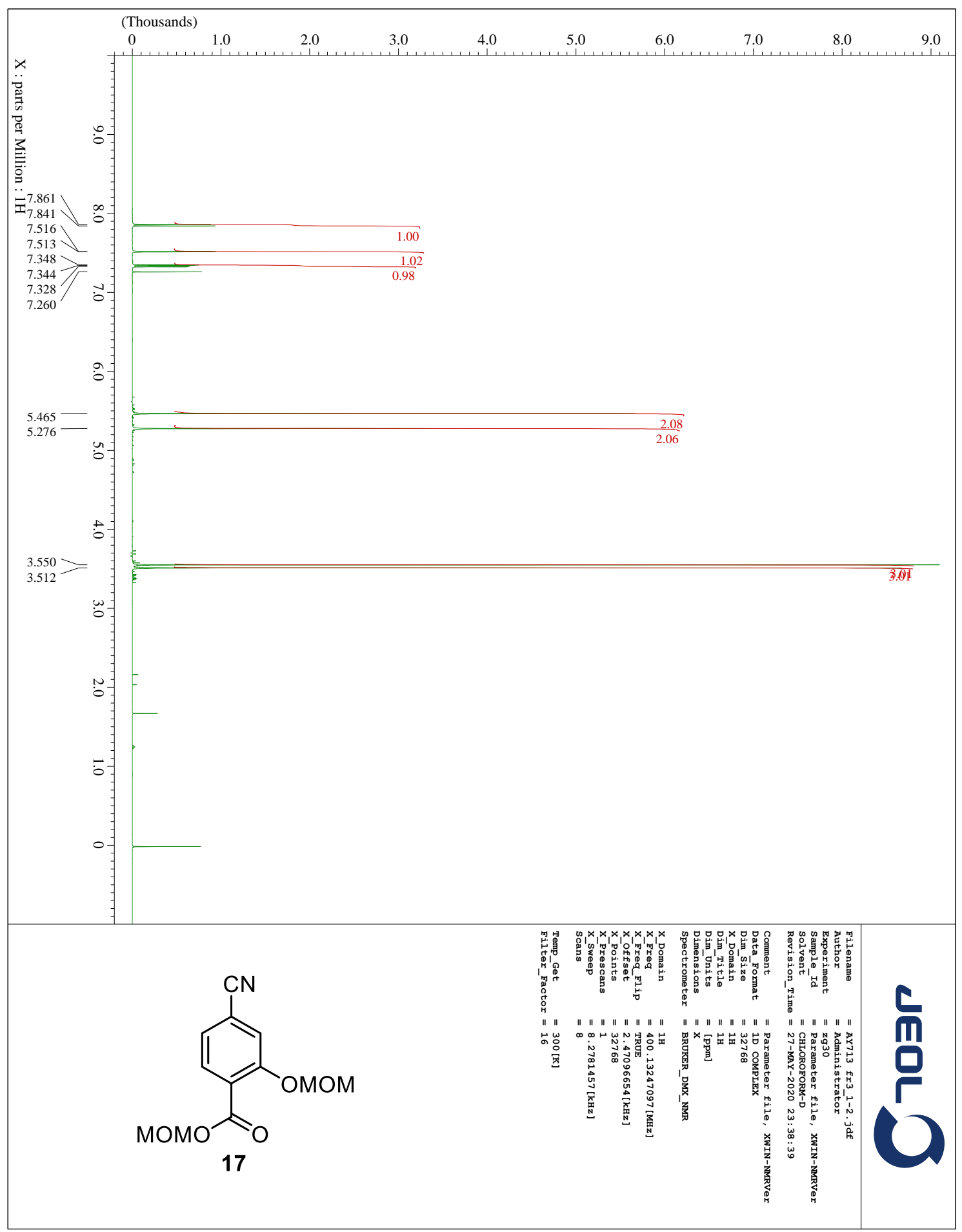


${ }^{13} \mathrm{C}\left\{{ }^{1} \mathrm{H}\right\}$ NMR spectrum (100 MHz) of 17 in $\mathrm{CDCl}_{3}$.

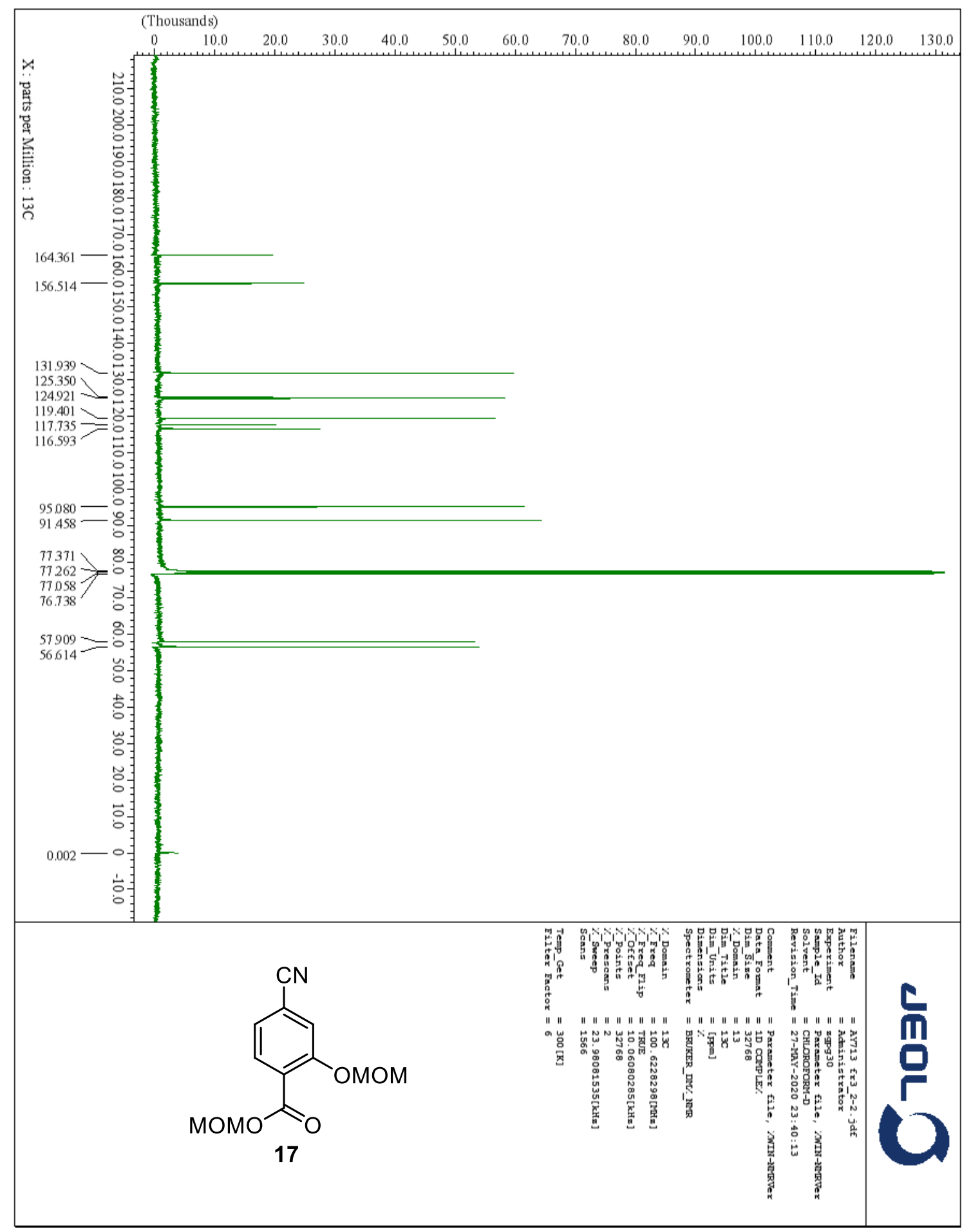


${ }^{1} \mathrm{H}$ NMR spectrum (400 MHz) of $\mathbf{1 8}$ in $\mathrm{CDCl}_{3}$.

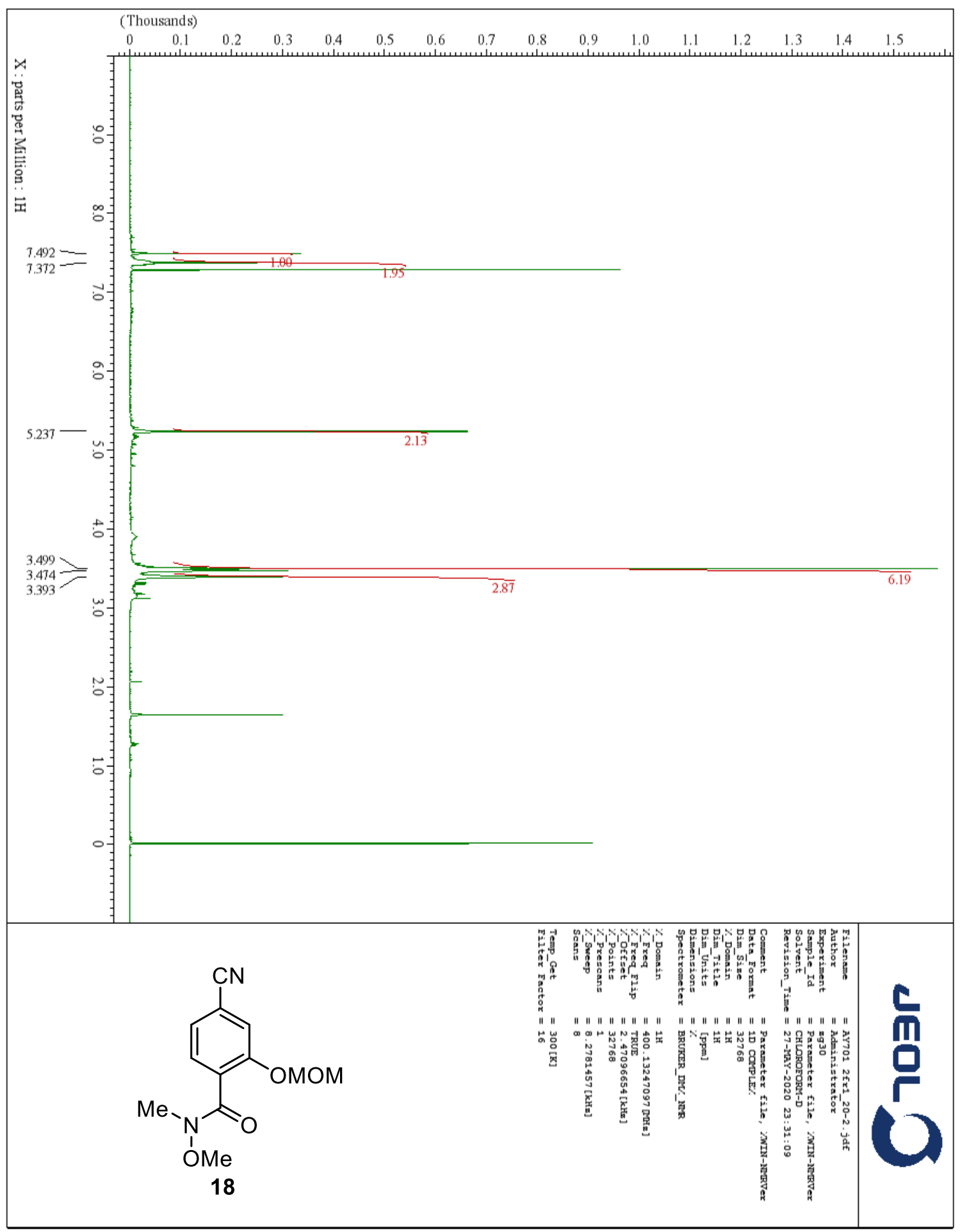


${ }^{13} \mathrm{C}\left\{{ }^{1} \mathrm{H}\right\}$ NMR spectrum (100 MHz) of 18 in $\mathrm{CDCl}_{3}$.

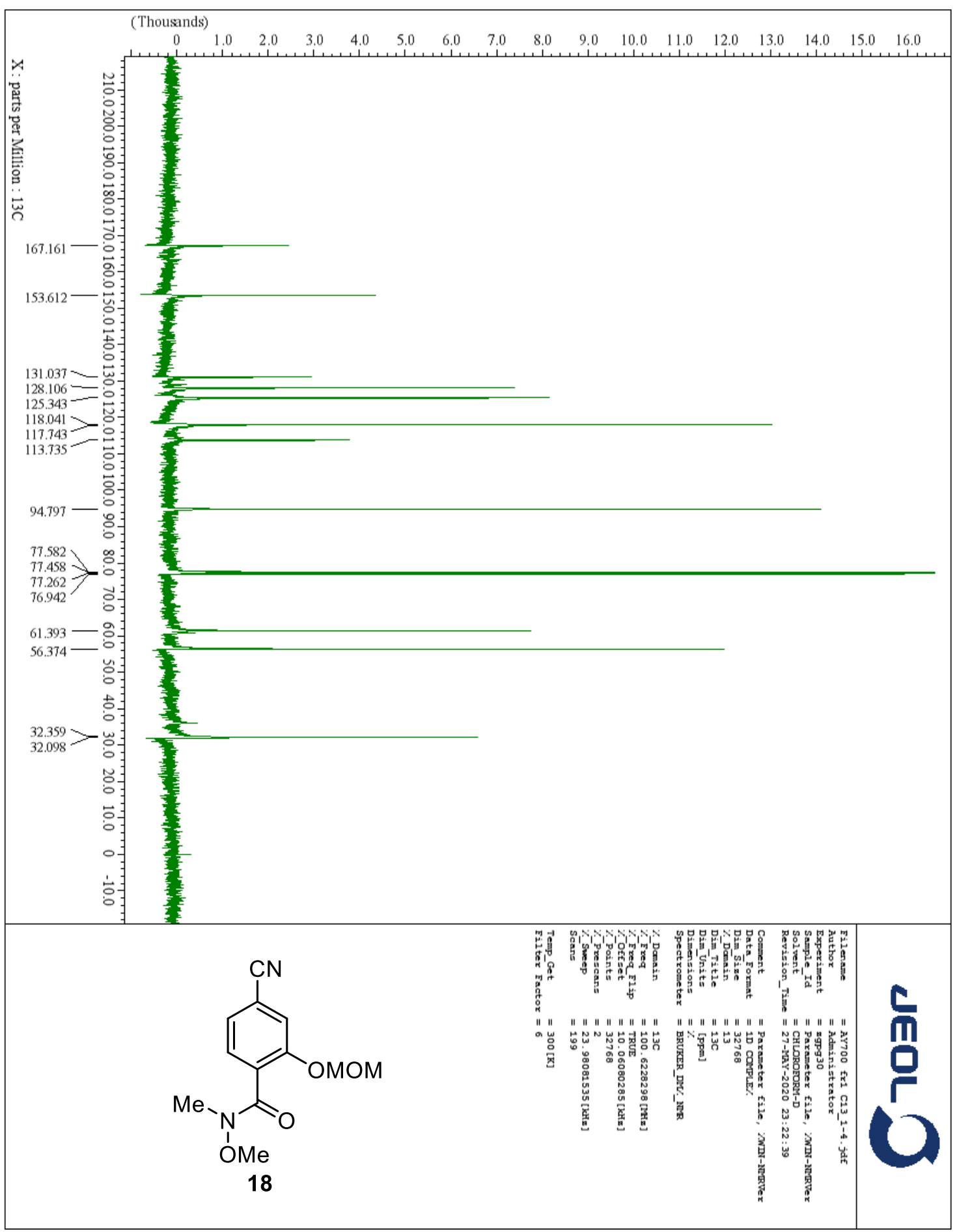


${ }^{1} \mathrm{H}$ NMR spectrum (400 MHz) of 20 in $\mathrm{CDCl}_{3}$.

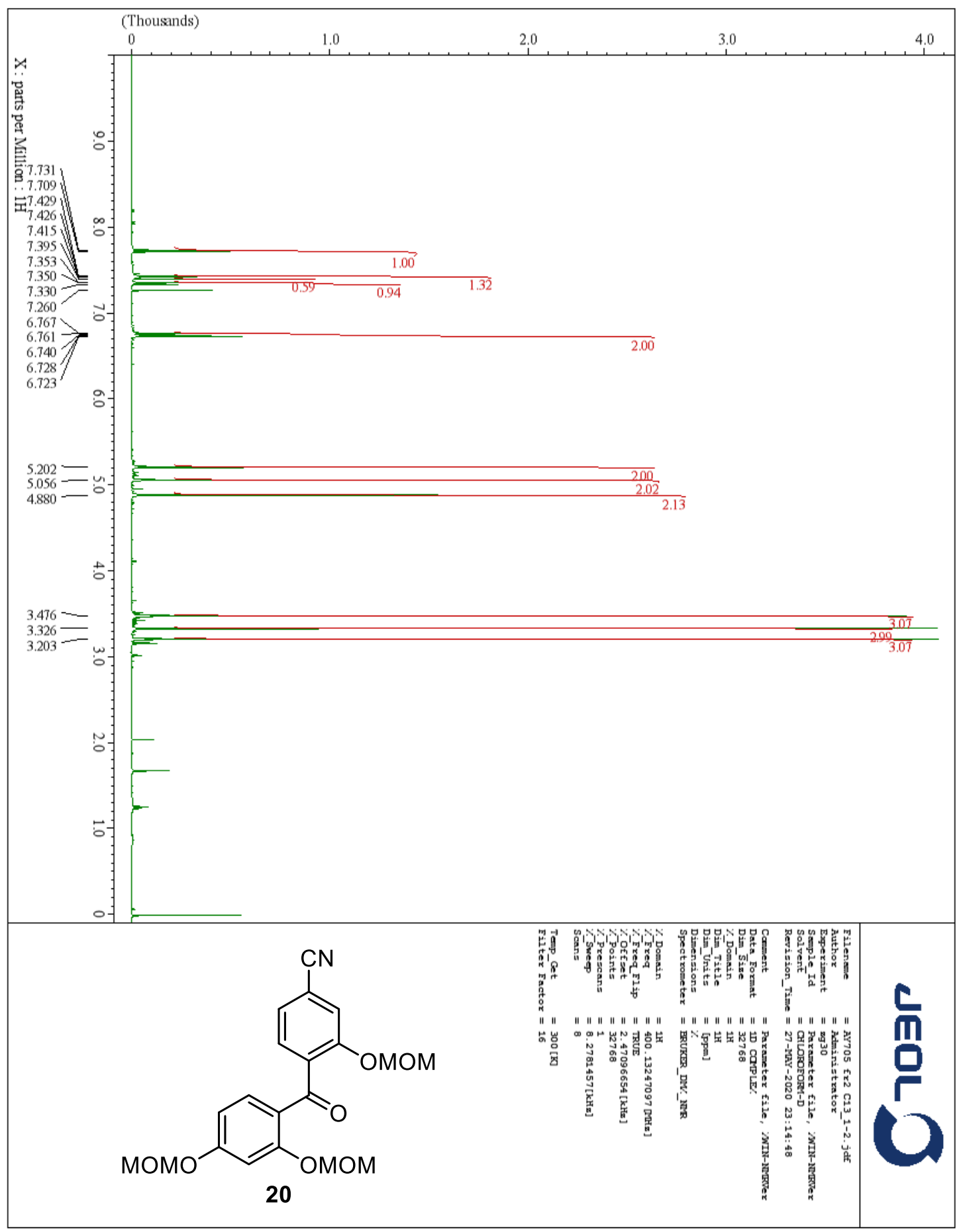


${ }^{13} \mathrm{C}\left\{{ }^{1} \mathrm{H}\right\}$ NMR spectrum (100 MHz) of 20 in $\mathrm{CDCl}_{3}$.

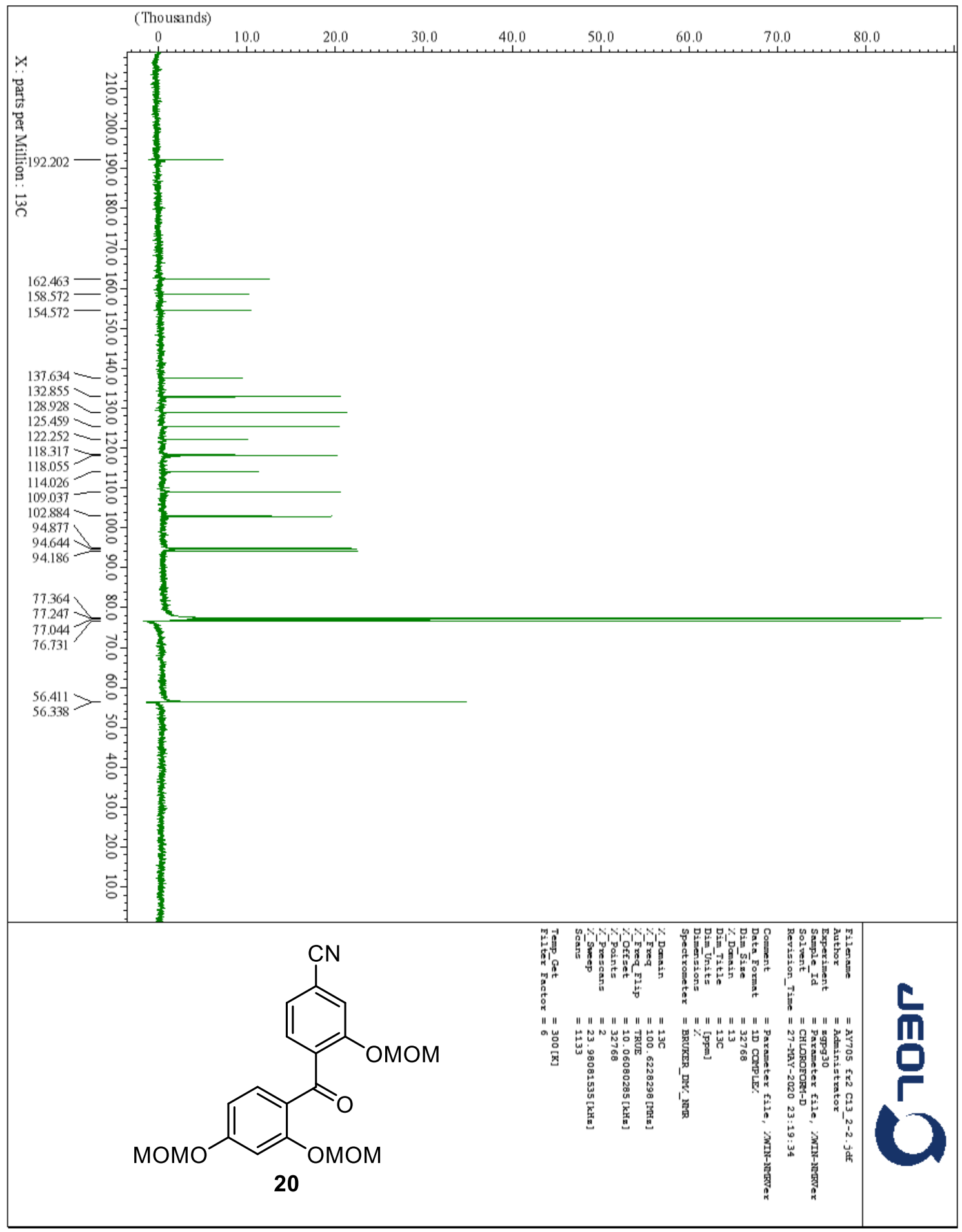


${ }^{1} \mathrm{H}$ NMR spectrum (400 MHz) of 22 in $\mathrm{CDCl}_{3}$.

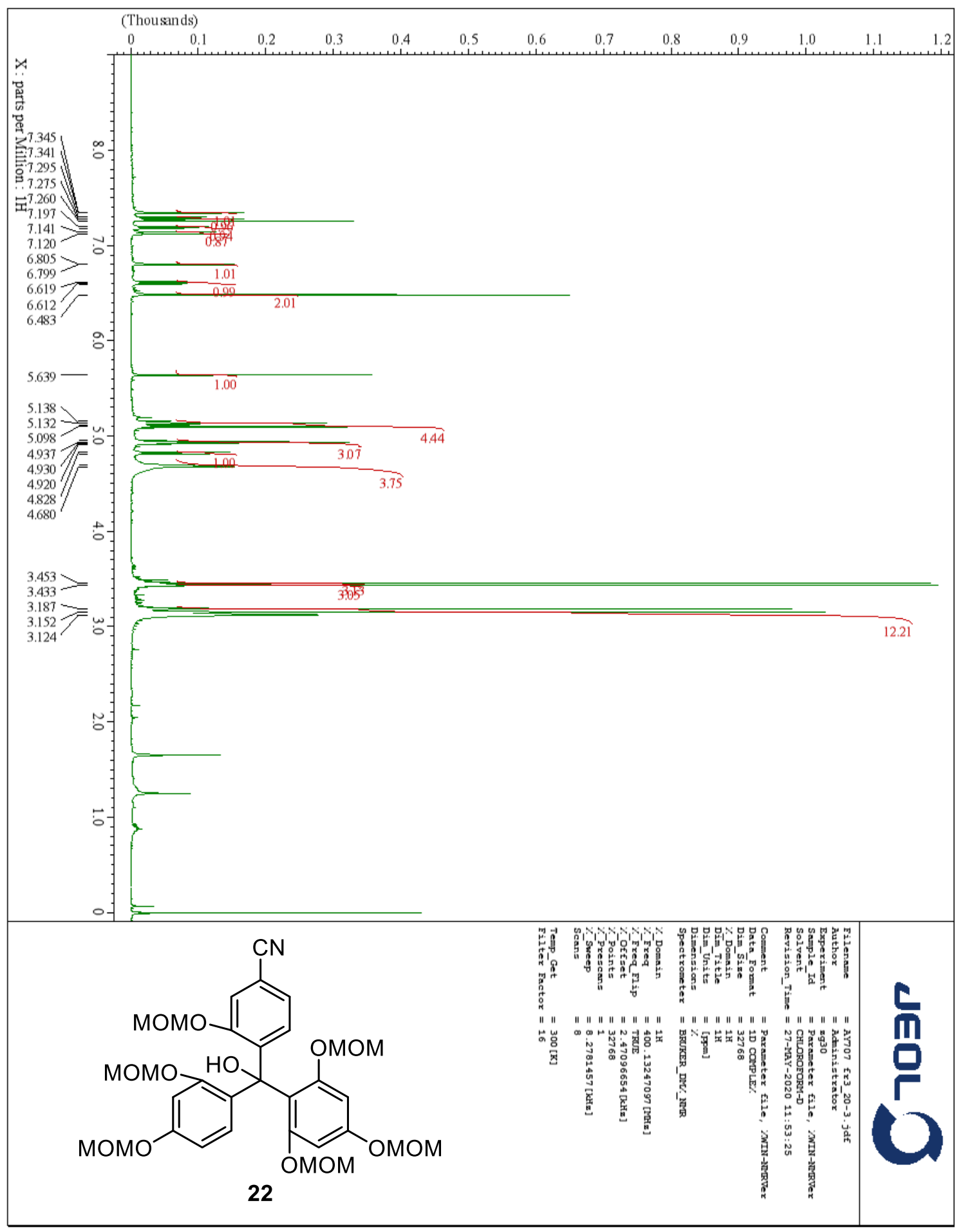


${ }^{13} \mathrm{C}\left\{{ }^{1} \mathrm{H}\right\}$ NMR spectrum (100 MHz) of 22 in $\mathrm{CDCl}_{3}$.

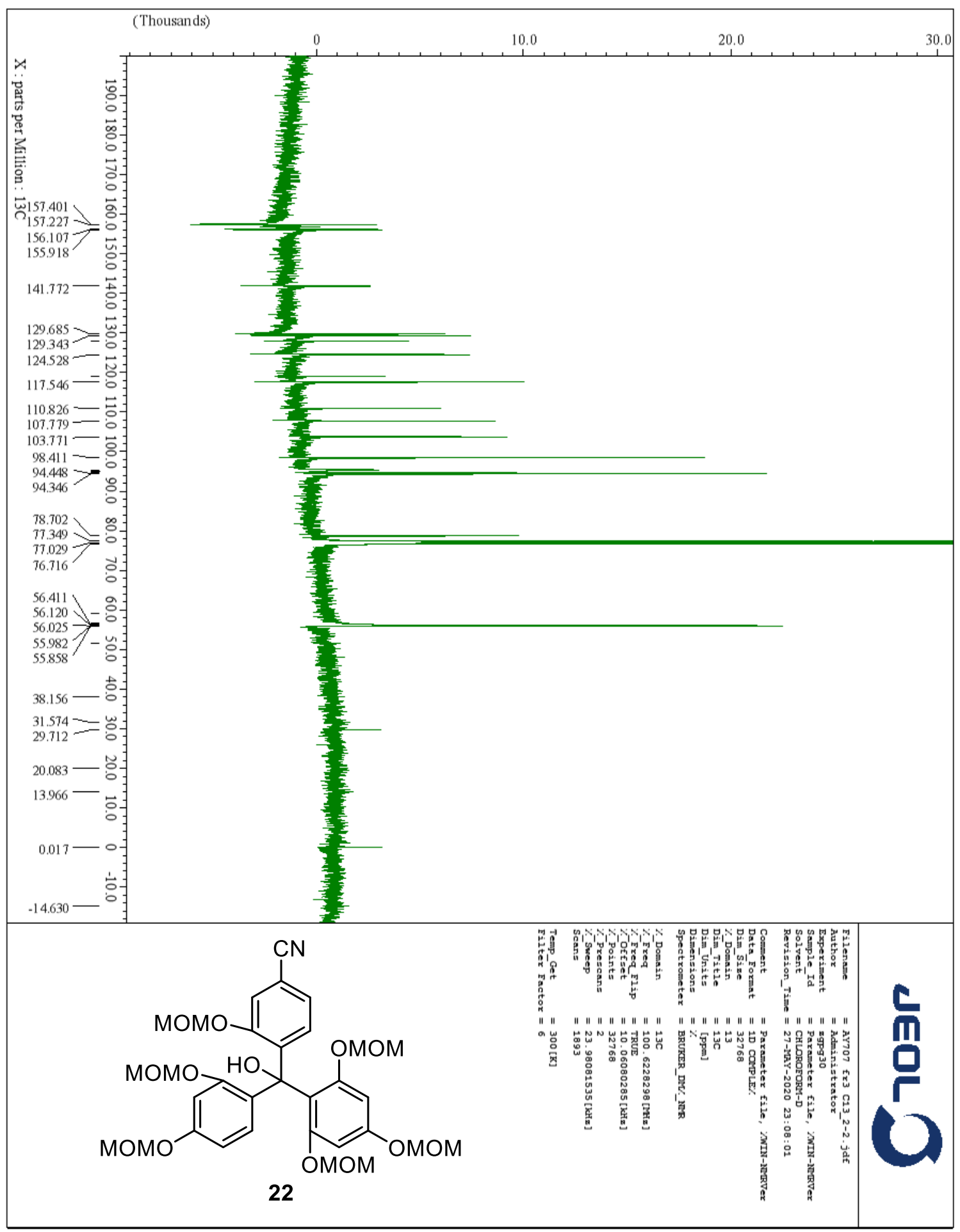


${ }^{1} \mathrm{H}$ NMR spectrum (400 MHz) of $\mathbf{1 0 b}$ in $\mathrm{CDCl}_{3}$.

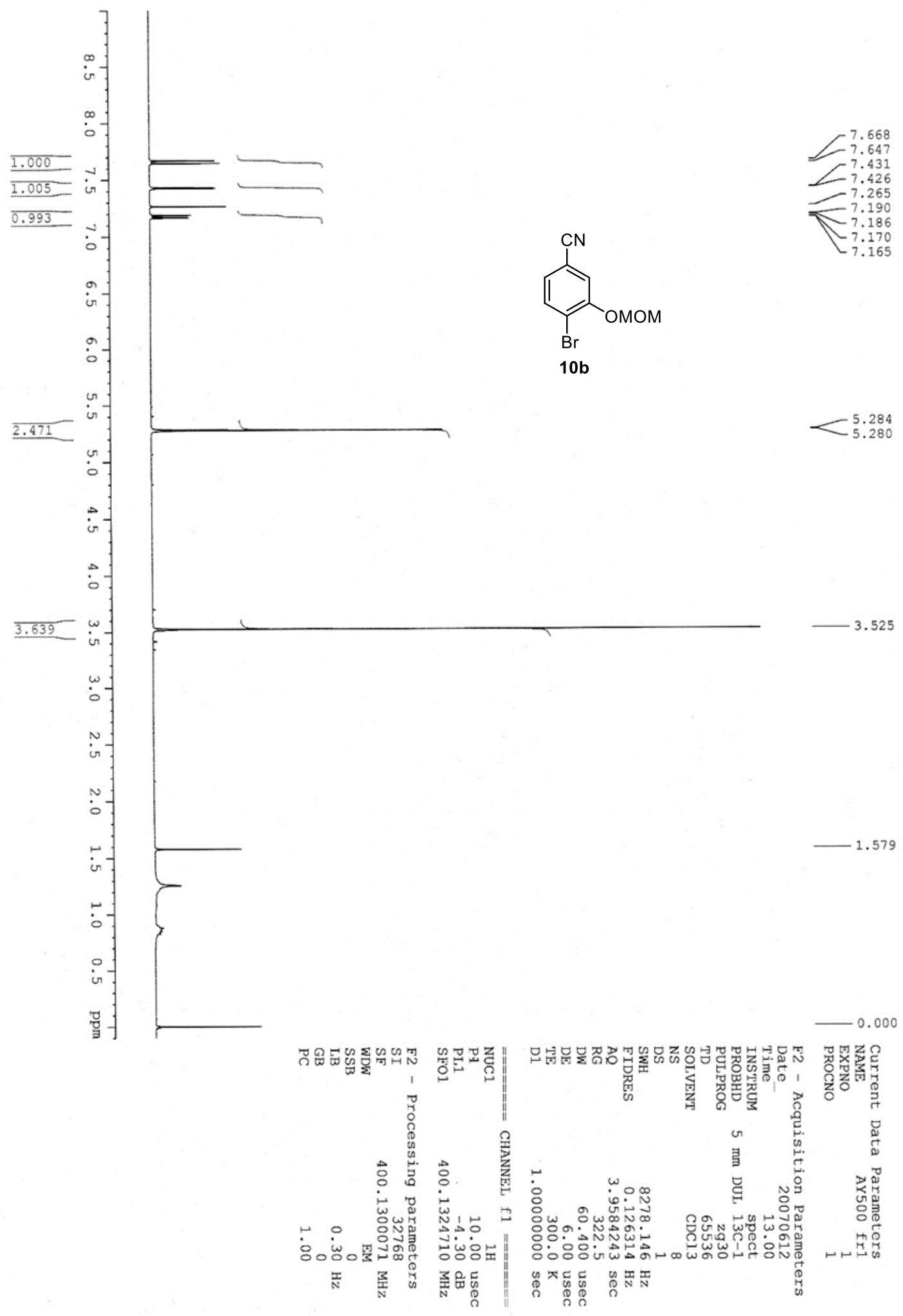


${ }^{13} \mathrm{C}\left\{{ }^{1} \mathrm{H}\right\}$ NMR spectrum $(100 \mathrm{MHz})$ of $\mathbf{1 0 b}$ in $\mathrm{CDCl}_{3}$.

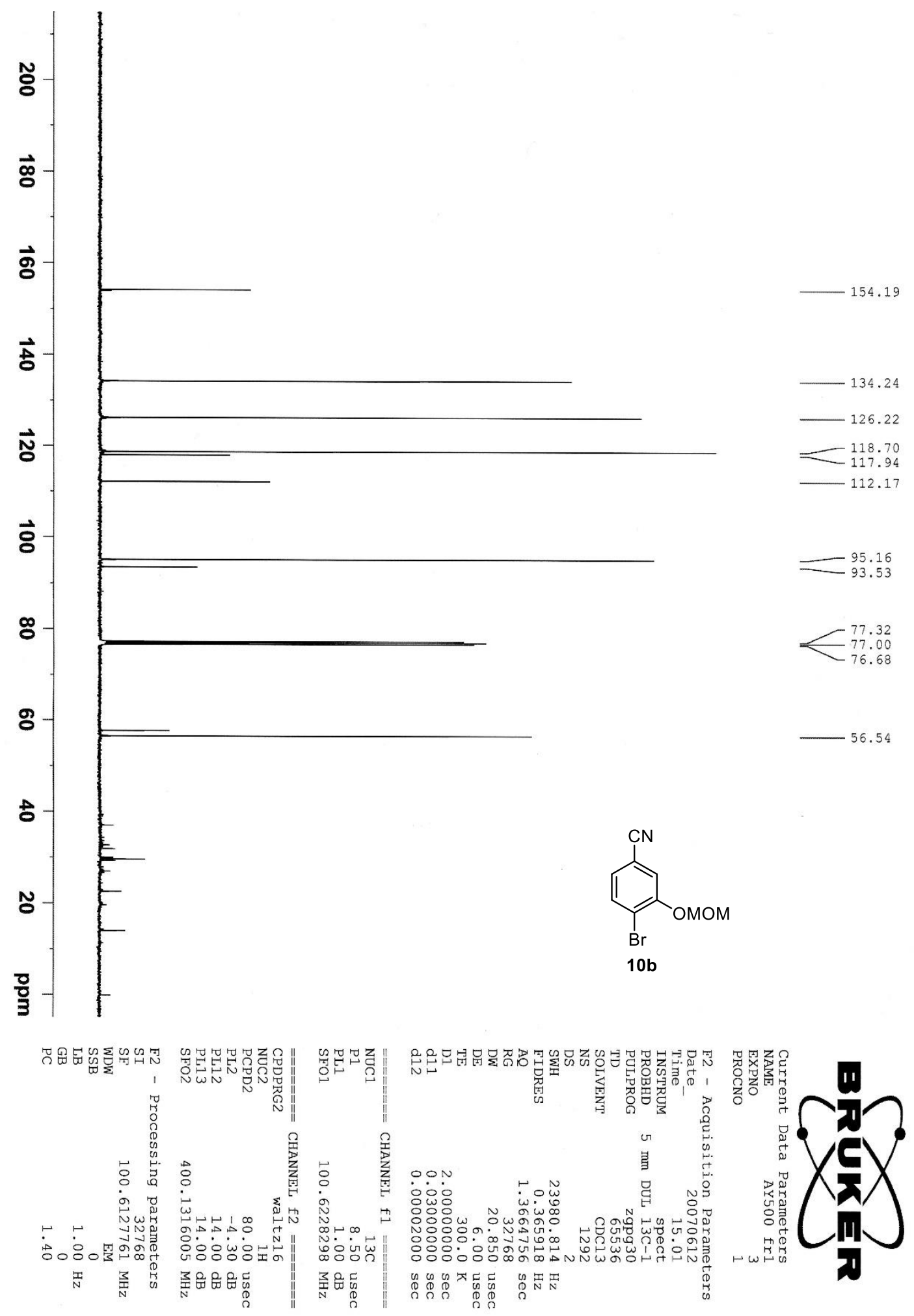


${ }^{1} \mathrm{H}$ NMR spectrum (400 MHz) of $\mathbf{1 2 b}$ in $\mathrm{CDCl}_{3}$.

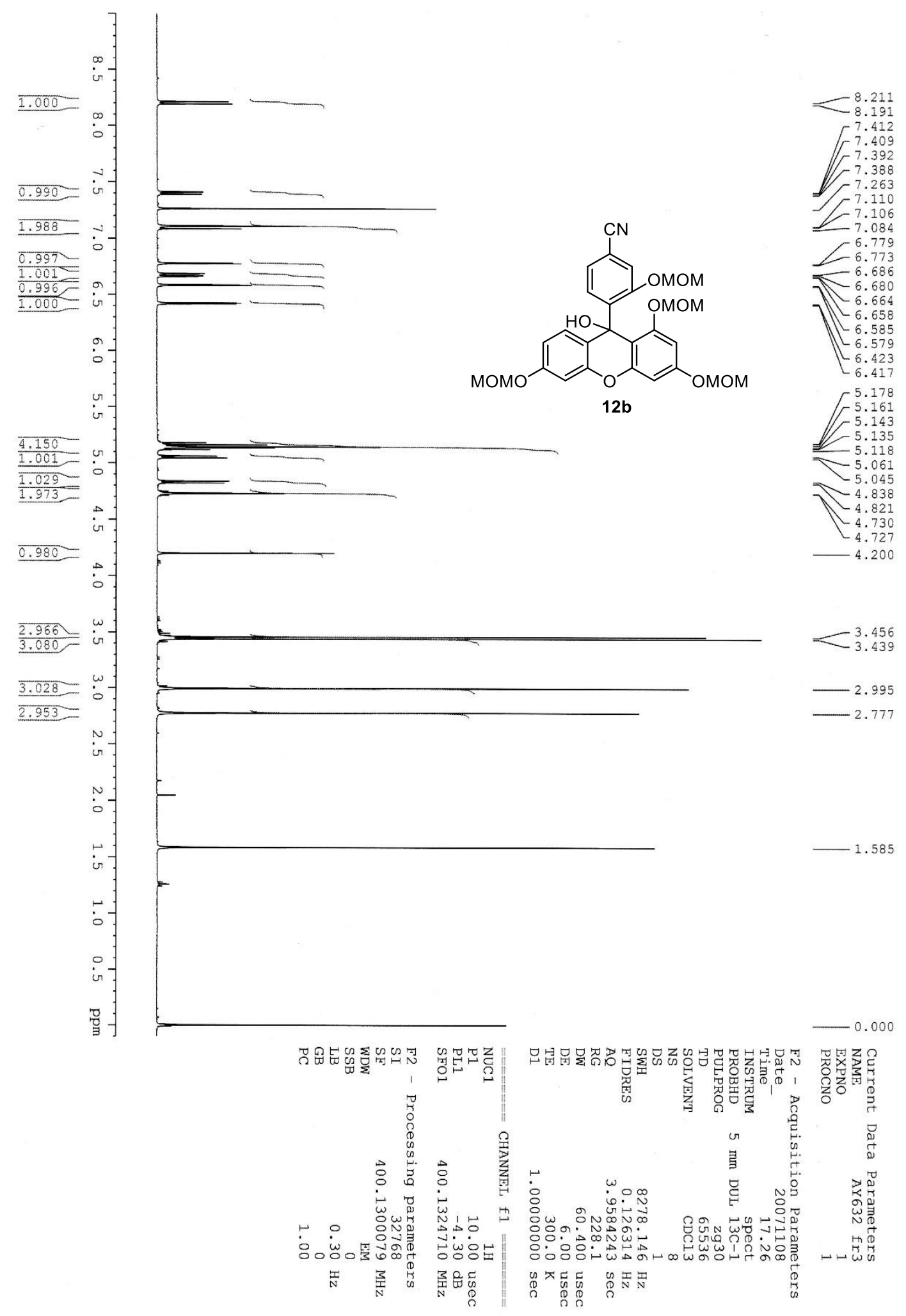


${ }^{13} \mathrm{C}\left\{{ }^{1} \mathrm{H}\right\}$ NMR spectrum $(100 \mathrm{MHz})$ of $\mathbf{1 2 b}$ in $\mathrm{CDCl}_{3}$.

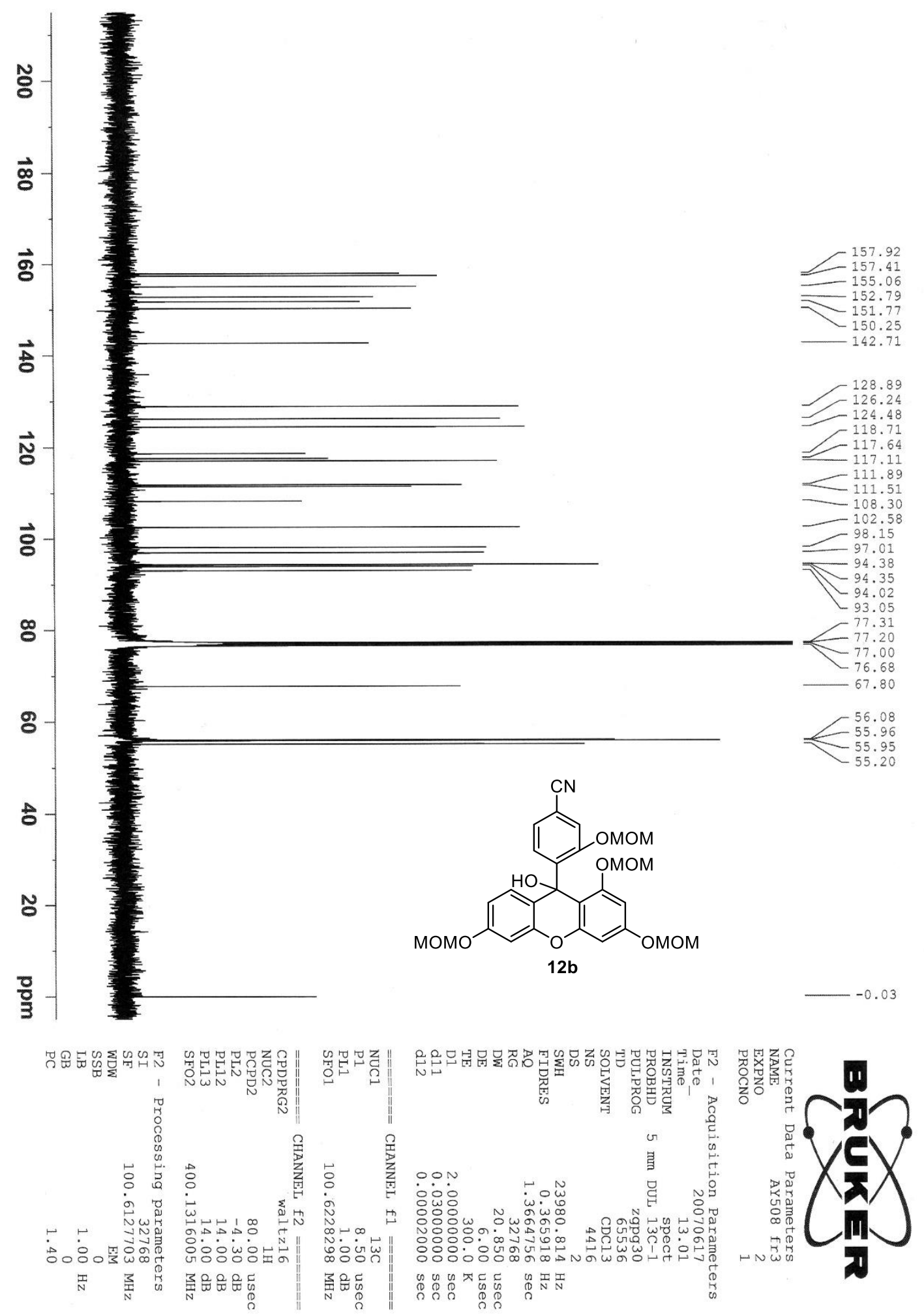


${ }^{1} \mathrm{H}$ NMR spectrum $(400 \mathrm{MHz})$ of $\mathbf{1 2 a}$ in $\mathrm{CDCl}_{3}$.

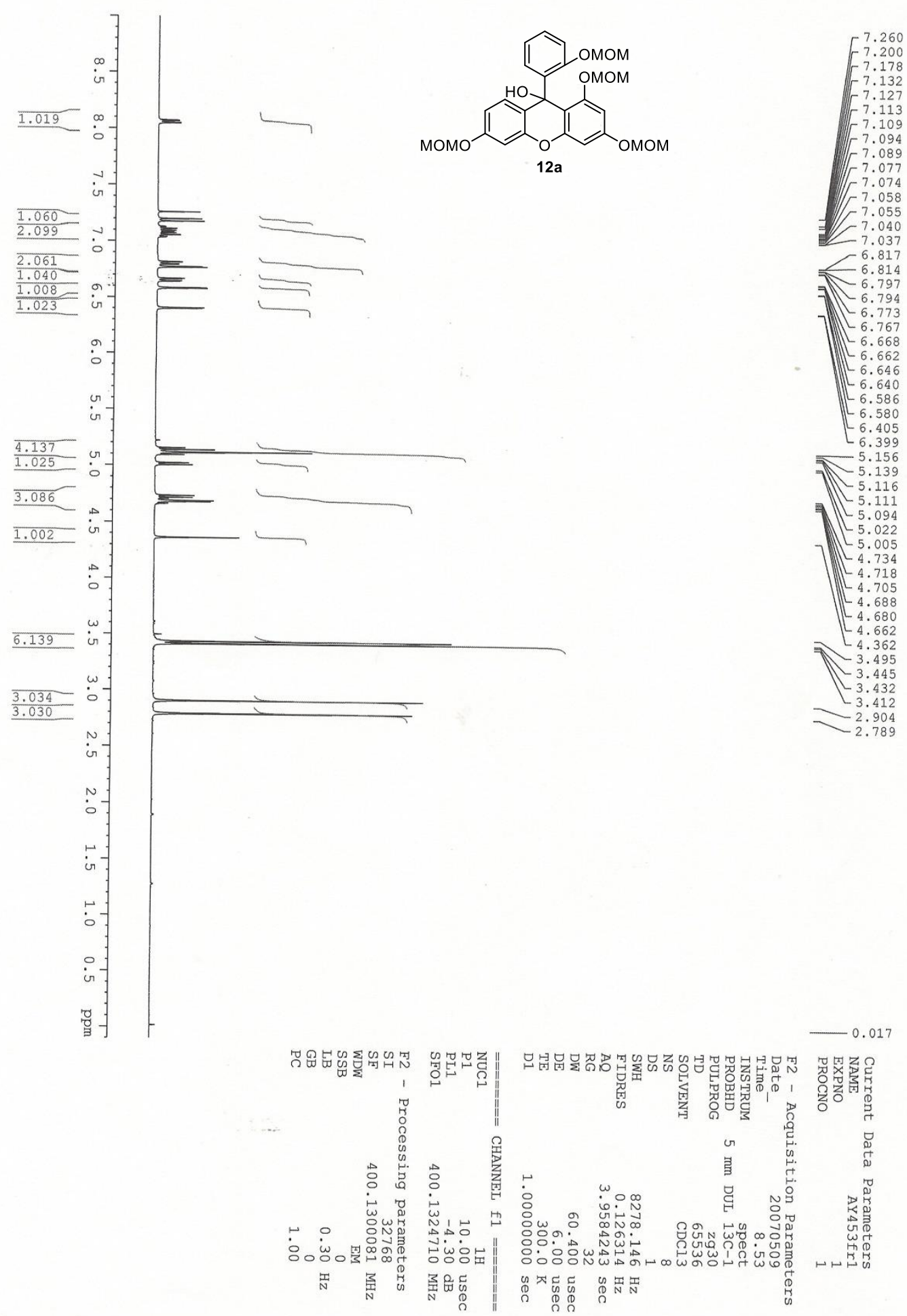


${ }^{13} \mathrm{C}\left\{{ }^{1} \mathrm{H}\right\}$ NMR spectrum $(100 \mathrm{MHz})$ of $\mathbf{1 2 a}$ in $\mathrm{CDCl}_{3}$.
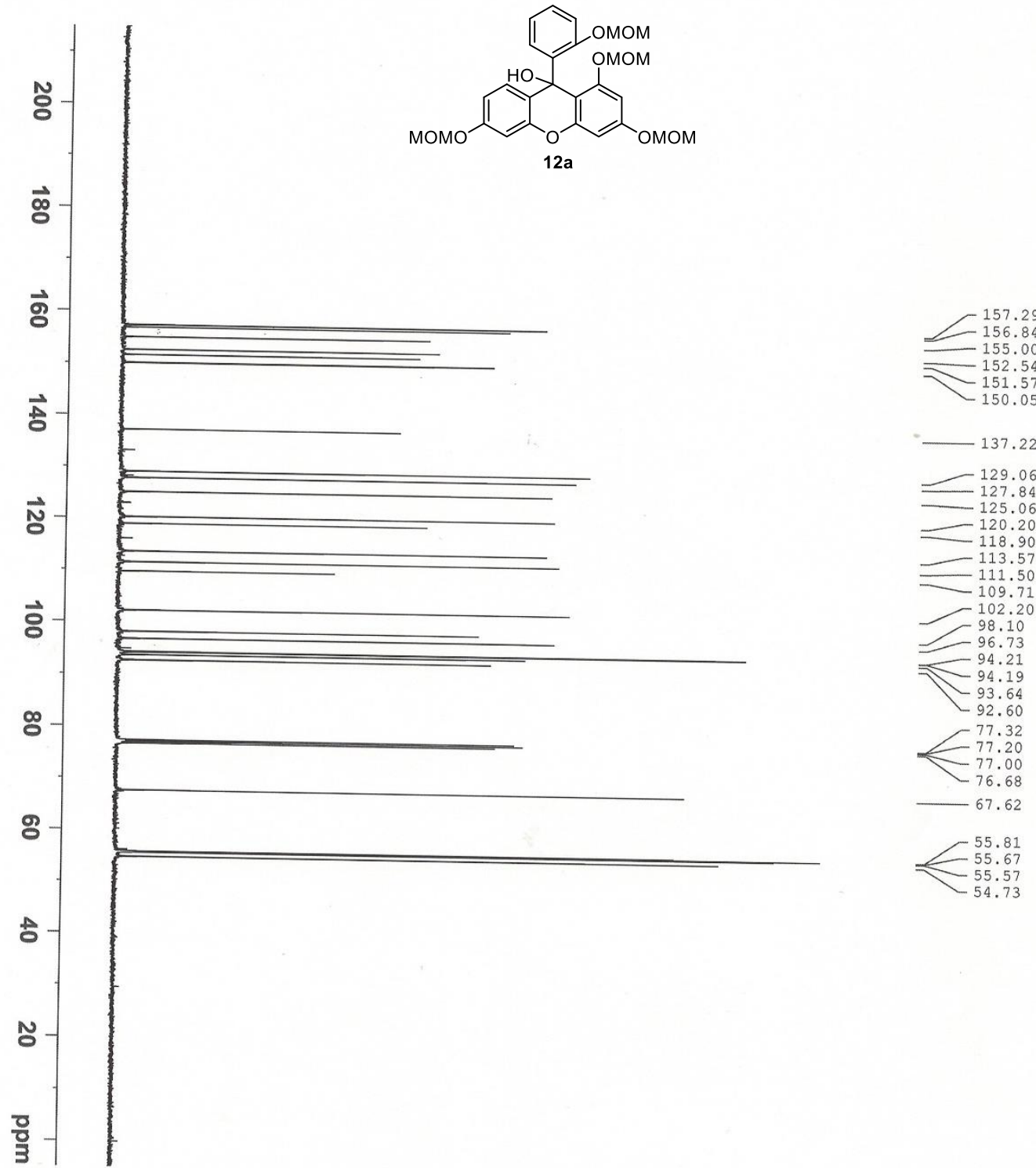
127.84
-125.06 120.20 $-118.90$ $\begin{array}{r}113.5 \\ -111.50 \\ \hline\end{array}$ 109. 98.10 96.73 - 94.21 $-94.19$ $\simeq 93.64$ $-77.32$ $\sim 77.00$ $-76.68$ $-67.62$ 55.81
-55.67

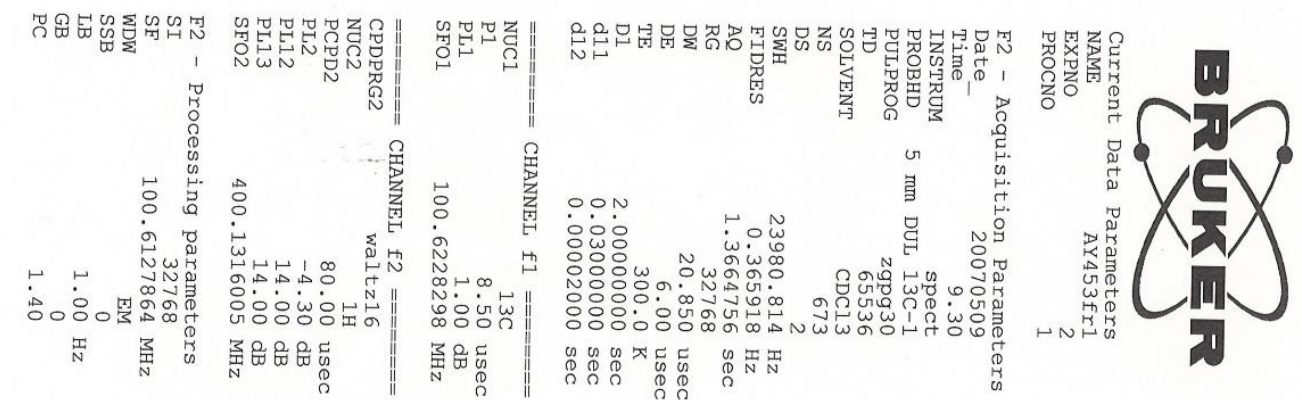


${ }^{1} \mathrm{H}$ NMR spectrum $(400 \mathrm{MHz})$ of 14 in $\mathrm{CDCl}_{3}$.

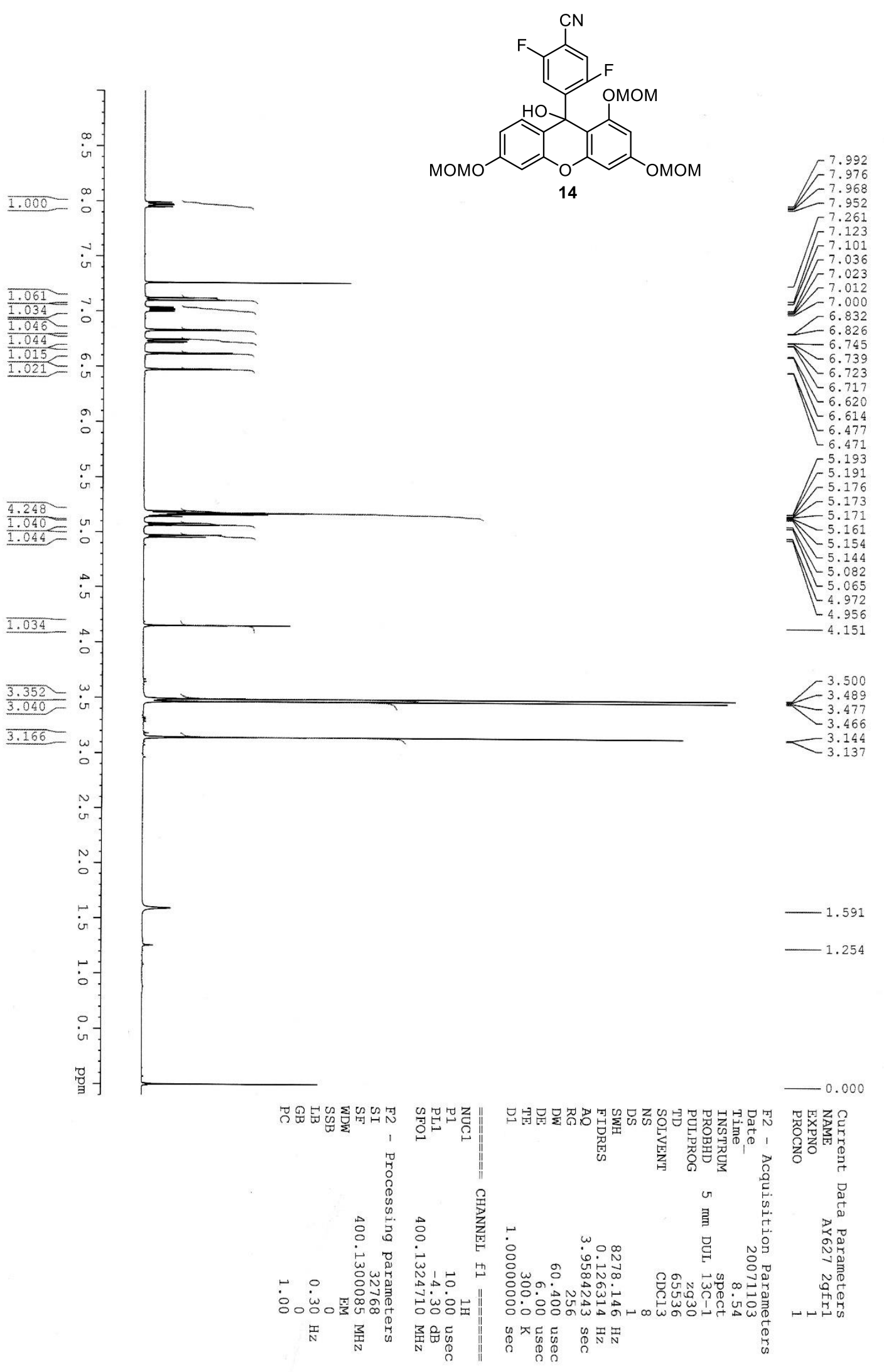


${ }^{13} \mathrm{C}\left\{{ }^{1} \mathrm{H}\right\}$ NMR spectrum $(100 \mathrm{MHz})$ of 14 in $\mathrm{CDCl}_{3}$.

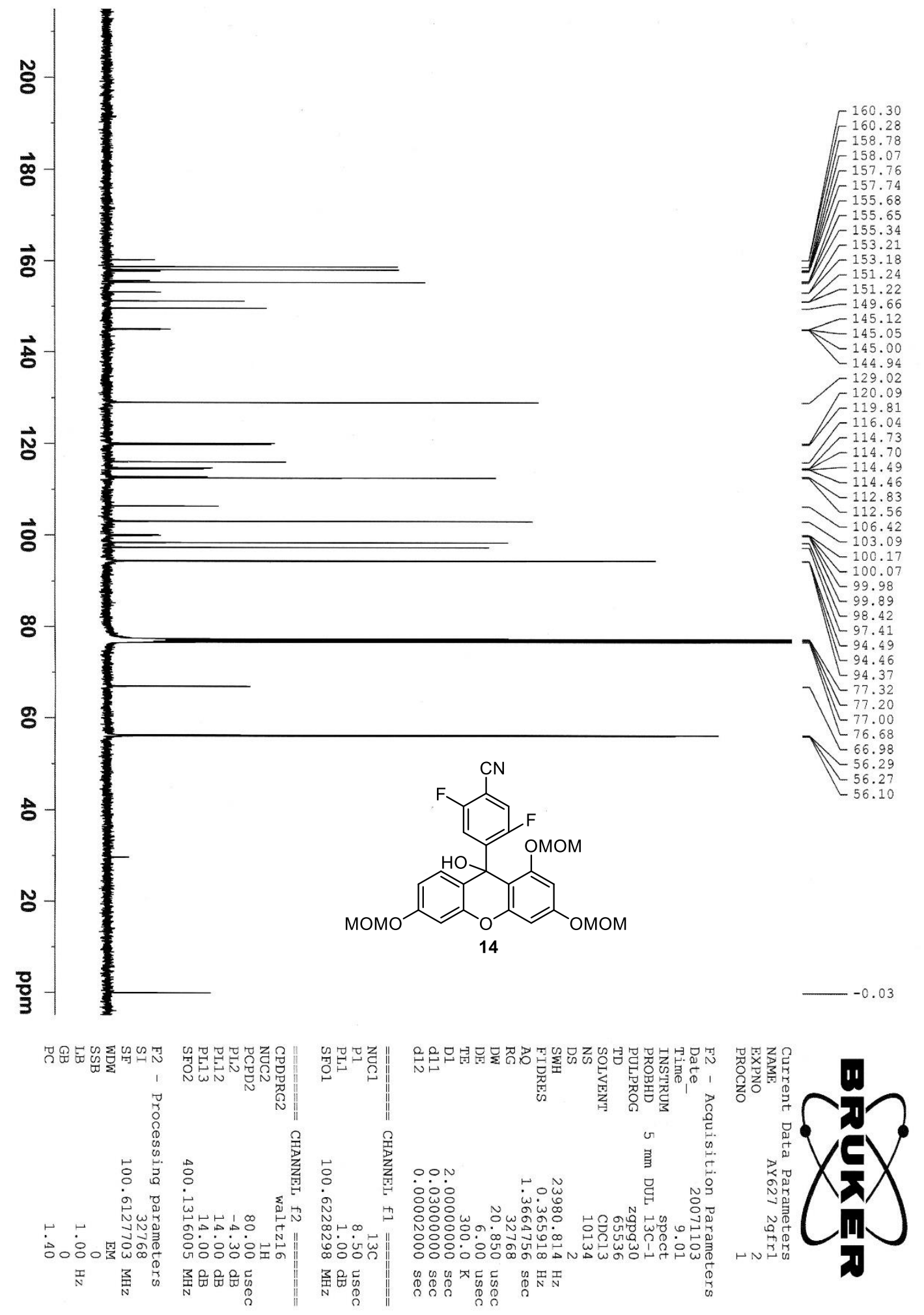


HRMS (ESI/FT-ICR-MS) of 4. Calcd for $\mathrm{C}_{19} \mathrm{H}_{11} \mathrm{O}_{4}[\mathrm{M}+\mathrm{H}]^{+}$303.0652, Found 303.0664.

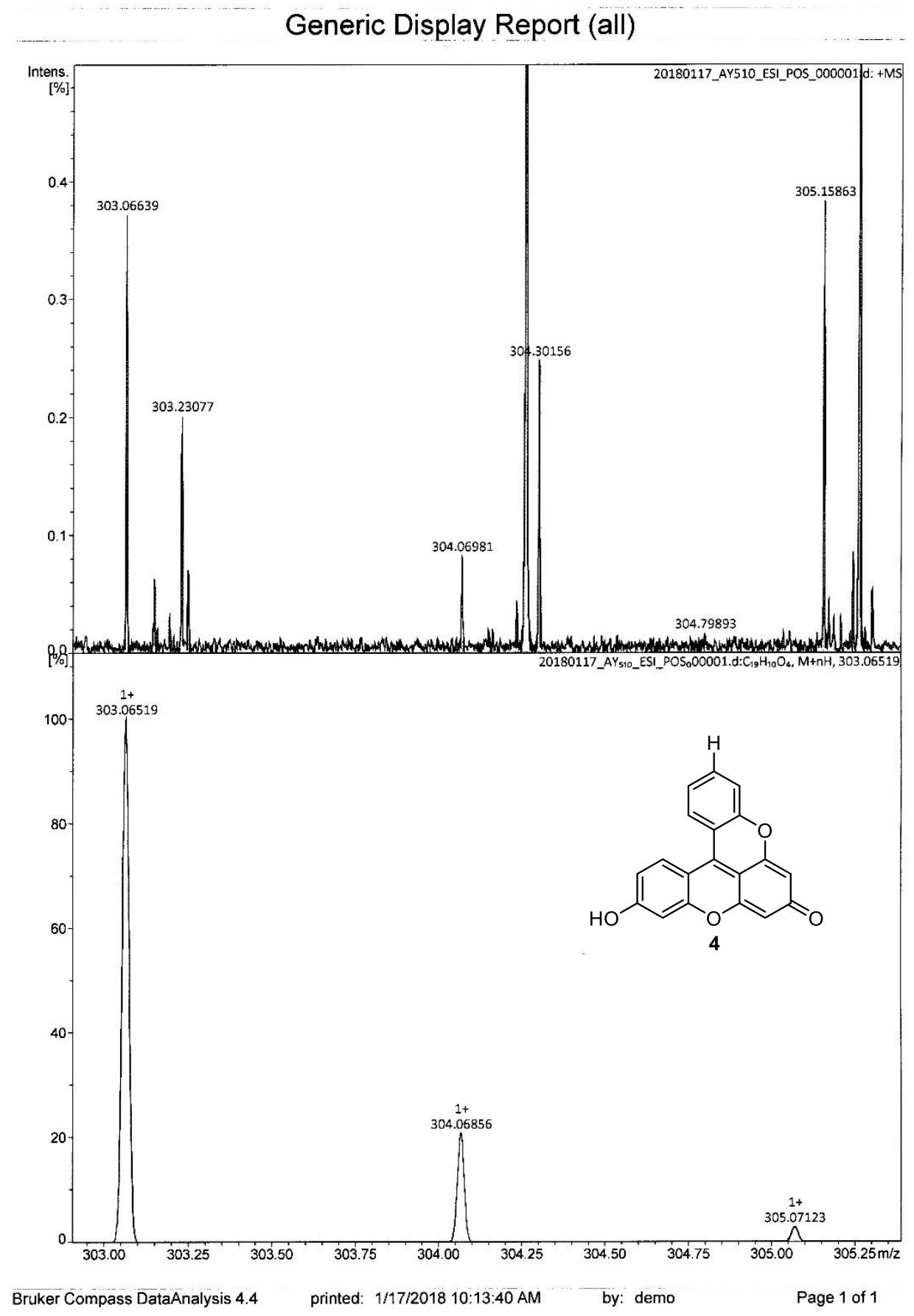


HRMS (ESI/FT-ICR-MS) of 5. Calcd for $\mathrm{C}_{20} \mathrm{H}_{10} \mathrm{O}_{6}[\mathrm{M}+\mathrm{H}]^{+}$347.0550, found 347.0553.

\section{Display Report}

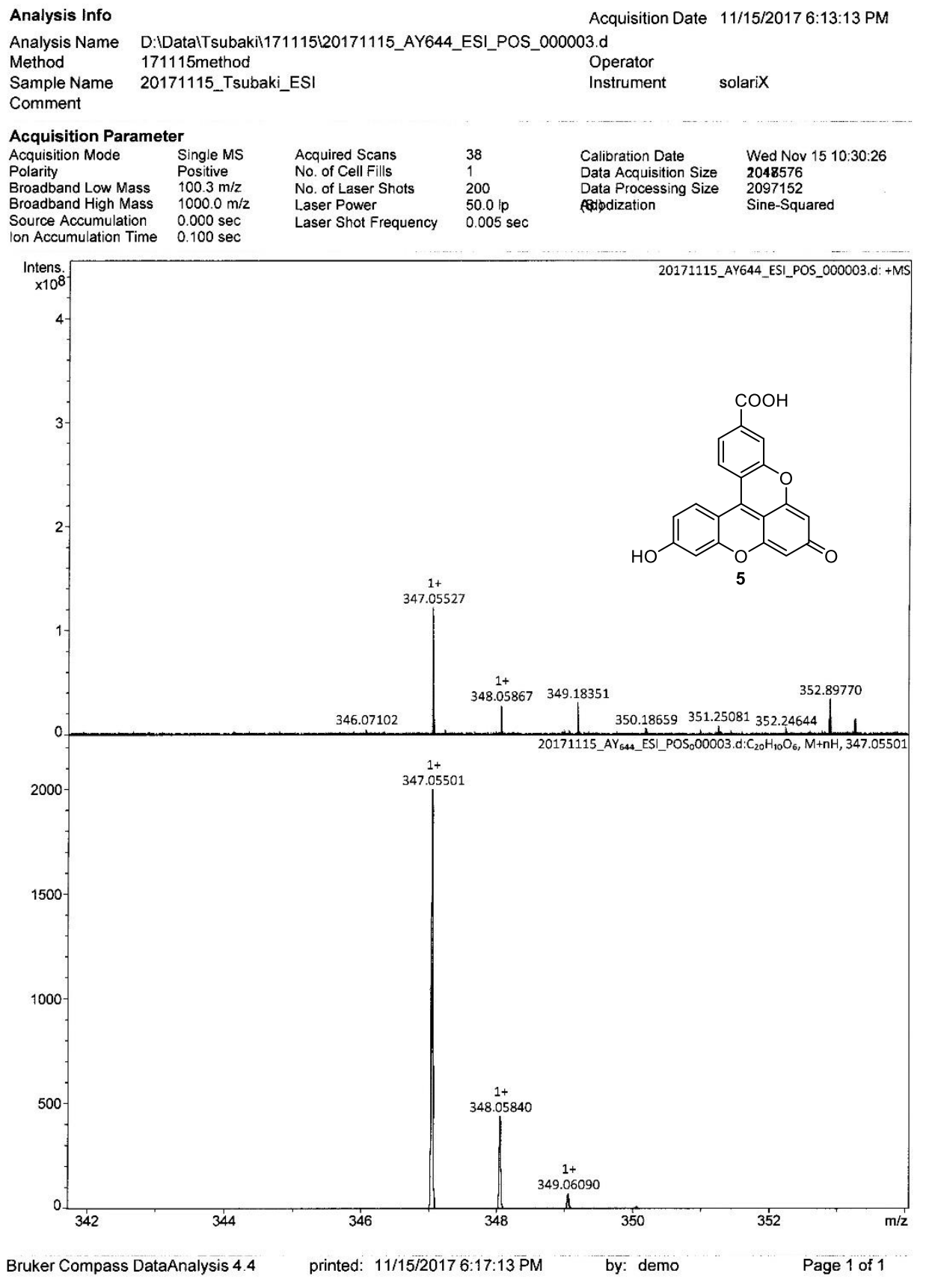


HRMS (ESI/FT-ICR-MS) of 6. Calcd for $\mathrm{C}_{21} \mathrm{H}_{13} \mathrm{O}_{6}\left([\mathrm{M}+\mathrm{H}]^{+}\right)$361.0707, Found 361.0713.

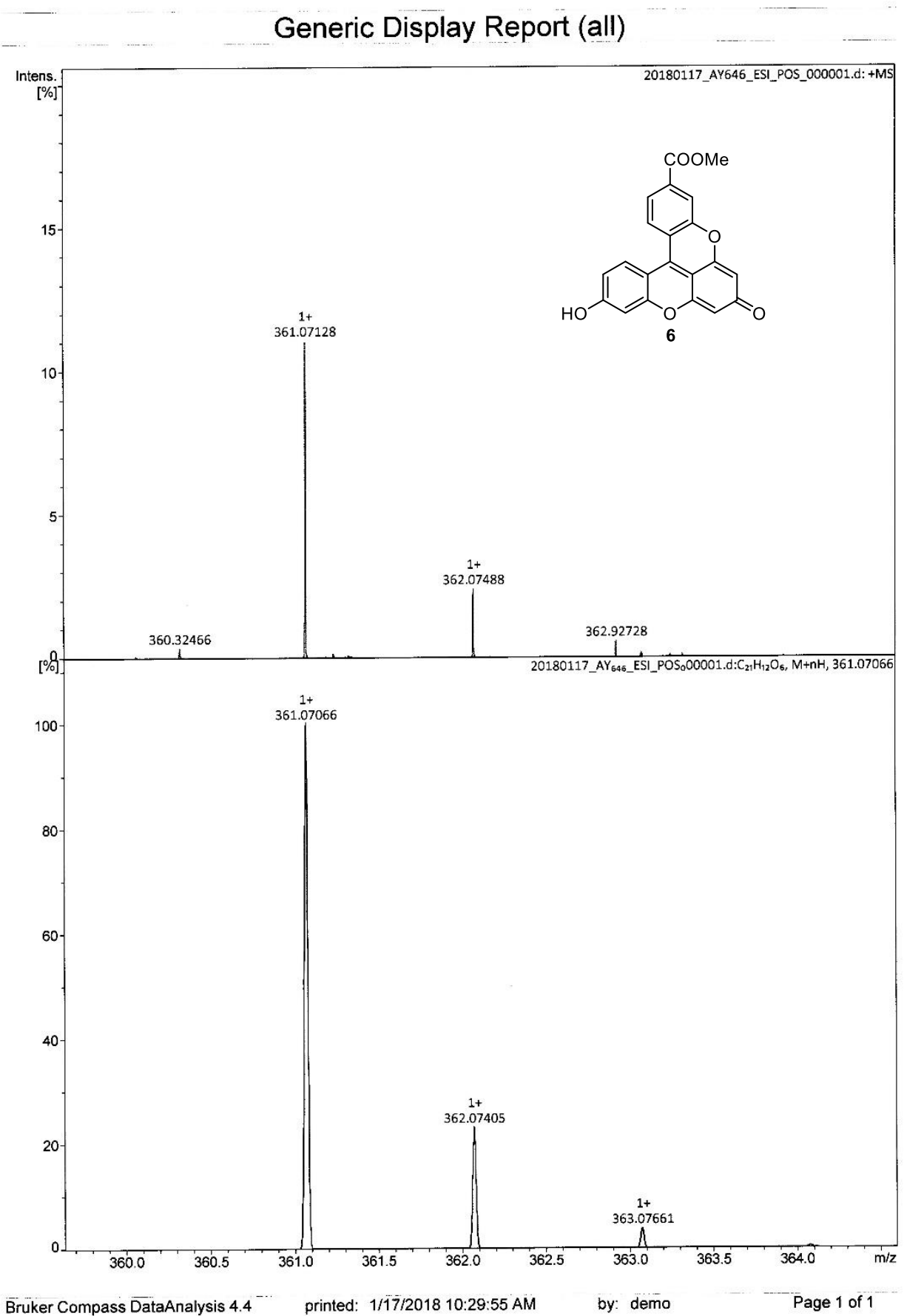

Bruker Compass DataAnalysis 4.4 
HRMS (ESI/FT-ICR-MS) of 7. Calcd for $\mathrm{C}_{20} \mathrm{H}_{10} \mathrm{NO}_{4}[\mathrm{M}+\mathrm{H}]^{+}$328.0604, Found 328.0609.

Generic Display Report (all)

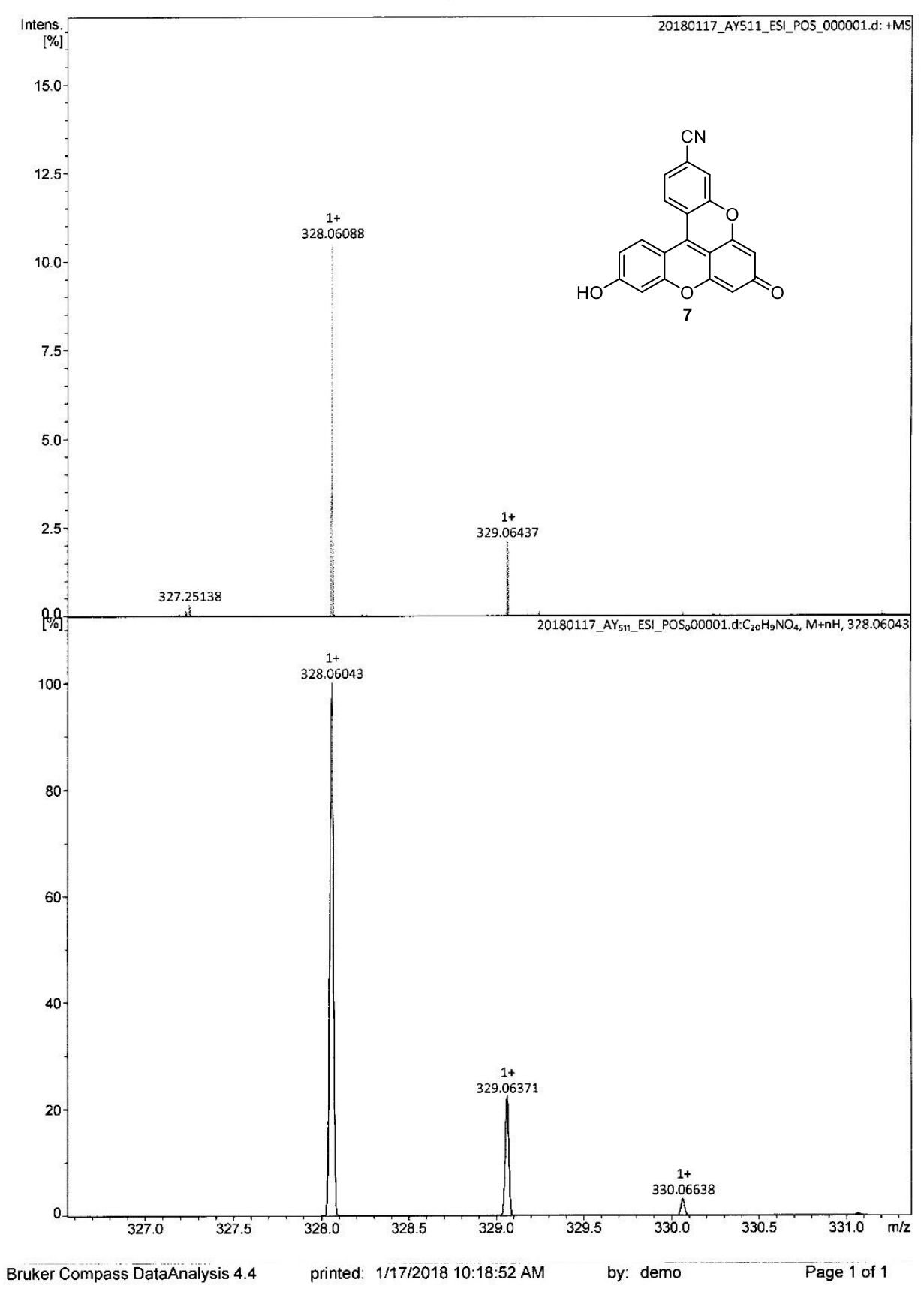


HRMS (ESI/FT-ICR-MS) of 8. Calcd for $\mathrm{C}_{20} \mathrm{H}_{9} \mathrm{FNO}_{4}[\mathrm{M}+\mathrm{H}]^{+}$346.0510, Found 346.0514 .

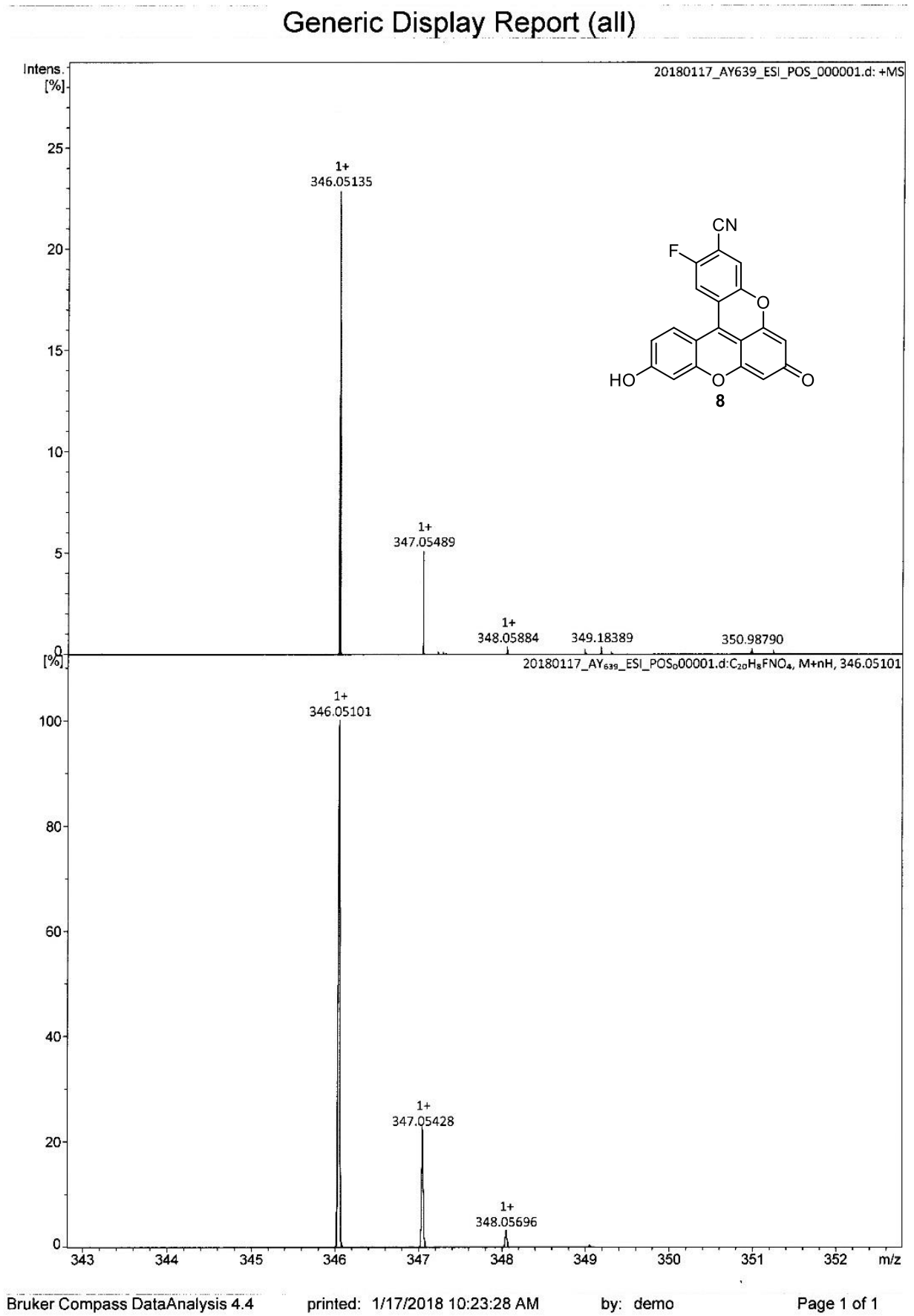


HRMS (ESI/FT-ICR-MS) of 10b. Calcd for $\mathrm{C}_{9} \mathrm{H}_{8}{ }^{79} \mathrm{BrNO}_{2} \mathrm{Na}[\mathrm{M}+\mathrm{Na}]^{+}$263.9631, Found 263.9643.

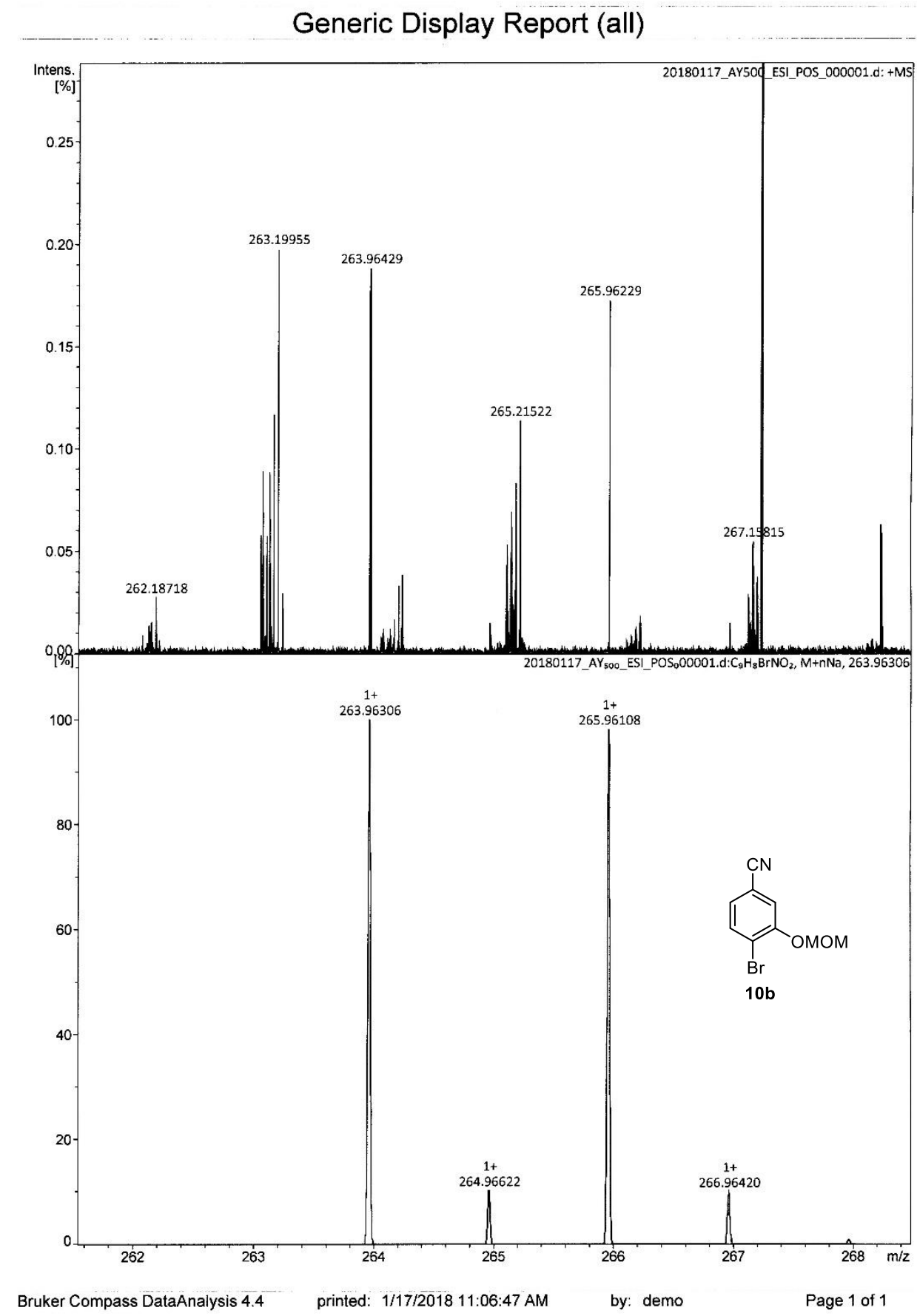


HRMS (ESI/FT-ICR-MS) of 12a. Calcd for $\mathrm{C}_{27} \mathrm{H}_{30} \mathrm{O}_{10} \mathrm{Na}[\mathrm{M}+\mathrm{Na}]^{+}$537.1731, Found 537.1716

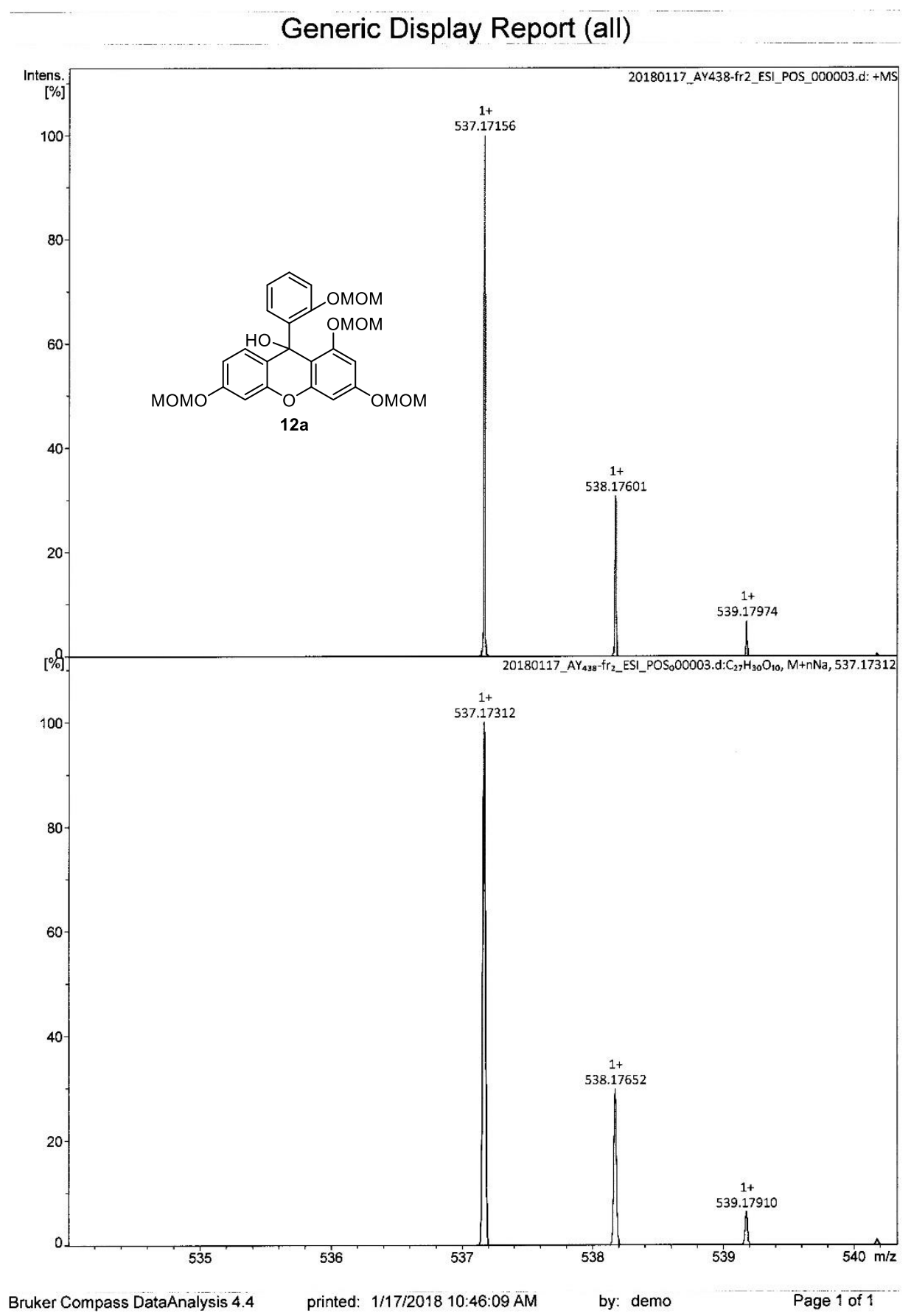


HRMS (ESI/FT-ICR-MS) of 12b. Calcd for $\mathrm{C}_{28} \mathrm{H}_{29} \mathrm{NO}_{10} \mathrm{Na}$ [M+Na] ${ }^{+}$562.1684, Found 562.1676.

Generic Display Report (all)

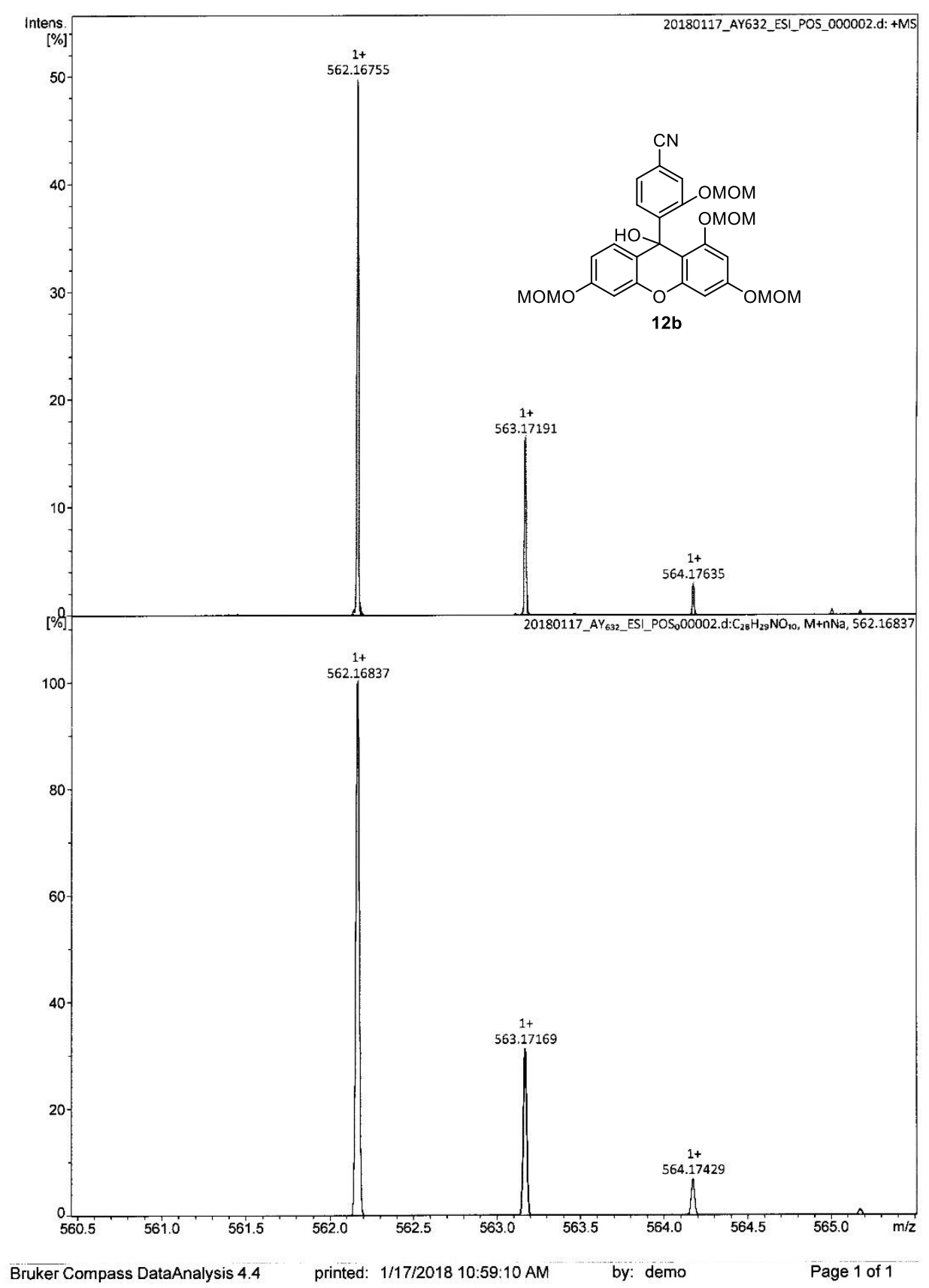


HRMS (ESI/FT-ICR-MS) of 14. Calcd for $\mathrm{C}_{26} \mathrm{H}_{23} \mathrm{~F}_{2} \mathrm{NO}_{8} \mathrm{Na}[\mathrm{M}+\mathrm{Na}]^{+}$538.1284, Found 538.1275.

\section{Generic Display Report (all)}

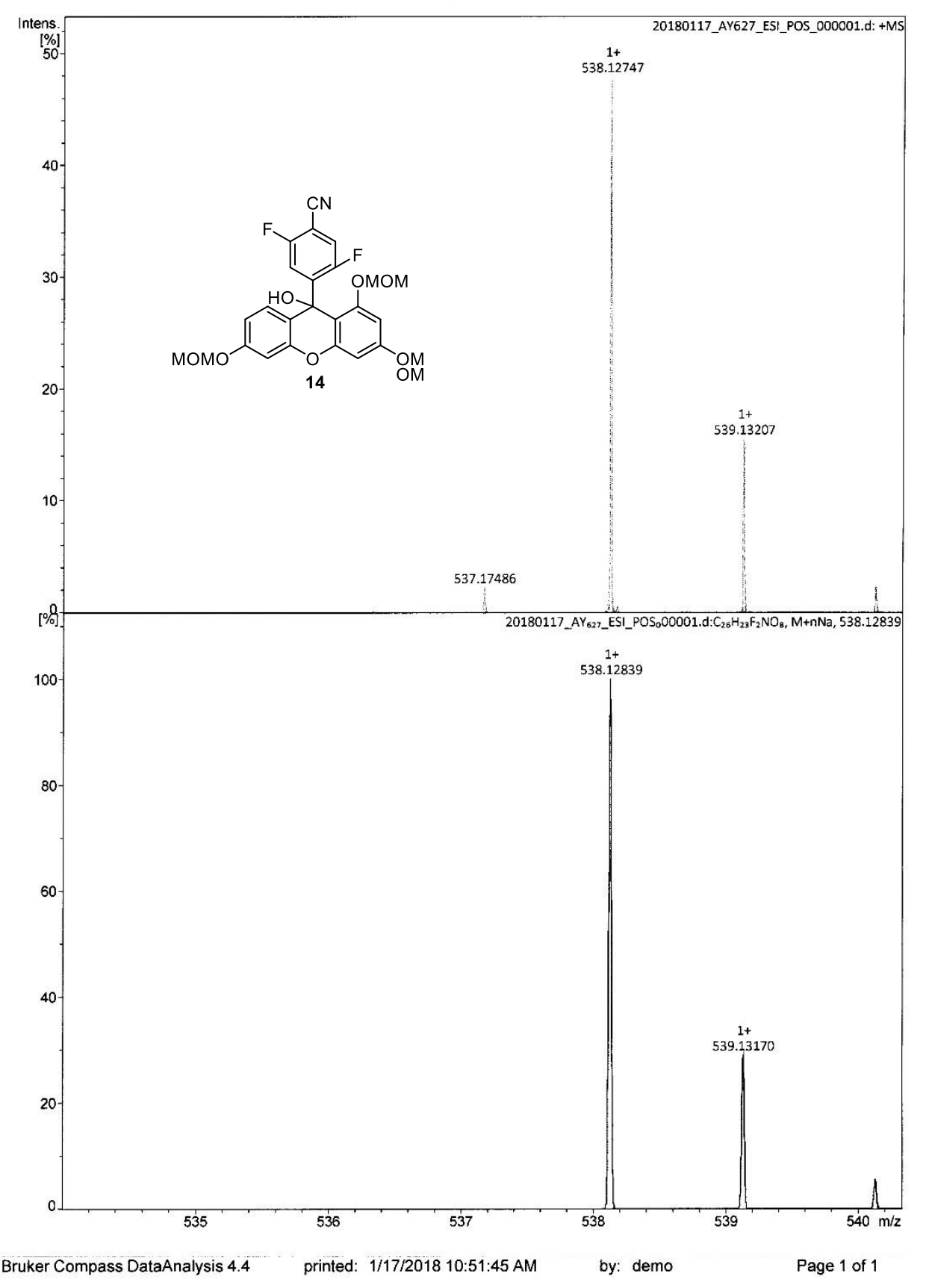


HRMS (ESI/FT-ICR-MS) of 17. Calcd for $\mathrm{C}_{12} \mathrm{H}_{13} \mathrm{NO}_{5} \mathrm{Na}$ [M+Na] $]^{+}$274.0686, Found 274.0678.

\section{Display Report}

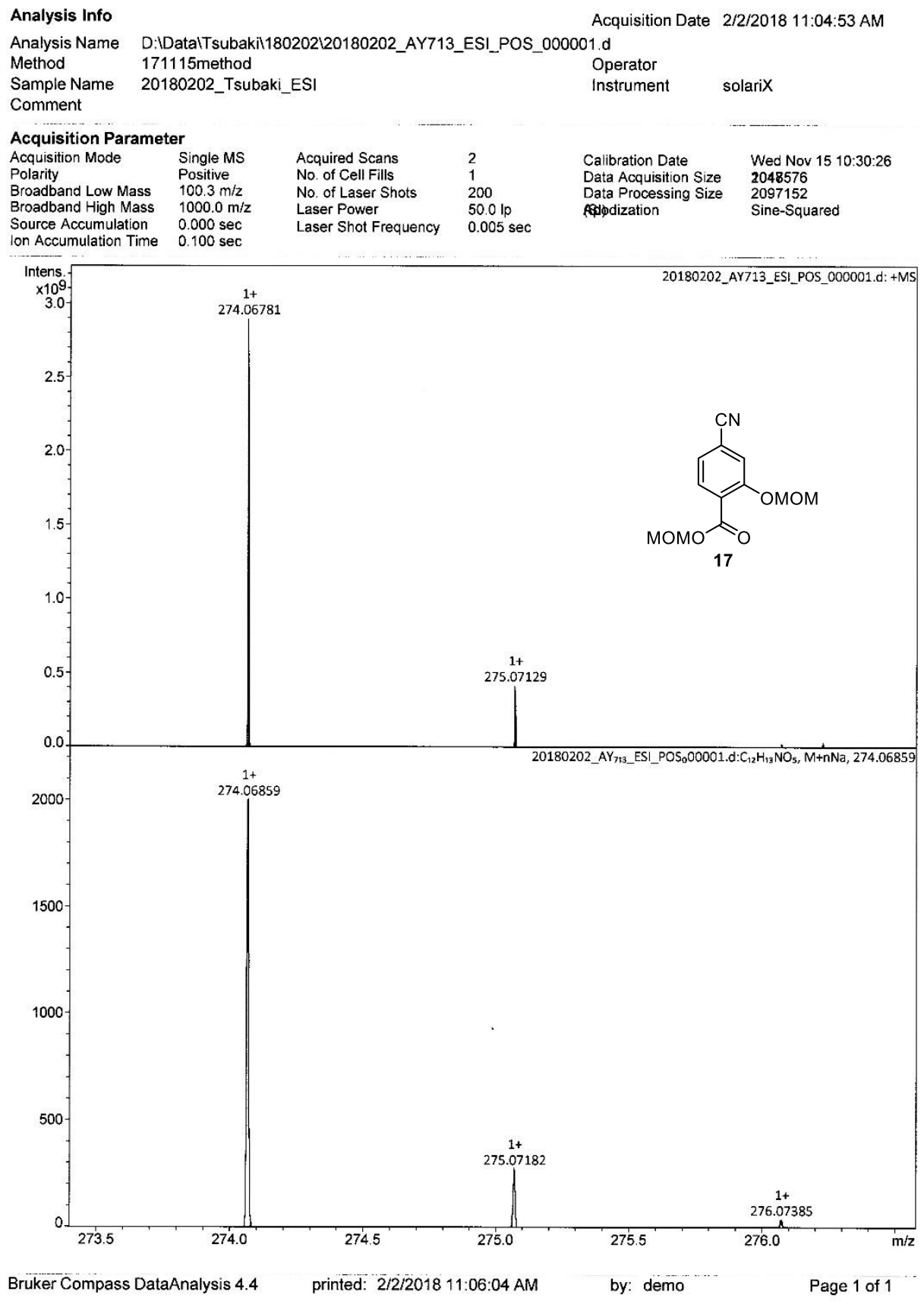


HRMS (ESI/FT-ICR-MS) of 18. Calcd for $\mathrm{C}_{12} \mathrm{H}_{14} \mathrm{~N}_{2} \mathrm{O}_{4} \mathrm{Na}[\mathrm{M}+\mathrm{Na}]^{+}$273.0846, Found 273.0842.

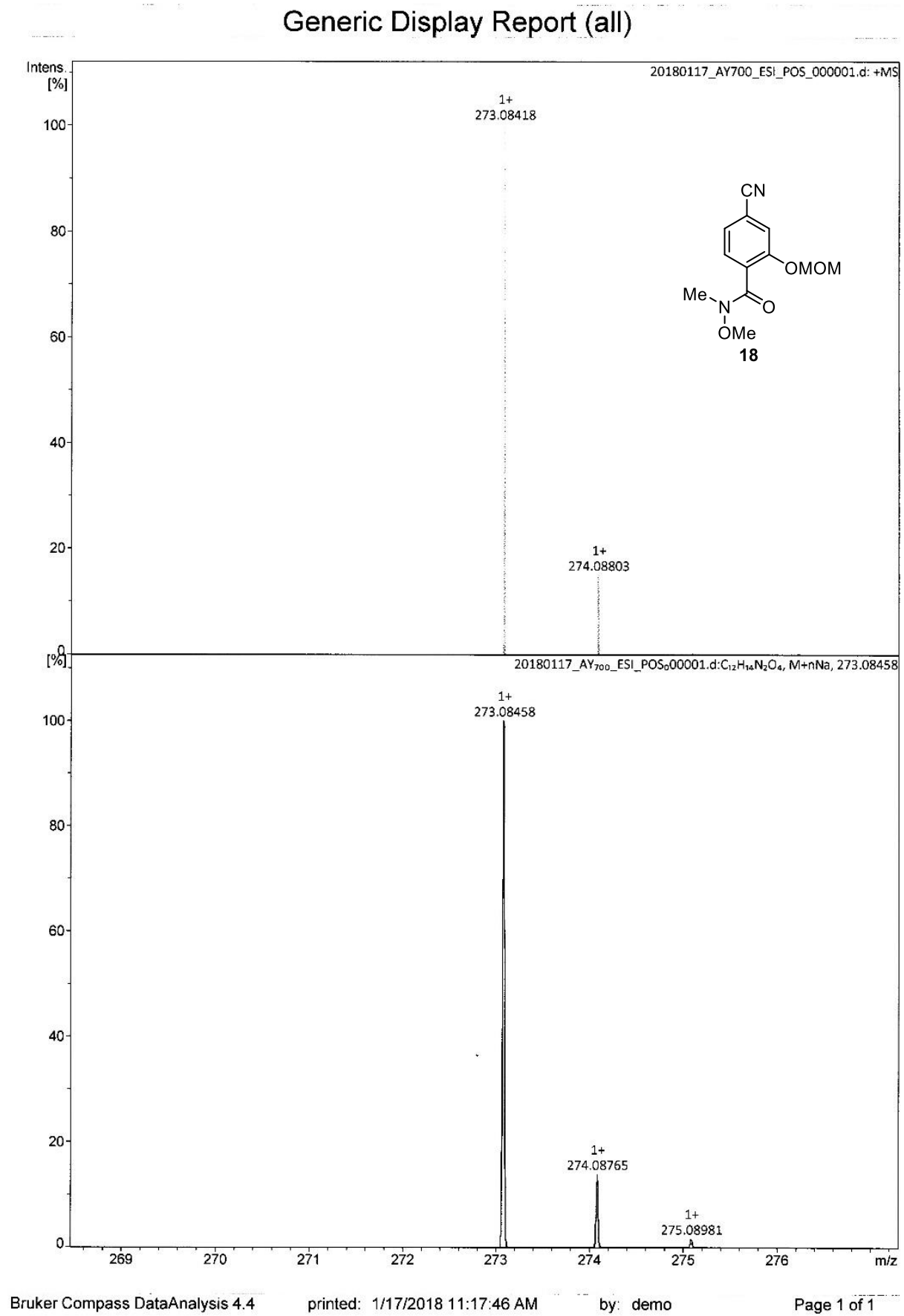


HRMS (ESI/FT-ICR-MS) of 20. Calcd for $\mathrm{C}_{20} \mathrm{H}_{21} \mathrm{NO}_{7} \mathrm{Na}$ [M+Na] ${ }^{+} 410.1210$, Found 410.1210.

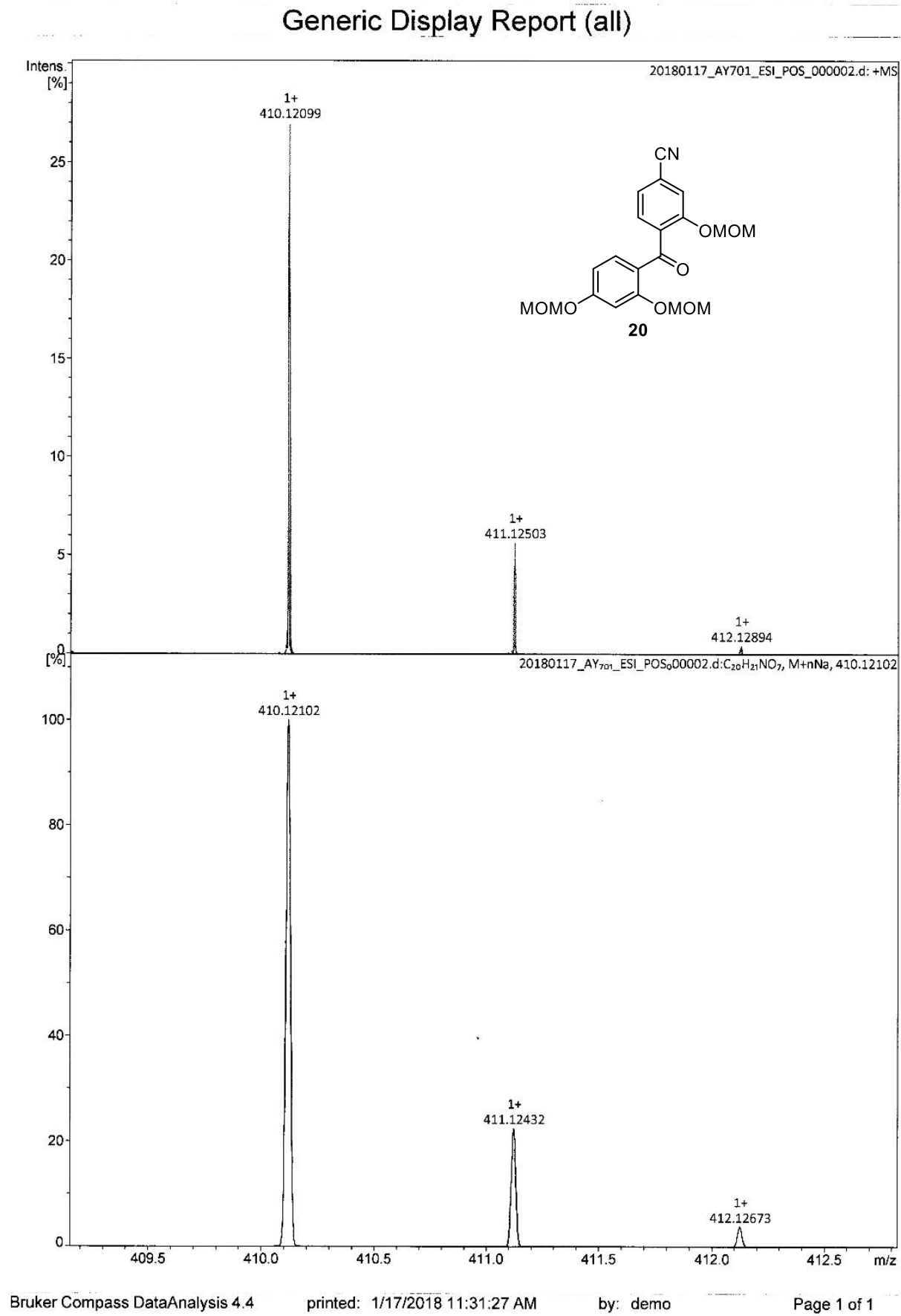


HRMS (ESI/FT-ICR-MS) of 22. Calcd for $\mathrm{C}_{32} \mathrm{H}_{39} \mathrm{NO}_{13} \mathrm{Na}[\mathrm{M}+\mathrm{Na}]^{+}$668.2314, Found 668.2314.

Window Display Report

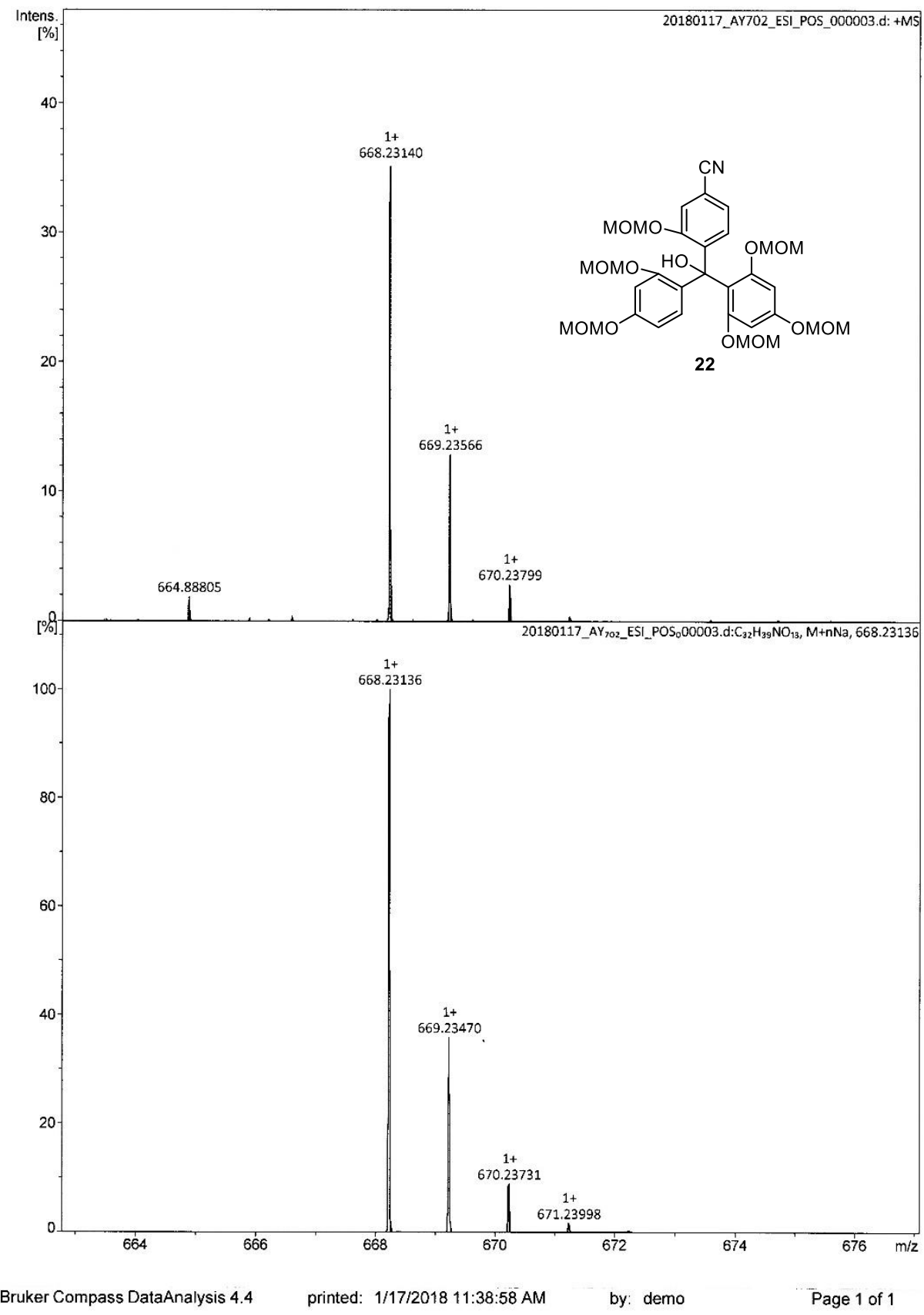

